\title{
Unintended pregnancies in Kenya: A country profile
}

Joyce Mumah

Caroline W. Kabiru

Carol Mukiira

Jessica Brinton

Michael Mutua

See next page for additional authors

Follow this and additional works at: https://knowledgecommons.popcouncil.org/departments_sbsr-rh

Part of the Demography, Population, and Ecology Commons, Family, Life Course, and Society Commons, International Public Health Commons, Maternal and Child Health Commons, Obstetrics and Gynecology Commons, and the Women's Health Commons How does access to this work benefit you? Let us know!

\section{Recommended Citation}

Mumah, Joyce, Caroline W. Kabiru, Carol Mukiira, Jessica Brinton, Michael Mutua, Chimaraoke O. Izugbara, Harriet Birungi, and lan Askew. 2014. "Unintended pregnancies in Kenya: A country profile," STEP UP Research Report. Nairobi: African Population and Health Research Center. 


\section{Authors}

Joyce Mumah, Caroline W. Kabiru, Carol Mukiira, Jessica Brinton, Michael Mutua, Chimaraoke O. Izugbara, Harriet Birungi, and lan Askew 


\section{STEP}

STRENGTHENING EVIDENCE FOR PRORAMMING ON UNINTENDED
KENYA

RESEARCH

REPORT

APRIL 2014

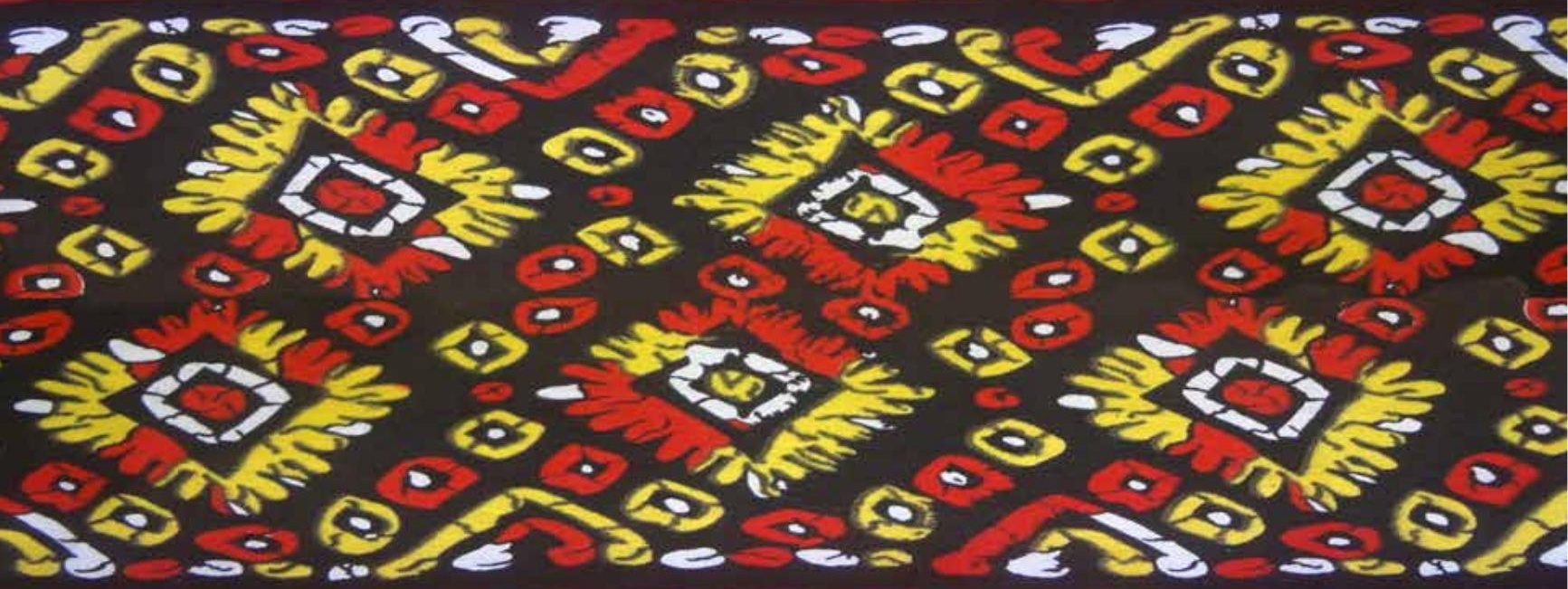

\section{Unintended Pregnancies in Kenya: A Country Profile}

JOYCE MUMAH, CAROLINE W. KABIRU, CAROL MUKIIRA, JESSICA BRINTON, MICHAEL MUTUA, CHIMARAOKE IZUGBARA, HARRIET BIRUNGI AND IAN ASKEW
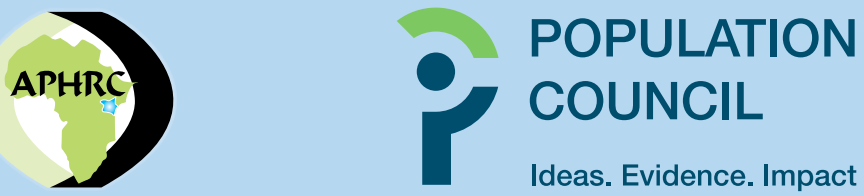



\section{Unintended Pregnancies in Kenya: A Country Profile}

JOYCE MUMAH', CAROLINE W. KABIRU', CAROL MUKIIRA', JESSICA BRINTON ${ }^{1}$, MICHAEL MUTUA ${ }^{1}$, CHIMARAOKE IZUGBARA ${ }^{1}$, HARRIET BIRUNG| ${ }^{2}$ AND IAN ASKEW ${ }^{2}$

${ }^{1}$ African Population and Health Research Center ${ }^{2}$ Population Council

STEP UP RESEARCH REPORT

April 2014 
The STEP UP (Strengthening Evidence for Programming on Unintended Pregnancy) Research Programme Consortium generates policy-relevant research to promote an evidence-based approach for improving access to family planning and safe abortion. STEP UP focuses its activities in five countries: Bangladesh, Ghana, India, Kenya, and Senegal. STEP UP is coordinated by the Population Council in partnership with the African Population and Health Research Center; icddr,b; the London School of Hygiene and Tropical Medicine; Marie Stopes International; and Partners in Population on Development. STEP UP is funded by UK aid from the UK Government. www.stepup.popcouncil.org

\section{APHRC}

AFRICAN POPULATION AND HEALTH RESEARCH CENTER

The African Population and Health Research Center, Inc. (APHRC) is an international nonprofit, research institute with headquarters in Nairobi, Kenya. APHRC's mission is to be a global center of excellence, consistently generating and delivering relevant scientific evidence for policy and action on population, health, and education in Africa. APHRC brings together a multi-disciplinary team of African scholars to lead the development of priority research programs and enhance the use of research findings for policy formulation and program improvement in sub-Saharan Africa. The Center was established in 1995 as a program of the Population Council and became an autonomous research institution in 2001. www.aphrc.org

\section{POPULATION \\ COUNCIL \\ Ideas. Evidence. Impact}

The Population Council confronts critical health and development issues-from stopping the spread of HIV to improving reproductive health and ensuring that young people lead full and productive lives. Through biomedical, social science, and public health research in 50 countries, we work with our partners to deliver solutions that lead to more effective policies, programs, and technologies that improve lives around the world. Established in 1952 and headquartered in New York, the Council is a nongovernmental, nonprofit organization governed by an international board of trustees. www.popcouncil.org

Suggested citation: Mumah, J, Kabiru, CW, Mukiira, C, Brinton, J, Mutua, M, Izugbara, C, Birungi, H. and Askew, I. 2014. "Unintended Pregnancies in Kenya: A Country Profile," STEP UP Research Report. Nairobi: African Population and Health Research Center.

\section{(c) 2014 African Population and Health Research Center}

Please address any inquiries about STEP UP to the RPC co-directors:

Dr. Harriet Birungi, hbirungi@popcouncil.org

Dr. lan Askew, laskew@popcouncil.org

Funded by 


\section{Contents}

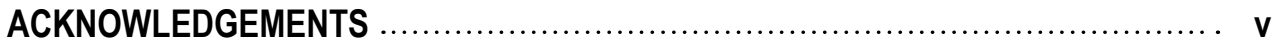

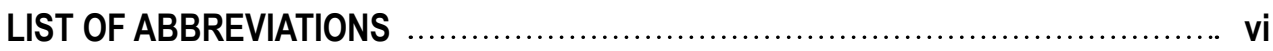

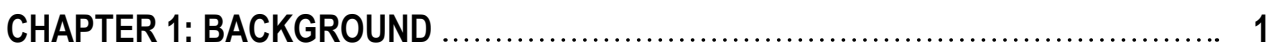

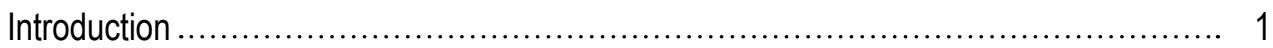

Outcomes of unintended pregnancy ........................................................... 3

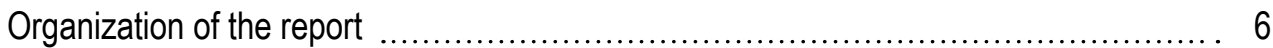

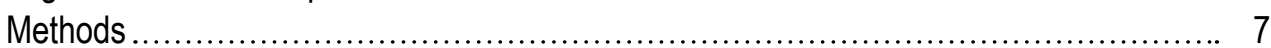

Validation process for recommendations ..................................................... 7

\section{CHAPTER 2: SEXUAL AND REPRODUCTIVE HEALTH RIGHTS IN KENYA:}

THE LEGAL, POLICY AND SOCIO-CULTURAL CONTEXT ............................ 9

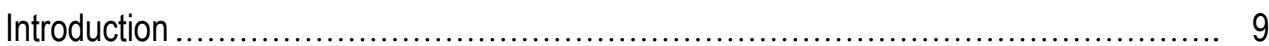

Reproductive health, family planning and abortion laws and policies -

brief history and current status .............................................................. 10

Legal system and mechanism for protecting relevant human rights ........................ 14

Sexual and reproductive health among vulnerable groups.................................... 15

Socio-cultural norms concerning family formation and childbearing ....................... 19

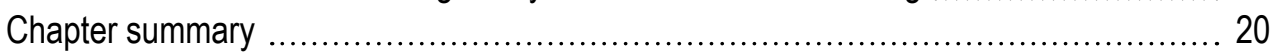

CHAPTER 3: FAMILY PLANNING AND REPRODUCTIVE HEALTH INDICATORS: TREND

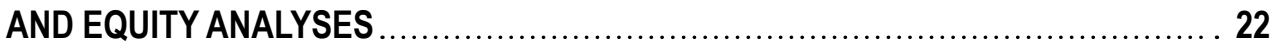

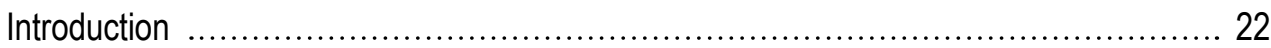

Family planning: awareness, attitudes, and use ............................................... 22

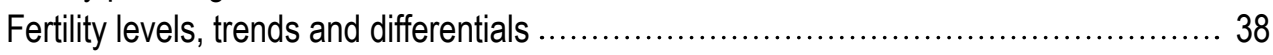

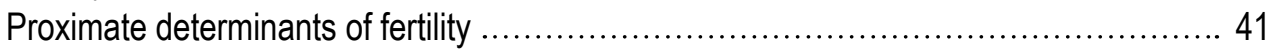

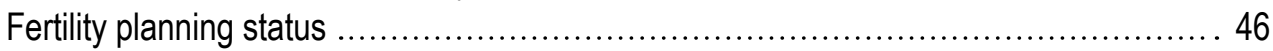

Family planning among vulnerable populations ….......................................... 50

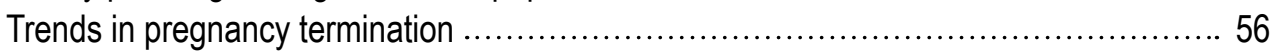

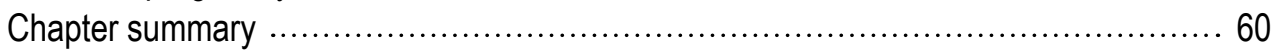

\section{CHAPTER 4: AVAILABILITY, COST AND QUALITY OF FAMILY PLANNING AND}

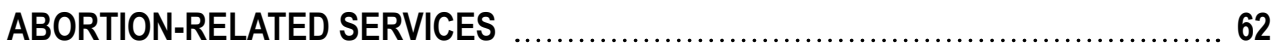

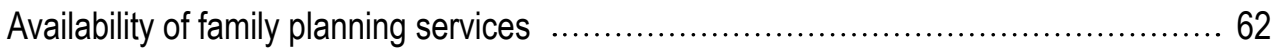

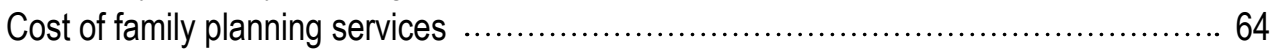

Infrastructure and resources to support family planning provision ............................6 66

Management practices to support quality family planning ...................................... 70

Abortion and post-abortion care service provision .......................................... 75

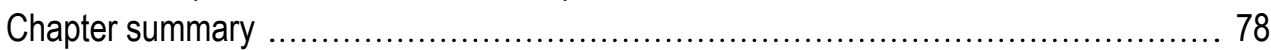


CHAPTER 5: FINANCING AND DELIVERY MECHANISMS

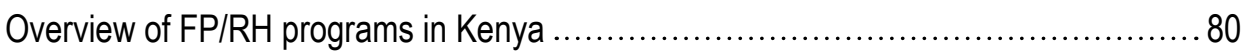

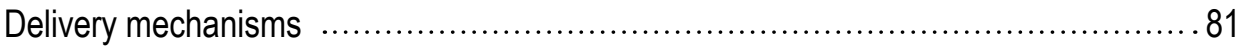

Financing mechanisms

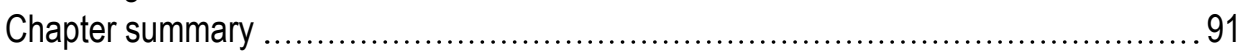

CHAPTER 6: POLICY CONTEXT AND RECOMMENDATIONS ….......................92

Policy and programmatic recommendations to address unintended pregnancies

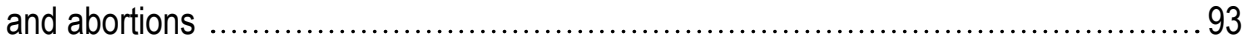

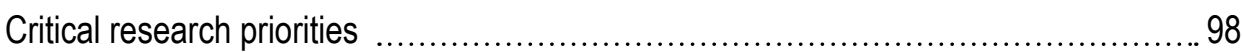

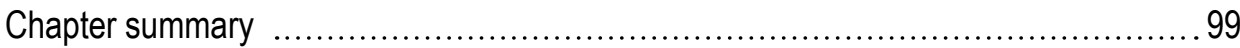

REFERENCES … 100

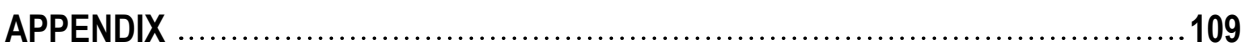




\section{Acknowledgements}

This report was prepared by Joyce Mumah, Caroline Kabiru, Carol Mukiira, Jessica Brinton, Michael Mutua, Chimaraoke Izugbara from the African Population and Health Research Center (APHRC), and Harriet Birungi and lan Askew from the Population Council, under the Strengthening Evidence for Programming on Unintended Pregnancy (STEP UP) Research Programme Consortium, funded by UKaid from the Department for International Development. The STEP UP Research Consortium is coordinated by the Population Council and includes APHRC, International Centre for Diarrheal Disease Research, Bangladesh (icddr, b), London School of Hygiene \& Tropical Medicine (LSHTM), Marie Stopes International (MSI), and Partners in Population and Development (PPD).

The authors thank Jean-Christophe Fotso, formerly of the African Population and Health Research Center, for his contributions to the STEP UP project, as well as Lawrence Ikamari and George Odwe for their valuable contributions to the preparation of this report. The authors also thank the validation workshop participants: Agnes Nakato, John Nyamu, Meschack Ndolo, George Odipo, Namuunda Mutombo, Patrick Mugirwa, Batula H. Abdi, Milka Choge, Selina Orrso-Coutts, Bertrand Guillemot, and Jerusha Karuthiru, who gave tremendous inputs on the report and participated in the development of the policy and programmatic recommendations that make up Chapter 6 . Finally, the contributions of Charles Oisebe and John Anampiu of NCPD are acknowledged.

Analysis and writing time for Joyce Mumah, Caroline Kabiru, Carol Mukiira, Jessica Brinton, Mike Mutua and Chimaraoke Izugbara was supported by funding from the STEP UP project (Grant SR1109D-6), Gates Urban Health Project through a grant from the Bill and Melinda Gates Foundation (Grant OPP1021893) and general support grants to APHRC from Sida (Grant number 2011-001578), and the William and Flora Hewlett Foundation (Grant number 2012-7612). 


\section{List of Abbreviations}

$\begin{array}{ll}\text { AIDS } & \text { Acquired Immune Deficiency Syndrome } \\ \text { ANC } & \text { Antenatal Care } \\ \text { APHRC } & \text { African Population and Health Research Center } \\ \text { ARH\&D } & \text { Adolescent Reproductive Health and Development } \\ \text { ART } & \text { Anti-retroviral therapy } \\ \text { CBD } & \text { Community-based Delivery } \\ \text { CHWs } & \text { Community Health Workers } \\ \text { CPR } & \text { Contraceptive Prevalence Rate } \\ \text { CRR } & \text { Center for Reproductive Rights } \\ \text { CSA } & \text { Centre for the Study of Adolescents } \\ \text { CYP } & \text { Couple Years of Protection } \\ \text { D\&C } & \text { Dilation and Curettage } \\ \text { DALYs } & \text { Disability-adjusted Life Years } \\ \text { DFID } & \text { Department for International Development } \\ \text { DHMT } & \text { District Health Management Team } \\ \text { DRH } & \text { Division of Reproductive Health } \\ \text { EVA } & \text { Electric Vacuum Aspiration } \\ \text { FBO } & \text { Faith-based Organization } \\ \text { FHI } & \text { Family Health International } \\ \text { FHOK } & \text { Family Health Options Kenya } \\ \text { FIDA } & \text { Federation of Women Lawyers - Kenya } \\ \text { FP } & \text { Family Planning } \\ \text { FPAK } & \text { Family Planning Association of Kenya } \\ \text { GoK } & \text { Government of Kenya } \\ \text { HIV } & \text { Human Immunodeficiency Virus } \\ \text { ICD } & \text { International Classification of Diseases } \\ \text { ICPD } & \text { International Conference on Population and Development } \\ \text { IDPs } & \text { Internally Displaced Persons } \\ \text { IEC } & \text { Information, Education, Communication } \\ \text { IPPF-ARO } & \text { International Planned Parenthood Federation - Africa Regional Office } \\ \text { IRH/FP } & \text { Integrated Rural Health and Family Planning Program } \\ \text { IUD } & \text { Intrauterine Device } \\ \text { KAIS } & \text { Kenya AIDS Indicator Survey } \\ \text { KDHS } & \text { Kenya Demographic and Health Survey } \\ \text { KEML } & \text { Kenya Essential Medicines List } \\ \text { KfW } & \text { Kreditanstalt für Wiederaufbau - German Development Bank } \\ \text { KHCR } & \text { Kenya Human Rights Commission } \\ \text { KHPF } & \text { Kenyan Health Policy Framework } \\ \text { KMA } & \text { Kenya Medical Association } \\ \text { KNBS } & \text { Kenya National Bureau of Statistics } \\ & \end{array}$




$\begin{array}{ll}\text { KNSPWD } & \text { Kenya National Survey for Persons with Disabilities } \\ \text { KOGS } & \text { Kenya Obstetrics and Gynaecological Society } \\ \text { KSPA } & \text { Kenya Service Provision Assessment Survey } \\ \text { LMIC } & \text { Low and Middle Income Countries } \\ \text { MCH } & \text { Maternal and Child Health } \\ \text { MMR } & \text { Maternal Mortality Ratio } \\ \text { MOH } & \text { Ministry of Health } \\ \text { MOMS } & \text { Ministry of Medical Services } \\ \text { MOPHS } & \text { Ministry of Public Health and Sanitation } \\ \text { MSK } & \text { Marie Stopes Kenya } \\ \text { MVA } & \text { Manual Vacuum Aspiration } \\ \text { MYWO } & \text { Maendeleo ya Wanawake Organization } \\ \text { NCAPD } & \text { National Coordinating Agency for Population \& Development } \\ \text { NCPD } & \text { National Council for Population and Development } \\ \text { NGO } & \text { Non-governmental Organization } \\ \text { NHA } & \text { National Health Accounts } \\ \text { NHIF } & \text { National Health Insurance Fund } \\ \text { NHSSP } & \text { National Health Sector Strategic Plans } \\ \text { NIDI } & \text { Netherlands Interdisciplinary Demographic Institute } \\ \text { NRHP } & \text { National Reproductive Health Policy } \\ \text { NRHS } & \text { National Reproductive Health Strategy } \\ \text { OVC } & \text { Orphans and Vulnerable Children } \\ \text { PAC } & \text { Post-abortion Care } \\ \text { PC } & \text { Population Council } \\ \text { PHC } & \text { Primary Health Care } \\ \text { PoA } & \text { Program of Action } \\ \text { PPD } & \text { Partners in Population and Development } \\ \text { PPP } & \text { Public-Private Partnership } \\ \text { PSI } & \text { Population Services International } \\ \text { RBF } & \text { Results-Based Financing } \\ \text { RH } & \text { Reproductive Health } \\ \text { RHRA } & \text { Reproductive Health Rights Alliance } \\ \text { SRH } & \text { Sexual and Reproductive Health } \\ \text { SSA } & \text { Sub-Saharan Africa } \\ \text { STI } & \text { Sexually Transmitted Infections } \\ \text { TFP } & \text { Temporary Family Planning } \\ \text { TFR } & \text { Total Fertility Rate } \\ \text { UNFPA } & \text { United Nations Population Fund } \\ \text { UNICEF } & \text { United Nations Children's Fund } \\ \text { USAID } & \text { United States Agency for International Development } \\ \text { WHO } & \text { World Health Organization } \\ \text { YFS } & \text { Youth Friendly Services } \\ & \text { ThO }\end{array}$




\section{CHAPTER 1}

\section{Background}

\subsection{Introduction}

Fertility rates remain high in Kenya, with an average total fertility rate (TFR) of 4.6 children during a woman's lifetime. ${ }^{1}$ According to the Kenyan National Bureau of Statistics, if women were to achieve their ideal family size, the TFR for Kenya would drop to 3.4 children per woman, ${ }^{1}$ with the gap between the desired and actual family size being greatest among the poor. Most notably, if fertility rates remain at the same level, it is projected that the proportion of women within reproductive ages will grow from 48 percent in 2009 to about 51 and 55 percent in 2040, assuming low-fertility and high fertility scenarios (see Figure 1.1). ${ }^{2}$ This growth has implications not only for the number of pregnancies that would result because of this increase but also for the concomitant increase in demand for reproductive health services.

Figure 1.1: Projected percentage of women of reproductive age, Kenya

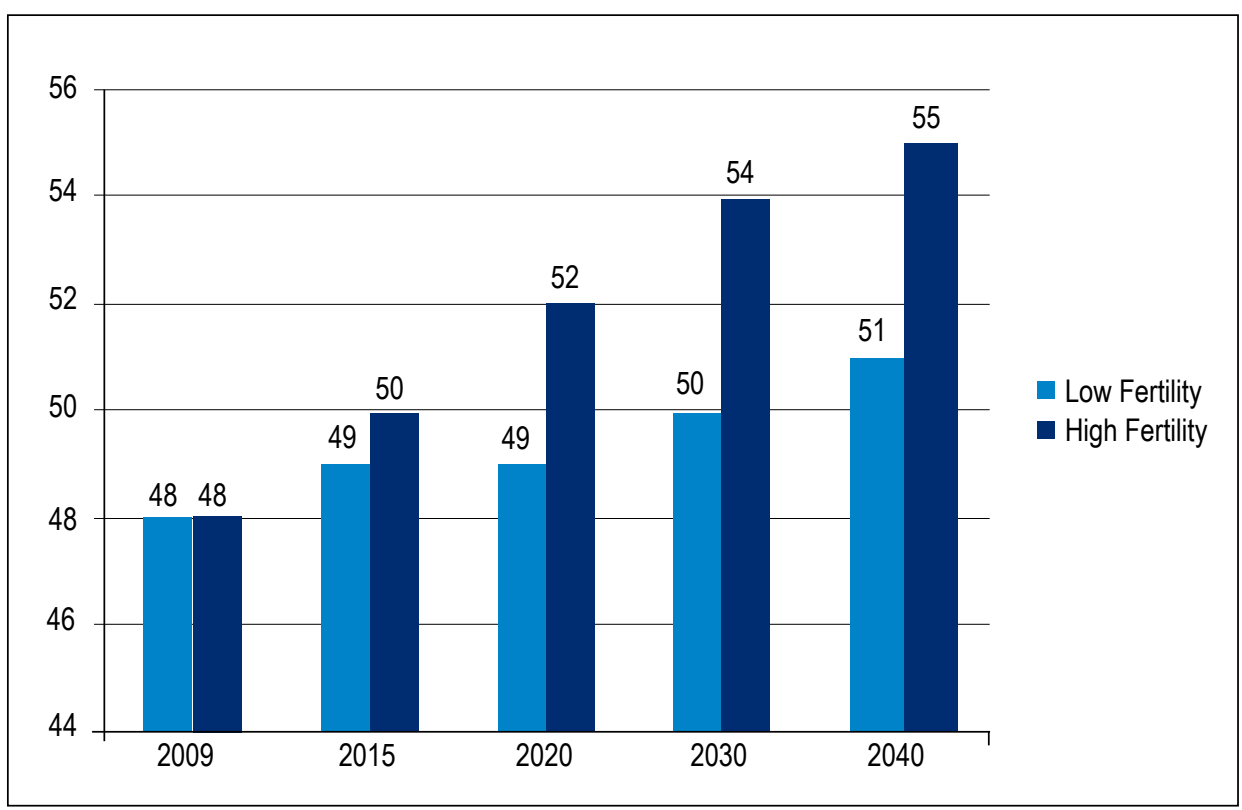

Source: Population Stabilization: Kenya Case ${ }^{2}$

Over 40 percent of pregnancies in Kenya are unintended; that is either mistimed or unwanted. The high number of unplanned pregnancies stems largely from an unmet need for contraceptives - one in four married women in Kenya have an unmet need and the national modern contraceptive prevalence rate is estimated at 39 percent. ${ }^{1}$ Unintended 
pregnancies have significant implications for the health and well-being of women and children.

Approximately 14 percent of pregnancies in Kenya end in abortion. Most of these abortions are performed by unskilled people, often in conditions that do not meet minimal medical standards and are not followed with the appropriate post-abortion care. These unsafe abortions result in about 2,600 deaths of women and girls annually in Kenya. ${ }^{3}$

In 2002, it was estimated that there were close to 317,000 spontaneous or induced abortions; that is, for every 100 pregnancies in Kenya, there were about 29 abortions. ${ }^{4}$ Though the distinction between spontaneous and induced abortions is not often made in estimates, one report estimates that about 40 percent of abortions in Kenya are induced. ${ }^{3}$ Other pregnancy-related complications such as hemorrhage, hypertensive disorders, and obstructed labor increase maternal deaths and disease and are major impediments to safe motherhood (see Table 1.1).

Table 1.1: Kenya demographic and reproductive health highlights at-a-glance

\begin{tabular}{|l|c|}
\hline Indicators & Numbers \\
\hline Population, mid 2012 & 43,013 Million \\
\hline Average age at first marriage, all women & 20 \\
\hline Average age at first intercourse, all women & 18.2 \\
\hline $\begin{array}{l}\text { Total fertility rate (average number of children born to a woman during her } \\
\text { lifetime) }\end{array}$ & 4.6 \\
\hline Females giving birth by age 20 & $46 \%$ \\
\hline Contraceptive use among married women ages 15-49, modern methods & $39 \%$ \\
\hline Unmet need for contraception among currently married women & $26 \%$ \\
\hline Maternal deaths per 100, 000 live births & 530 \\
\hline Lifetime risk of maternal death & 1 in 38 \\
\hline Levels of unintended pregnancy (including mistimed and unwanted) & $43 \%$ \\
\hline Births attended by skilled personnel & $44 \%$ \\
\hline Infant mortality rate (infant deaths per 1,000 live births) & 59 \\
\hline Children who are exclusively breastfed at ages less than 6 months & $32 \%$ \\
\hline Abortion Policy, 2011 & $\begin{array}{c}\text { Prohibited, or permitted } \\
\text { only to save a woman's } \\
\text { life }\end{array}$ \\
\hline
\end{tabular}

Sources: Population Reference Bureau 2011 and 2012 World Population Data Sheet ${ }^{5,6}$; Kenya Demographic and Health Survey 2008/091; WHO Atlas of Health Statistics of the African Region, $2012^{7}$ 


\subsection{Outcomes of unintended pregnancy}

\subsubsection{Maternal mortality and morbidity in Kenya}

Maternal mortality is defined by the ICD-10 as "the death of a woman while pregnant or within 42 days of termination of pregnancy, irrespective of duration and site of the pregnancy, from any cause related to or aggravated by the pregnancy or its management but not from accidental or incidental causes. ${ }^{8}$ Maternal mortality is the top cause of death in developing countries for women of reproductive age. It is estimated that there are about 287,000 women who die each year from pregnancy-related causes, globally. ${ }^{9}$ Low and middle income countries (LMICs) account for about 99 percent of the global maternal deaths, with sub-Saharan Africa (SSA) having the highest regional maternal mortality ratio (MMR), estimated at 500 maternal deaths for every 100,000 live births.

MMR estimates for Kenya vary widely depending on the source used. For example, the Kenya Demographic and Health Survey reports that the MMR in 1998 was 590 per 100,000 live births. This number dropped to 414 in $2003 .{ }^{10}$ However, in 2010 a slightly higher MMR of 488 was recorded, a reversal in gains seen with regard to maternal mortality. ${ }^{1}$ Latest estimates from WHO/UNICEF/UNFPA/World Bank put MMR in Kenya at 360 per 100,000 live births in 2010, a drop from estimates of 460 per 100,000 live births in 1990, while the Population Reference Bureau puts it at 530 per 100, 000 live births. However, despite disparities in numbers, all estimates indicate that MMR in Kenya has seen insufficient declines in the last 10 years. Overall, it is estimated that the risk of maternal mortality in Kenya is still high at 1 in 38 in comparison to 1 in 7,300 for women in the developed world. It is reported that adolescents and women of older reproductive age and women with parity above four face increased maternal mortality risk. ${ }^{11}$ Overall, MMR levels are worrying because maternal deaths in Kenya largely occur from preventable causes including hemorrhage ( 25 percent), sepsis ( 15 percent), hypertensive disorders (12 percent), complications of unsafe abortion (13 percent), and obstructed labor (8 percent), among other direct and indirect causes. ${ }^{12}$

Having an unwanted pregnancy is a significant risk factor for adverse health outcomes, including maternal mortality and morbidity. For women who decide to terminate a pregnancy, the main reasons for deaths vary, but the majority of deaths are as a result of complications from unsafe abortions. According to estimates from Kenya's National Coordinating Agency for Population \& Development (NCAPD) 13 percent of maternal deaths result from unsafe abortions. ${ }^{12}$ In contrast, Ziraba and colleagues ${ }^{13}$ show that abortion in two informal settlements in Nairobi was a significant contributor to maternal mortality and was directly linked to about 31 percent of maternal deaths between 2003 and $2005 .{ }^{13}$ Most of these maternal deaths occurred because abortion were not managed properly, with less than 50 percent of women seeking care at a health facility. Evidence shows that the health-seeking behaviors of women who report their pregnancy to be unwanted or mistimed tended to be different from women who report their pregnancies to be wanted..$^{14}$ Women who report unwanted pregnancies are less likely than those who report wanted pregnancies to receive antenatal care (ANC) before the sixth month or to benefit from supervised delivery. Women who report unwanted pregnancies have significantly higher odds of postpartum depression. 
According to Marston and Cleland, 14 births in Kenya that were reported as unintended were 1.2 times more likely to be unattended than births that were wanted, as well as 20 percent more likely to receive inadequate ANC. Magadi and colleagues ${ }^{15}$ also show that unwanted and mistimed pregnancies among women in Kenya results in fewer antenatal visits and delayed timing of the first antenatal visit. Further, in their study of women in two informal settlements in Kenya, Fotso and colleagues ${ }^{16}$ found that women reporting unwanted pregnancies were less likely to deliver at appropriate health facilities.

The 2008/09 KDHS reports that the proportion of births attended by skilled personnel is about 44 percent, though wide disparities exist across different regions. This proportion is just a 2 percentage point increase from 42 percent recorded by the KDHS in 2003. Considering the unpredictability of most obstetric emergencies, with life-threatening complications occurring in 15 percent of all pregnancies ${ }^{17}$, every pregnant woman is potentially at risk of developing a complication. Therefore, that the majority of births are still not attended by skilled personnel is problematic.

For every woman who succumbs to maternal death, many more suffer injuries, infections, and disabilities brought about by pregnancy or childbirth complications, such as obstetric fistula, which results from obstructed labor. Globally, it is estimated that for every maternal death, about 30 women suffer disability or injury that stems from pregnancy complications, childbirth or abortion. ${ }^{18}$ According to estimates from the World Health Organization, maternal conditions account for about 8 percent of the total global burden of disease. ${ }^{7}$ Moreover, it is estimated that unwanted fertility and unsafe abortion account for 12 to 30 percent of maternal disability-adjusted life years (DALYs) across different countries in the developing world. ${ }^{19}$ According to Tsui and colleagues, ${ }^{20}$ about 2 million years of life are lost to disability due to the maternal burden of disease in SSA. In Kenya, it is estimated that maternal conditions account for about 6 percent of the total burden of disease. ${ }^{21}$ One of the few hospital-based studies on abortion approximates that about 21,000 women are admitted each year to Kenya's public hospitals for treatment of complications from incomplete and unsafe abortion, spontaneous or induced. In a country where 43 percent of births are reported as unplanned and with contraceptive rates at 39 percent, ${ }^{1}$ it can logically be assumed that women who carry an unintended pregnancy to term, as a result of an unmet need for family planning, suffer unnecessary and preventable death and disability. ${ }^{22}$

\subsubsection{Miscarriages}

Miscarriages, the spontaneous loss of a pregnancy before the 20th week, contribute to additional abortion-related morbidity and mortality. It is estimated that 15 percent of pregnancies end in spontaneous miscarriages or still births. ${ }^{23}$ Ziraba and colleagues ${ }^{13}$ note that over two thirds of deaths that were classified as maternal deaths in Health and Demographic Surveillance Sites (HDSS) run by the African Population and Health Research Center (APHRC) were as a result of direct maternal complications including miscarriages. According to another survey conducted by APHRC, ${ }^{24}$ about 18 percent of women who had reported that their last pregnancy was unintended lost their pregnancy 
through a miscarriage. Overall, 79 percent of women in this study who did not carry their pregnancies to term reported that the pregnancy ended as a result of a miscarriage, while 20 percent reported a still birth.

\subsubsection{Infant and child health}

A systematic review conducted in 2009 estimated that unintended pregnancies, compared to intended pregnancies, are associated with higher odds of adverse neonatal outcomes such as low birth weight and preterm births. ${ }^{18}$ Published studies also note that in five countries including Kenya unintended pregnancy is associated with an increased likelihood of incomplete child vaccinations by age 1. For example, previous estimates showed that women who reported their pregnancy was unwanted at conception were 1.6 times less likely to have taken the children for the full set of vaccines than women who reported the pregnancy as wanted..$^{10}$ Other scholars have found that though there was no direct association between pregnancy desirability and adverse birth outcomes, there was an indirect association between pregnancy desirability and premature birth and baby size. ${ }^{15}$ Existing evidence also suggests a child mortality disadvantage for children born from unintended pregnancy (see Figure 1.2). ${ }^{25}$

Figure 1.2: Trends in neonatal and post-neonatal mortality, KDHS 1993 to 2008

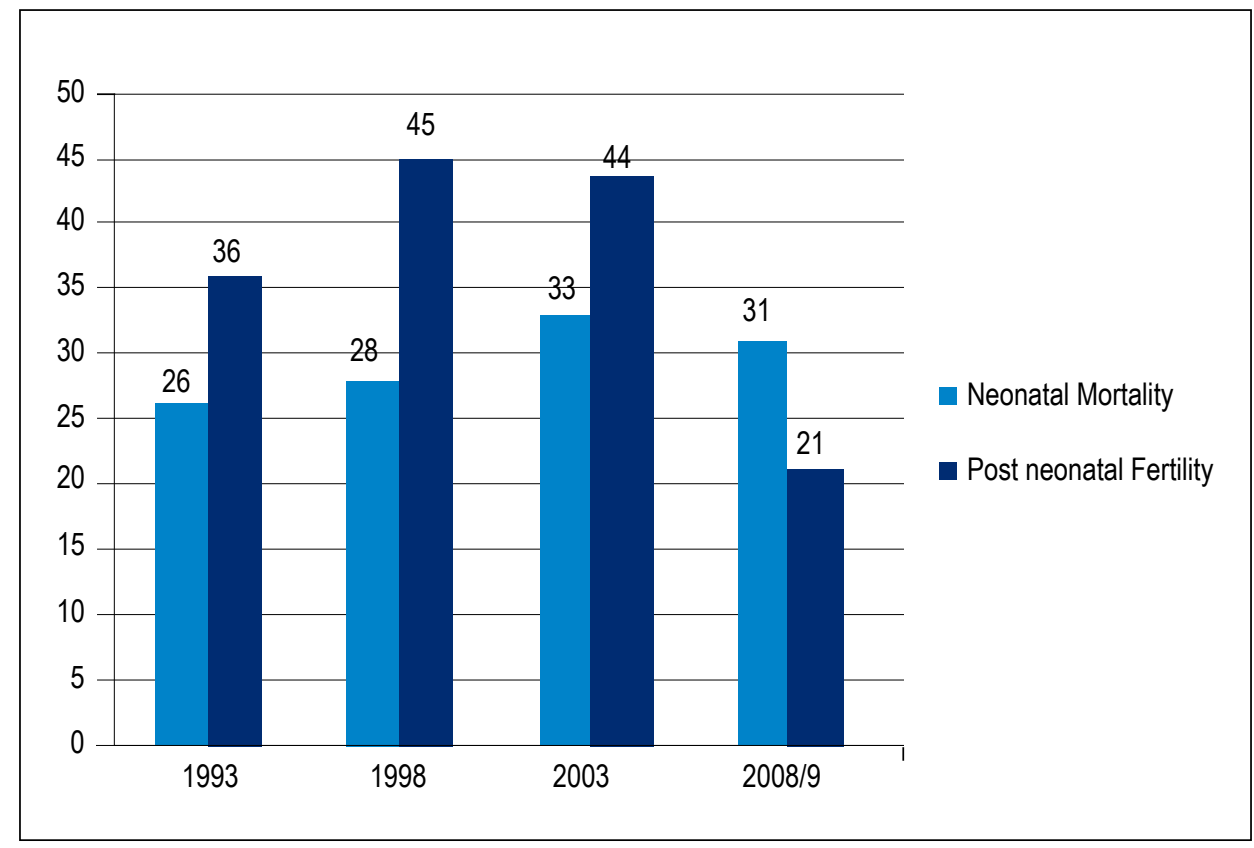

Source: 1993, 1998, 2003 and 2008/09 Kenya Demographic and Health Surveys

As noted earlier, the literature has shown an association between factors such as maternal age, timing, and parity and adverse pregnancy outcomes. Characteristically, the probability 
that an infant will die during childhood is greater if the mothers are too young or too old, born within 24 months of a previous birth or born to mothers with high parity. The 2008/09 KDHS indicates that about 6 percent of births are to girls aged below 18 years, 8 percent of births are within 24 months of a previous birth and 22 percent are to women with three or more births. ${ }^{1}$ Though estimates for Kenya are not readily available, it is estimated that in SSA, prematurity and low birth weight account for 3.9 percent of total DALYs, while neonatal infections account for another 3.8 percent of total burden of disease in the region. ${ }^{7}$ These estimates have significant implications for Kenya; especially as 47 percent of pregnancies among adolescent girls aged 15 to 19 are unplanned, ${ }^{1}$ implying a significant risk for not only children but for the adolescent mother as well. If every pregnancy and childbirth is an exposure to risk of maternal death, then every unintended pregnancy in a high maternalmortality setting such as Kenya subjects a woman to a life-threatening event. Moreover, as about 23 percent of births within 24 months in Kenya are mistimed, a high burden of childhood disease could be averted if unintended pregnancies were reduced. ${ }^{1}$

\subsection{Organization of the report}

The report draws on data from four Kenya Demographic and Health Surveys (KDHS) (1993, 1998, 2003 and 2008/09), the Kenya AIDS Indicator Survey (KAIS) (2007), the Kenya Service Provision Assessment (KSPA) (2004 and 2010) and the Kenya National Survey for Persons with Disabilities (KNSPWD) (2008). Levels of key family planning and reproductive health indicators are set out, as well as fertility-and abortion indicators in Kenya. An equity lens was used, which differentiates these indicators by age, marital status, region, education and wealth. The report also looks at differential access to and quality of family planning and abortion/post-abortion services to assess their current situation, as well the various financing and delivery mechanisms for these crucial services.

Chapter 2 provides an overview of reproductive health from a human-rights perspective. It presents information on sexual and reproductive health (SRH) rights in Kenya from a legal-, policy- and socio-cultural standpoint. This chapter gives a brief history of, and describes the current status of reproductive health, family planning and abortion laws and policies, the legal system and mechanism for protecting relevant human rights. It further provides an overview of vulnerable groups and the socio-cultural norms and trends concerning family formation and childbearing.

Chapter 3 focuses on family planning and reproductive health, specifically on measures of family planning, contraceptive use, fertility levels, trends and differentials, fertility preferences, family planning use among vulnerable populations and the magnitude of abortion. This chapter also covers SRH indicators such as age at first birth/marriage, teenage pregnancy, and the ideal number of children desired and the levels of unwanted fertility. Differential analysis is performed in the chapter to provide a better understanding of the trends and patterns affecting different subsets of the population

Chapter 4 covers indicators for access to and quality of family planning and abortion and post-abortion services. Specifically, it examines access to information and services, availability of services and access to abortion and post abortion care. 
Chapter 5 examines the various financing and delivery mechanisms for reproductive health in Kenya. This chapter assesses the current situation of various delivery mechanisms such as the clinic-based approach, community-based delivery, and social marketing of family

planning services. Financing of reproductive health is assessed by examining different funding mechanisms including government, donors, cost sharing, output-based financing and health insurance schemes.

Finally, Chapter 6 summarizes the report and discusses the key challenges facing reproductive health with a special focus on unintended pregnancy in Kenya. The chapter ends with policy and programmatic implications.

\subsection{Methods}

The methodology for this country profile combines extensive desk reviews of existing literature and secondary data analysis of existing data sets. Desk reviews included examination of government documents, charters, declarations, conventions, peerreviewed publications, published and unpublished research and reports. Existing data sets used in this report included the Kenya Demographic and Health Surveys (KDHS) (1993, 1998, 2003, and 2008/2009), the Kenya Service Provision Assessment (KSPA) (2004 and 2010), the Kenya AIDS Indicator Survey (KAIS) (2007) and the Kenya National Survey for Persons with Disabilities (KNSPWD) (2008). The KDHS data sets are national household surveys designed to collect demographic and health information from samples of women of reproductive age and from samples of men aged 15 to 54 years of age. The KDHS collects data on key variables such as fertility, marriage, sexual activity, fertility preferences, family planning and maternal and child health, among other indicators. Additional data was derived from the 2004 and 2010 KSPA, which is a facility-based survey that describes how health facilities in Kenya provide basic- and advanced-level services for child health, maternal health, family planning, and HIVIAIDS and other communicable diseases. Both data sets include a nationally representative sample including hospitals, health centers, maternity, clinics and dispensaries. The 2008 KNSPWD was a national sample survey of more than 14,000 households of persons with disabilities. The survey sought to know the nature, types and causes of disabilities, coping mechanisms, nature of services available to them, and community perceptions and attitudes towards people with disability.

Data management and analyses were done in STATA 12.1. Differential analyses were conducted for chapters 3 and 4 by age, education, wealth, residence and province. The ultimate goal was a trend analysis, done in an equity context, so changes over time and subsets that were vulnerable to the main outcome were captured.

\subsection{Validation process for recommendations}

In order to develop report recommendations that are comprehensive and involve consultation from a wide range of key stakeholders, the STEP UP Research Consortium held a validation workshop from Thursday September 12 through Saturday September 14, 2013. The workshop participants included researchers from APHRC and Population 
Council, reproductive health representatives from the Ministry of Health, funders (DfID, KfW and USAID), service delivery organizations (Marie Stopes Kenya (MSK), Family Health Options Kenya (FHOK)), and policy organizations (Partners in Population and Development (PPD)).

Day 1 of the workshop included an overview of each of the Kenya Country Profile Report chapters, led by the STEP UP Research Consortium, followed by a detailed discussion of the research findings. The discussion allowed for the group to provide feedback on the report and to ensure that all key policies and relevant information were included. On day 2 of the workshop, participants developed policy- and programmatic recommendations based on detailed discussions that provided crucial context and additional evidence of research to support them. The recommendations were discussed both in small groups and in a plenary session to ensure that feedback and input were received from each participant. Outcomes from the meeting included the development of 6 comprehensive policy- and programmatic recommendations. In addition, the group discussed a detailed way forward for each of the recommendations. Several of these suggested actions are provided in the 'way forward' text under recommendations. 


\section{CHAPTER 2}

\section{Sexual and Reproductive Health Rights in Kenya: The Legal, Policy and Socio-Cultural Context}

\subsection{Introduction}

Sexual and reproductive health $(\mathrm{SRH})$ is an essential human right as it relates to the health and well-being of individuals, families and society. A definition of reproductive health adopted in the 1994 United Nations International Conference on Population and Development (ICPD) in Cairo is that it is 'a state of complete physical, mental and social well-being and not merely the absence of disease in all matters relating to the reproductive system' ${ }^{26}$ The conference further acknowledged reproductive and sexual health rights of women as being vital to their health. SRH rights recognize the liberty of individuals and couples to responsibly and freely decide if, when and how often they want to have children, without any form of discrimination or coercion.

$\mathrm{SRH}$ rights are among the most sensitive and contentious of all human rights. ${ }^{27}$ About a third of the global burden of morbidity and early mortality among women of reproductive age is attributable to poor SRH. ${ }^{28}$ Consequently, it is essential for countries to have adequate and quality SRH services if couples and individuals are to have an improved quality of life. SRH rights encompass various human rights that are already incorporated in national laws and regional and international human rights documents. Kenya is a signatory to several international and regional declarations and commitments that assure the right to SRH. For instance, Kenya has committed to achieving the Millennium Development Goals (MDGs) that build on the achievements of the 1994 ICPD commitments, in which universal access to reproductive health is an explicit target. Kenya is also a signatory to: the Covenant on Civil and Political Rights (1966); the International Covenant on Economic, Social and Cultural Rights (1966); the Convention on the Elimination of all forms of Racial Discrimination (1966); the Convention on the Elimination of all forms of Discrimination against Women (1979); the Convention Against Torture and Other Cruel, Inhuman or Degrading Treatment or Punishment (1984); the Convention on the Rights of the Child (1989); and the Convention on the Rights of Persons with Disabilities (2006) among others.

At the regional level, Kenya is party to several declarations and commitments that assure the right to SRH, including the African Charter on Human and People's Rights (1981) and that of the Welfare of the Child (1990); the Protocol to the African Charter on Human and People's Rights on the Rights of Women in Africa also known as the Maputo protocol (2003); the MDGs; Abuja Declaration on HIVIAIDS, Tuberculosis and Other Related Infectious Diseases (2001). At the national level, the Kenyan Constitution guarantees health care rights including $\mathrm{SRH} .{ }^{29}$ The Constitution further underscores the importance of prioritizing the needs of vulnerable and marginalized groups in the provision of health 
care. It further posits that no person will be deprived of emergency medical treatment and that appropriate social security will be provided to those who are not able to support themselves and their dependents. ${ }^{29}$ Besides the Constitution, Kenya has several Acts of parliament that are meant to promote and protect SRH rights; some of which include the Sexual Offences Act 2003, the Children's Act 2001, and the Prohibition of Female Genital Mutilation Act 2011.

In the rest of this chapter we examine the legal-, policy-, and socio-cultural context of sexual and reproductive health and rights (SRHR) in Kenya. We begin with an outline of the history and current status of laws and policies with implications for sexual and reproductive health and rights. After this section, the mechanisms and legal systems for protecting relevant human rights in relation to SRH are covered. The third section examines non-discrimination and recognition of vulnerable groups and how SRH services and rights are extended to these groups. The chapter concludes with an assessment of socio-cultural norms and trends concerning family formation and childbearing over time.

\subsection{Reproductive health, family planning and abortion laws and policies - brief history and current status}

\subsubsection{Reproductive health and family planning laws and policies}

Kenya has had explicit and implicit population policies and strategies that have contributed to an environment that has enabled issues surrounding reproductive health to be tackled. Kenya was among the first African countries to have a population policy and a family planning (FP) program. ${ }^{30,31}$ In 1967, the Kenyan government adopted the first national population policy and established a national FP program under the Ministry of Health. The program laid emphasis on reducing the rate of population growth through limiting family size and increasing child spacing. The early development of the policy was largely influenced by the international population movement and mainly driven by the desire for recognition by the international community and not necessarily dedication to controlling population growth. This partly explains the implementation of the FP Program almost 20 years (i.e. in 1984) after the adoption of the policy.

The FP Program established guidelines to direct the implementation of the population policy - including how relevant laws on population issues were to be enacted, enforced and treated. The government increasingly showed more commitment to FP through the development of various national policies and guidelines in the 1980s and early 1990s. In 1982, with the support of the president, who was a proponent of reducing population growth, the National Council for Population and Development (NCPD) was formed to coordinate all population and development research activities in the country. The NCPD was also tasked with the role of supporting, coordinating and strengthening information, education, and communication (IEC) programs of other participating agencies. The 1980s and 1990s also saw FP activities delivered through a myriad of agencies, which included government health institutions, private hospitals, non-governmental organizations (NGOs) and faith-based organizations (FBOs). 
In 1994, Kenya became a signatory to the Program of Action (PoA) of ICPD. The conference stressed the need for governments to develop all-inclusive policies on reproductive health, programs and implementation plans accentuating the strategic role of information, education and community mobilization and participation ${ }^{26}$. The PoA had pledges to achieve the goal of universal access to reproductive health services for all countries by 2015 .

The Kenyan Health Policy Framework (KHPF) drew heavily from the 1994 ICPD and identified population growth management as a strategic imperative that was reemphasized in subsequent National Health Sector Strategic Plans (NHSSP I and II). A National Population Advocacy and IEC Strategy for Sustainable Development were established in 1996 by the NCPD. As a response to the ICPD PoA, the National Reproductive Health Strategy (NRHS) for the period 1997 to 2010 was also developed in 1996, and was the first action to operationalize the reproductive health agenda as recommended by the ICPD. The goal of the strategy was to provide a comprehensive and integrated system of reproductive health care through government, civil society organizations, and private sector facilities as outlined by the KHPF of 1994. The NRHS 1997 to 2010 laid the guidelines for the execution of the reproductive health program. However, implementation was hampered by inadequate funding, among other challenges, leading to declines in the quality of health service delivery and worsening health indicators. These worsening indicators included high levels of child and maternal mortality. ${ }^{32}$

The ICPD also informed the development of the National Population Policy for Sustainable Development, which was approved by Parliament in 2000. This policy succeeded the Population Policy Guidelines of 1984 and greatly built on the strength of the guidelines. In line with ICPD recommendations to make reproductive health services available, accessible, acceptable and affordable to young people, Kenya further developed the Adolescent Reproductive Health and Development (ARH\&D) policy in 2003. The policy underscores the relationship between the nation's development and the health of its youth and identifies the significant role that can be played by young people in enhancing their own health. The policy addresses various adolescent reproductive health issues and challenges including SRHR; harmful practices, including early marriage, female genital cutting and gender-based violence; drug and substance abuse; socio-economic factors; and the special needs of adolescents and young people with disabilities. ${ }^{33}$

In the mid-2000s, supporters of FP within the new government contributed to expanding policy. In 2004, the National Coordinating Agency for Population and Development (NCAPD) was established to replace the NCPD. After significant advocacy and increased support from international NGOs, the Kenyan Parliament allocated government funds toward FP in its budget for the first time, demonstrating national commitment by so doing.

In 2006, a Community Health Strategy was developed with the goal of improving access to health services and encouraging use of the health services, including FP, at the community level. This strategy also emphasized active participation of households and communities in development issues related to health. The following year, a population, urbanization and housing section was included in the medium-term strategic plan of Vision 
2030 based on the recognition that Kenya will become a predominately urban country. In addition, the Ministry of Health (MOH) officially adopted the National Reproductive Health Policy (NRHP) in 2007, the first national reproductive health policy. The policy provided a framework for the implementation of a comprehensive $\mathrm{RH}$ program, and the evaluation and modification of the NRHS 1997 to 2010. The policy laid guidelines for equitable and effective delivery of quality RH services in the country, and stressed the need to focus and reach underserved populations. The policy also aimed at guiding the planning of reproductive healthcare provision by stakeholders to ensure efficiency and homogeneity across services.

In 2009, the guidelines for provision of FP services were updated following the need to ensure that service providers are up to date with information on methods of contraception. The guidelines were also designed to ensure that clients seeking FP receive comprehensive care from the service providers. The 1997-2010 NRHS was revised in 2009 (2009-2015 $\mathrm{NRHS}$ ) to ensure that the inter-linkages between $\mathrm{RH}$ and all other sectors of development were properly identified and effectively addressed through a multi-sectoral approach.

In 2012, Kenya adopted a new population and development policy - the Population Policy for National Development - to address rapid population growth, which could pose a challenge to economic growth and reduce momentum for the attainment of the country's Vision 2030. The goal of the policy is to achieve a high quality of life for Kenyans by dealing with population growth in a sustainable way, given the available resources.

Since 2000 several other policies and strategies with implications for sexual and reproductive health and rights have been implemented. These include the Contraceptive Commodities Procurement Plan (2003-2006), which resulted in an improved organizational structure for managing the procurement and distribution of contraceptives within the $\mathrm{MOH}$ Division of Reproductive Health (DRH), along with better organization for lobbying for contraceptive commodities. It also included placement of a point person for contraceptives in the DRH and called for improved monitoring of contraceptive security.

Following the implementation of the Contraceptive Commodities Procurement Plan, the government prepared the National Contraceptive Commodities Security Strategy (20072012) with the aim of ensuring a continuous and affordable supply of contraceptives. With the expiration of this contraceptive strategy, the Kenyan government is yet to implement or develop a new one.

In 2009, the government implemented the National Condom Policy and Strategy (20092014), which aims to ensure that every Kenyan is able to access accurate information about condoms and a supply of these, irrespective of their geographical, economic or social status. To support this policy, the strategy focuses on expanding access to condoms, including the social marketing of both male and female condoms.

The National School Health Policy (2009) developed jointly by the Ministry of Public Health and Sanitation and the Ministry of Education, defines a comprehensive school health program that is meant to enable government to address the needs of learners, teachers and their families. ${ }^{34}$ The document covers a wide-range of health issues, including SRH, 
and life skills key in supporting young people's health. The policy recognizes the need to inform students on SRH and provide them with necessary skills to avert unwanted pregnancies, disease or sexual violence. The National School Health Policy approaches teen pregnancy from a human-rights angle and calls for the provision of counseling to a pregnant girl and her parents to ensure her well-being. The National School Health Policy also recognizes that girls have a right to education during and after pregnancy.

The National Reproductive Health and HIV and AIDS Integration Strategy (2009) sought to lay a framework for the integration of RH and HIV services. The aim of integration is to provide more comprehensive, convenient, acceptable and cost-effective $\mathrm{RH}$ and HIVIAIDS programs at all service-delivery points. The strategy provides the necessary framework for provision of coordinated RH and HIV integrated services across the two programs. The goal of this strategy is to increase access to comprehensive, high-quality, effective, efficient, affordable, and sustainable $\mathrm{RH}$ and HIVIAIDS services.

\subsubsection{Abortion laws and policies}

In Kenya, an estimated 2,600 women die from unsafe abortions annually and more than 21,000 women are hospitalized as a result of incomplete abortions and other abortionrelated complications. ${ }^{3}$ Unsafe abortion is estimated to account for 35 percent of maternal deaths in the country, a figure that is much higher than the global average of 13 percent. ${ }^{35}$ Increasing rates of sexual violence, poverty, limited access to FP information and services, and stigma against pregnant adolescents in Kenyan schools are key factors that lead to unintended pregnancy and consequently, in almost half the cases, unsafe abortion. ${ }^{3}$ Unsafe abortion is therefore a grim public health problem in Kenya that cannot be overlooked. The high rates of morbidity and mortality attributed to unsafe abortion have been blamed on Kenya's restrictive laws on abortion. ${ }^{3}$

In Kenya's previous Constitution, abortion was permitted only to protect a woman's life. However, the country's current Constitution explicitly permits abortion if it is conducted on the basis of advice from a trained health professional; if the case requires emergency treatment; if the life or health of the woman is in danger; or if it is permitted under any other written law. The Constitution further states that a person cannot be denied emergency treatment for any condition. ${ }^{29}$

It is not clear at present how extensive the new legal status of abortion is being comprehended and implemented in Kenya. ${ }^{4}$ Revisions are also yet to be completed to sections of the Kenyan Penal Code to reflect the provisions under the new Constitution. Many health practitioners may as a result be hesitant to carry out abortions for fear of the consequences in law. ${ }^{4}$ According to the Penal Code, self-inducing abortion or offering any other type of "unlawful" abortion is a criminal act punishable by a 7-to-14year prison sentence. ${ }^{29}$ Despite the legal restrictions and the health risks stemming from furtive abortion procedures, women in Kenya still obtain abortions from various sources - including unqualified providers. ${ }^{4}$

In October 2010, Kenya approved the Maputo Protocol which guarantees comprehensive rights to women such as to the right to have control over their RH. However, in an 
unparalleled move, Kenya entered its reservation with Article 14 (2) (C), prohibiting legal abortion in cases of rape and defilement and where the life and health of the mother and fetus are at risk. This move is inconsistent with Article 26(4) of the Constitution. As a result of incongruous and restrictive laws on abortion, high rates of clandestine abortions continue to occur. These include cases of women who genuinely qualify for lawful termination of pregnancy but who resort to unsafe abortions because of a lack of clear information on the abortion law.

In 2012, guidelines for provision of safe abortion care were launched. These guidelines recommend that all centers providing sexual health services should be youth friendly in order to reach as many young people as possible. The guidelines also define several health providers - including medical officers, clinical officers, nurses and midwives - who, having completed the required training can perform safe abortions in facilities that meet the criteria set forth in the guidelines.

Another important milestone in the abortion discourse was the registration of Mifepristone in 2012 and Misoprostol in 2008. These drugs are approved not only as a safe, noninvasive and effective method of early pregnancy termination, but also for the management of postpartum hemorrhage and the treatment of abortion complications. Misoprostol was listed in the Kenya Essential Medicines List (KEML) for the Ministry of Health in 2010, while Mifepristone was added in September 2012.

\subsection{Legal system and mechanism for protecting relevant human rights}

The government of Kenya has established various institutions to promote and protect the SRH rights of Kenyans. One of these is the Kenya National Commission on Human Rights, which, for example, constituted a public inquiry to investigate violations on SRH rights ${ }^{27}$ The High Court presents another avenue for investigating SRH violations. Through these avenues the government is obligated to respect, protect, and fulfil the SRH rights of Kenyans by making sure that necessary quality services are available and accessible.

Several NGOs have also been set up to protect and advocate for the SRH rights of individuals. Such organizations include the Center for Reproductive Rights (CRR), which uses the law to advance reproductive freedom as a fundamental human right, and the Reproductive Health Rights Alliance (RHRA), which is an alliance of advocates from medical-, legal-, women's rights- and reproductive health organizations that was formed to improve maternal health conditions. Member organizations of the RHRA include Africa Woman, the Centre for the Study of Adolescents, the Coalition on Violence Against Women, Family Heath Options Kenya, Federation of Women Lawyers (FIDA-Kenya), International Planned Parenthood Federation - Africa Regional Office (IPPF-ARO), the Kenya Human Rights Commission (KHRC), the Kenya Medical Association, the Kenya Obstetrics and Gynaecological Society, the National Nurses Association of Kenya, the Planned Parenthood Federation of America, individual activists, and representatives from law firms. The KHRC, a national NGO, seeks to secure the pledges made under the 
Constitution through advocacy initiatives and the meaningful participation of citizens in governance and policy creation.

In spite of the various measures to promote and protect the SRH rights of Kenyans, rights violations continue. For example, studies have shown that women seeking reproductive health services suffer physical and verbal abuse and detention in health facilities for inability to pay. ${ }^{3627,37}$ People living with HIVIAIDS also experience sexual and reproductive rights violations some of which include sterilization without consent and coercion to adopt an FP method preferred by the health care provider. ${ }^{27}$ Vulnerable and marginalized groups such as adolescents, people with disabilities, refugees and internally displaced persons also face a myriad of reproductive health rights violations. An inquiry by the KHRC on the extent of violation of reproductive health rights in Kenya showed that vulnerable groups were most exposed to SRH violations. Adolescents, for example, were noted to have difficulties accessing quality and friendly health care, including safe abortion services, STI services, ANC and skilled attendance at the time of delivery. Unintended pregnancies were also identified as a serious issue facing Kenyan adolescents. Several women with disabilities among those who testified at the inquiry complained of sexual harassment by health care workers. ${ }^{27}$

\subsection{Sexual and reproductive health among vulnerable groups}

In Kenya, vulnerable members of the population include, but are not limited to: people with disabilities; people infected or affected by HIVIAIDS; orphans and vulnerable children (OVC): the homeless; refugees and internally displaced people; adolescents and youth: and the poor in urban, rural and hard-to-reach areas.

\subsubsection{Adolescents}

Estimates from the 2009 Population and Housing Census show that adolescents constitute about 24 percent of the total population (9.2 million). Adolescents are defined as people aged between 10 and 19 years according to the World Health Organization (WHO). Adolescents are more vulnerable to STIs and pregnancy-related complications. ${ }^{38,}$ ${ }^{39}$ Studies have shown that adolescent girls are more likely to die while giving birth or during pregnancy than women 20 years and older..$^{40}$ Adolescents also lack comprehensive knowledge about the risks stemming from early sexual activity, as well as appropriate measures to prevent infection and pregnancy. ${ }^{41,42}$ Limited access of adolescent mothers to reproductive health services also predisposes them to higher risks of illness and death. Understanding the $\mathrm{RH}$ needs and rights of adolescents is therefore central to improving the health services offered to this vulnerable group.

According to the 2008/09 KDHS, about 26 percent of women and 58 percent of men between the ages of 15 and 24 who had never been married in Kenya had had sexual intercourse before the age of 18 , whereas 66 percent of women and 68 percent of men who had ever married had had sexual intercourse before the age of 18 . Because of 
inadequate knowledge and high levels of sexual activity among adolescents, levels of unmet need for contraceptives and unintended pregnancies is high, with an estimated 47 percent of the births in this group being unplanned. ${ }^{1}$ Among married adolescents, fertility behavior and regulation remains an issue, as about 30 percent of them in the latest KDHS reported having an unmet need for FP, especially the need for spacing births. Unfortunately, adolescents experiencing an unwanted pregnancy are more likely to resort to abortions, which are often illegal and done by unskilled attendants. A 2005 report by the Ministry of Health shows that an estimated half of all pregnancies of women aged 15 to 19 are terminated. ${ }^{43}$

In an attempt to address the RH needs, and to reduce fertility of adolescents, Kenya has in place a legal and policy framework that outlines measures aimed at addressing the SRH issues of adolescents. The goal of the 2003 ARH\&D Policy is to integrate adolescent health and development concerns into the national development process. In order to guide its implementation, the policy outlines several objectives and targets, including identifying the $\mathrm{RH}$ needs of adolescents and providing clear guidelines to deal with their health concerns. The 2005 National Guidelines for the Provision of Youth Friendly Services in Kenya outlines an essential RH services package for young people. The package includes: counseling; the provision of information and education on $\mathrm{RH}$; training in livelihood skills and life skills; the provision of contraceptives; the screening and treatment of STIs and HIVIAIDS; voluntary counseling and testing and comprehensive post-rape care. ${ }^{43}$ The 2007 Reproductive Health Policy stipulates that adolescents should have full access to SRH information and youth-friendly reproductive health services and that a multi-sectoral approach is adopted to address adolescents' SRH needs. In addition, the 2010-2012 Reproductive Health Communication Strategy identifies the provision of adequate information and universal access to $\mathrm{RH}$ services as a priority for young people for the purpose of improving their $\mathrm{RH}$.

Kenya's Constitution also protects the rights of adolescents to health care and guarantees protection from abuse and neglect, all forms of violence, harmful cultural practices, inhuman treatment and punishment, and hazardous or exploitative labor - Article 53 (NCLR, 2010). Article 43 ensures that adolescents enjoy the right to health care, including $\mathrm{RH}$ care. The 2006 Sexual Offences Act protects adolescents from sexual abuses namely incest, defilement and rape. The Counter Trafficking in Persons Act also seeks to guard adolescents from sexual abuse and spells out tough penalties for offenders.

Despite the various policies and guidelines that have been put in place to ensure proper $\mathrm{RH}$ for adolescents in Kenya, numerous challenges continue to be faced. For example, only 12 percent of health facilities actually provide the recommended comprehensive $\mathrm{RH}$ services to adolescents. ${ }^{44}$ Many Kenyan societies are yet to accept the reality of adolescent pre-marital sexuality, particularly for girls, which explains the frequent neglect of unmarried adolescents' RH needs. Unmet need for FP also continues to be a problem among adolescents. According to the 2008/09 KDHS, two-thirds of sexually active adolescents were not using a method of FP at the time the survey was conducted. The stigma that unmarried adolescents experience when they are seen at RH and HIV service centers is a great barrier to the use of $\mathrm{RH}$ services. ${ }^{45}$ 


\subsubsection{Adolescents living with HIV}

The population of adolescents infected with HIV in Kenya is expanding, partly as a result of the increased availability of antiretroviral treatment (ART), which has resulted in the increasing survival of children perinatally infected with HIV to adolescence ${ }^{45}$. HIV-positive adolescents face unique challenges as they transition to adulthood. There is limited data on HIV-positive adolescents in Kenya. However, research conducted in Uganda shows that about one-third had engaged in sexual intercourse, although disclosure on HIV status was low among those in a relationship at the time ${ }^{46} \mathrm{~A}$ study among HIV-positive adolescents in Kenya ${ }^{47}$ found that 2 in $10 \mathrm{HIV}$-positive adolescents who had consensual first sex had ever used a method of prevention and among those who had ever been sexually active less than half reported current use of contraceptives.

A dearth of programs address the RH needs of HIV-positive adolescents. ${ }^{45}$ Many of the programs that have begun integrating HIVIAIDS treatment and FP tend to target adults. The lack of appropriate services for this vulnerable group means that they are often unable to negotiate contraceptive use or even access contraceptive methods ${ }^{48}$ Other programmatic challenges include the lack of providers with specific skills to handle the unique SRH needs of this group and insufficient funding. ${ }^{49}$ Overall, HIV care support programs do not seem to address the reproductive desires or needs of HIV-positive adolescents. Consequently, there is a need for research on relationships among adolescents living with HIV and their implications not only for HIV prevention but also for contraceptive information and use, especially among those who are or desire to be sexually active. ${ }^{47}$

\subsubsection{Persons with disabilities}

The prevalence of disability in Kenya is estimated at 5 percent, which includes people with physical disabilities and those whose impairments are visual, auditory, mental, speech- and self-care related. ${ }^{50}$ According to the Kenya National Survey for Persons with Disabilities (KNSPWD) main report, ${ }^{50}$ more people with disabilities live in rural areas than in urban areas. People living with disabilities in Kenya face various challenges, which include stigma, abandonment, maltreatment and isolation. This is particularly so when disability is regarded as a curse and disgrace to the family. Seven percent of people living with disabilities, for example, reported being denied school enrolment because of their disability and a mere two percent reported having attained a university level education. ${ }^{50}$ Further, a large proportion of people with disabilities (69 percent) cannot easily access health services.

The Kenyan Constitution provides for rights to life and health for all people, including those with disabilities. The government also recognizes disability as an important consideration in national planning. For example, the government developed a national policy to abolish inequality in the provision of services, as well as to ensure that services are available to all people living with disabilities. The government also strives to offer a wide range of services to people living with disabilities. However, the services reach only a meager proportion and are not equally distributed among the various disabilities. 
Discrimination against the disabled is prohibited under the 2003 Persons with Disabilities Act, No 14. The Act provides for representation of people with disability, through the Council of Persons with Disabilities, in the implementation of health programs under the Ministry of Health. These programs enable people with disabilities access medical services in both the public and private health facilities at a reasonable cost. Although, no provision is made for people with disabilities under the 2007 NRHP, the NRHS addresses the RH needs of people living with disabilities. This is done through two strategies: raising awareness about people living with disabilities and strengthening the capacity of health systems to provide quality $\mathrm{RH}$ services to people living with disabilities as well as improve access to services.

\subsubsection{Orphans and vulnerable children (OVC)}

Although the actual number of OVC is not known, partly due to a lack of consensus on a uniform definition, it is currently estimated that there are about 2.4 million orphans in Kenya, with about 47 percent orphaned as a result of HIVIAIDS. ${ }^{51}$ The government is currently working on a country definition of OVC and a conclusive agreement is yet to be reached. The current working definition is a child aged below 18 years whose parent or parents have died. ${ }^{52}$

One of the strategies in the NRHP is to improve access and use of RH services among vulnerable groups including OVC and one of the ways it intends to achieve this goal is by promoting strategies that reduce inequities in $\mathrm{RH}$ care access. The SRH needs of OVC, however, remain neglected.

\subsubsection{Refugees and internally displaced persons (IDPs)}

A Refugee Act was approved by the Kenyan Parliament in 2006. The Act provides legal authority for handling refugee matters, creates an institutional framework, formalizes organizational processes, and formalizes the handling of refugees as a government function. Section 16(a) provides that refugees shall be entitled to the rights and be subject to the obligations contained in the international conventions to which Kenya is a party. By this provision, the stipulations on $\mathrm{SRH}$ that are included in all human rights treaties ratified by Kenya are applicable to refugees. Although the Constitution protects the rights of minorities, including IDPs, Kenya is yet to adopt a legal framework that recognizes and provides for the safety and support of IDPs. However an IDP policy in Kenya is currently under development.

Despite these measures, refugees and IDPs continue to face problems related to lack of access to SRH services, including FP and maternal health care, among others. The reasons for these problems stem from IDPs' moving to new environments (such as camps), which rarely have the services. ${ }^{53}$ This is even worse for people living with disability who reside in refugee or IDP camps, as they are exposed to multiple vulnerabilities. In addition to the inadequate access to SRH services, refugees and IDPs also experience sexual violence while in camps..$^{52}$ It is therefore necessary that refugees and IDPs camps be linked to proper and functional health care facilities that provide SRH services. 


\subsection{Socio-cultural norms concerning family formation and childbearing}

Cultural values and social norms in different communities influence views on fertility and reproduction. ${ }^{54,55}$ The socio-cultural influence on childbearing and family formation in Kenya, just as in other countries in SSA, was particularly prominent during the colonial period and the high fertility rates that were experienced in Kenya were attributed to, among other factors, the strong socio-cultural factors relating to marriage, age at first union and infant mortality levels. ${ }^{56}$ The changes in fertility over time are evident from the various surveys that have been conducted. Results show a dramatic drop in the total fertility rate from a high of 8.1 in the late 1970s to about 6.7 in the late 1980s and to about 5.0 in the 1990s. ${ }^{10}$ This section examines key socio-cultural norms that are likely to have influenced family formation and childbearing and have contributed to the changes in fertility levels in Kenya.

\subsubsection{Shifts in marriage patterns}

Marriage has a strong effect on fertility and is considered one of the most important proximate determinants of fertility. ${ }^{57,58}$ Over the years, there has been a shift in marriage patterns, including an increase in age at first marriage, a decline in polygamy and an increase in pre-marital childbearing, among others. Such shifts have contributed to the decline in the fertility in Kenya. Marriage, for example, is a primary indicator for exposure of women to risk of pregnancy and increased age at first marriage shown to reduce the exposure to the risk of early childbearing.$^{59}$ Data from the KDHS indicate that the gap between age at sexual initiation and median age at first marriage is increasing. Today, although marriage is still seen as a basis of family formation, the stigma that comes with sexual intercourse out of marriage is being eroded, and a rise in single motherhood is observed. ${ }^{60}$ The increase in childbearing outside marriage is reflected in the KDHS, which shows an increasing trend in the number of births from unmarried women between 1989 and 2008. ${ }^{1,61}$

\subsubsection{Age at first marriage}

The median age at first marriage has been on the rise in Kenya. In 1989 it was estimated at about 17.4 years ${ }^{61}$ The median age rose to 18.8 in 1993 to 19.7 in 2003 and again rose slightly to 20 in 2008 (KDHS 1989, 1993, 2003, 2008). The minimum age for marriage according to the Children's Act, Customary Law and Sharia Law in Kenya is 18;62 however, there are other statutes in place such as the Hindu Marriage and Divorce Act and the Marriage Act that allow marriage at the age of 16 years. In some ethnic groups one is allowed to marry after undergoing certain rites of passage such as circumcision, female genital mutilation, and removal of front teeth. Consequently, early marriage continues to be a common occurrence. According to the 2008/09 KDHS, half of all women get married by the age of 20 years. Rural women, those living in poor households, and women with 
no education enter marriage almost three years earlier than women in urban areas, those from wealthier households, and those with higher levels of education.

\subsubsection{Polygyny}

Polygyny has been shown to raise fertility levels. It has been associated with the explosive population growth in SSA countries since the 1950s. ${ }^{63}$ Polygyny is associated with very early age at first marriage among girls, which exposes them to early pregnancy. It also encourages remarriage of separated, divorced, or widowed women, which helps extend reproductive duration. ${ }^{64}$ The prevalence of polygyny has declined substantially over the years in Kenya as in other countries in SSA. The result of the economic demands of maintaining more than one wife is that fewer polygamous marriages exist. ${ }^{64}$

The levels of polygyny in Kenya are ethnically heterogeneous. Levels of polygyny range from 9 percent among the Kikuyus to 33 percent among the Luos, who, reportedly, have the highest prevalence of polygyny in the country. ${ }^{63,65}$ Though levels of polygyny have declined, polygyny is still permissible if a marriage is contracted under customary law or if it is conducted under Islamic law. Men continue to have more than one wife, though the practice is mainly carried out through 'concubineage' where only the first wife is declared and others kept without a marriage declaration. ${ }^{66}$

In the 1960s and 1970s when polygyny was more common, it is argued to have contributed to the high fertility levels in the country. ${ }^{63,64}$ In urban Kenya, the proportion of women in polygamous unions dropped from 25 percent to 18 percent between 1977 and 1989 and in rural Kenya it has varied from 30 percent to 25 percent. ${ }^{67}$ The latest estimates put the levels of polygyny at 13 percent. ${ }^{1}$

\subsubsection{Initiation of childbearing}

The increase in the age at which women initiate childbearing in many parts of SSA is considered to be one of the causes of fertility decline. ${ }^{69}$ Just as age at first marriage, age at first birth in Kenya has been on the rise over the decades. ${ }^{62}$ The KDHS indicate a marginal rise in the median age at first birth (18.7 to 19.8 years) between 198961 and 2008/091 for women aged 25 to 29. Education and women's increased participation in the workforce have been said to play a key role in increasing the age at first birth.

\subsection{Chapter summary}

- In Kenya SRH is recognized as a key human right and several measures have been taken to assure this right. The new Constitution, for example, provides fundamental guiding principles that clearly stipulate the right to $\mathrm{RH}$ care and services. Kenya also has a robust population, FP and $\mathrm{RH}$ policy environment and various $\mathrm{RH}$ policies have been developed to promote $\mathrm{RH}$. 
- Despite the high number of policies and strategies to promote $\mathrm{SRH}$, disconnect exists between policies and action. Kenya's RH indicators remain poor and a myriad of SRH challenges continue to be faced, some of which include a high rate of unintended pregnancies and unsafe abortions. These challenges give rise to high morbidity and mortality especially among adolescents and other vulnerable populations.

- $\mathrm{SRH}$ rights, especially those of vulnerable members of the population - people infected or affected by HIVIAIDS, OVC, refugees and internally displaced persons and adolescents and youth - continue to be violated and efforts to prevent and redress these violations are urgently needed.

- Several socio-cultural factors influence childbearing and family formation in Kenya. Shifts in marriage patterns, which include increase in age at first marriage, decline in polygyny and an increase in pre-marital childbearing, have contributed to changes in fertility levels over time. 


\section{CHAPTER 3}

\section{Family Planning and Reproductive Health Indicators: Trend and Equity Analyses}

\subsection{Introduction}

Family planning is the most effective intervention to prevent unintended pregnancies and abortion, with direct and indirect effects on improved maternal-, infant- and child health and survival. In Kenya where fertility levels and the number of women with unmet need for family planning have remained high, it is essential to examine the drivers of high fertility, unintended pregnancies and abortion through an equity lens. This chapter describes: women's knowledge; ever use and current use of contraceptive methods; partner knowledge and approval of contraception; sources of modern methods; access to FP services; and incidence of abortion. The chapter also examines FP among vulnerable populations. The main focus of this chapter is married women and unmarried women who are sexually active, as they are exposed to the risk of pregnancy and, therefore, at greater need of contraception.

\subsection{Family planning: awareness, attitudes and use}

\subsubsection{Awareness of family planning}

Figure 3.1 shows the level of awareness of FP methods among women in Kenya aged 15 to 49 according to their marital status in the $2008 / 09 \mathrm{KDHS}$. About 95 percent of all women reported knowing a method of contraception. The most commonly known methods among all women were male condoms, injectables, and the pill. A substantially low proportion of women were aware of long-acting- or permanent methods such as implants, the intrauterine device (IUD), or sterilization - particularly male sterilization.

Figure 3.1: Percentage of all women, currently married women, and sexually active unmarried women aged 15-49 who know a contraceptive method, KDHS 2008/09

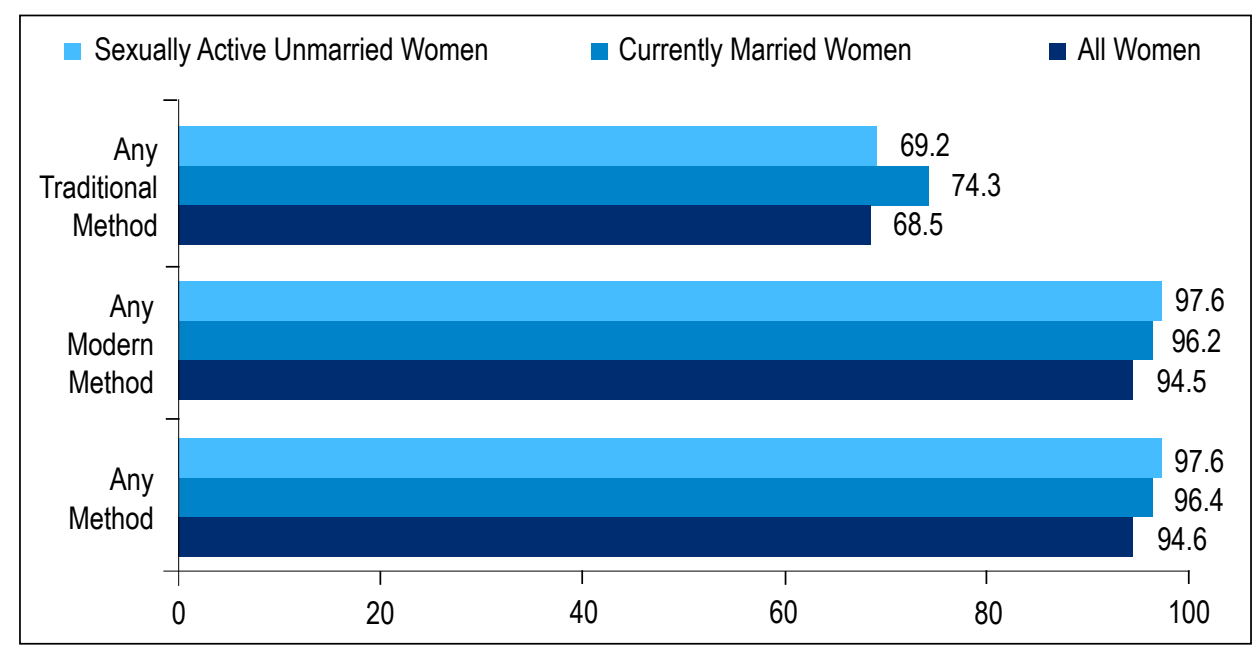




\subsubsection{Trends in knowledge of contraceptive methods}

Figure 3.2 shows trends in knowledge of modern family planning methods among women in Kenya from 1993 to 2008/09. Overall, trends show consistently high knowledge of modern methods though a slight decrease was observed for sexually active unmarried women in 2008/09 (see Tables A1 and A2 in the appendix for more detailed information on knowledge of contraceptive by specific method type). The most commonly known methods were the pill, injectables and male condoms. The most notable change across the years is the increasing number of women who are aware of long-acting methods of contraception. For example, in 1993, 13 percent of women knew about implants while in 2008/09, 67 percent of women were aware of this method.

Figure 3.2: Percentage of currently married and sexually active unmarried women aged 15-49 who know specific modern contraceptive methods, KDHS 1993, 1998, $2003,2008 / 09$

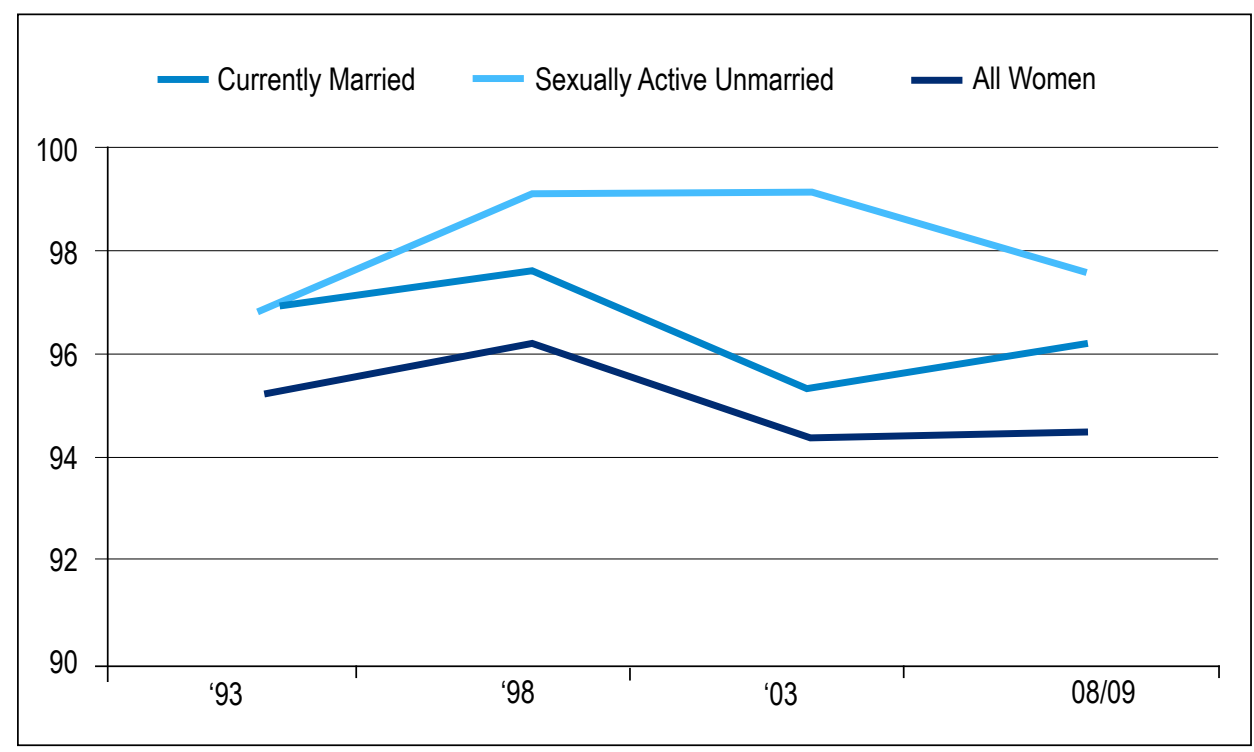

\subsubsection{Knowledge of contraceptive method by background characteristics}

Tables A3 and A4 in the appendix provide detailed information on knowledge of specific FP methods by women's background characteristics. Levels of awareness remained high over the years, especially for modern contraceptive knowledge. Across all years, awareness of contraceptive methods was higher among urban women compared with their rural counterparts. Education was positively associated with method awareness, with a greater proportion of women with at least secondary education during the 1993 to 2008/09 period being aware of any method, modern method, and traditional method than those with less than secondary education. Among women with no education, the 
proportion of women aware of any modern method declined substantially between 1993 (91 percent) and 2008/09 (77 percent). Across all years, a greater proportion of women from the most wealthy and middle wealth tertiles than in the least wealthy tertile were aware of any method or any modern method. Data also show that contraceptive knowledge was widespread across all the provinces.

\subsubsection{Approval of family planning}

The level of approval of contraception is an indicator of potential willingness of a population to accept the use of FP methods. Figure 3.3 shows the level of approval of FP for the currently married and the sexually active unmarried for Kenya between 1993 and 2003. There was a gradual decline in the levels of approval for FP between 1993 and 2003 for currently married women but not for sexually active unmarried women. Figure 3.4 shows the levels of approval by age of respondent. Results show that about 92 percent of currently married women aged 15 to 24 approved of FP in 1993 but this percentage decreased to 76 percent by 2003 . Similar trends were observed among currently married women in the other age groups, with declines in levels of approval seen between 1993 and 2003.

Figure 3.3: Percentage of currently married and sexually active unmarried women who approved of family planning, KDHS 1993 to 2003 (2008/09 KDHS did not directly report on approval of FP planning and was therefore not included in this analysis)

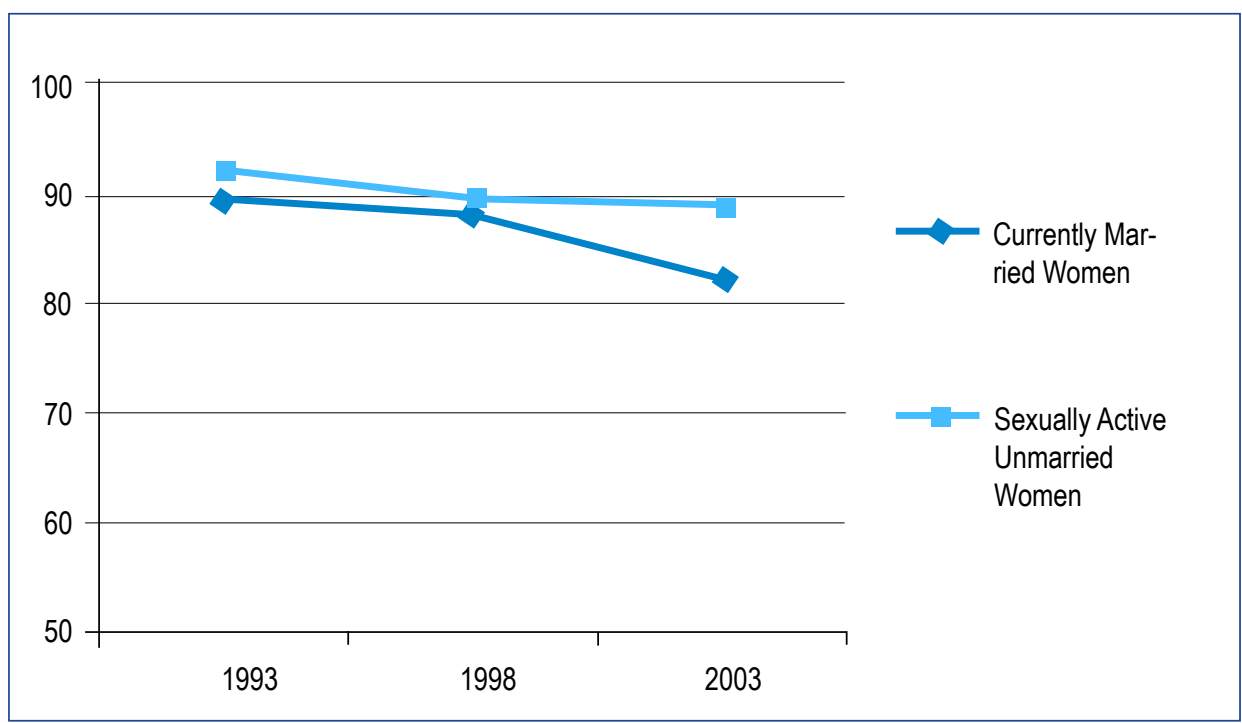

Table A5 in the appendix provides detailed information on approval of FP by selected background characteristics. Approval of FP was positively associated with level of education and household wealth. Levels of approval were consistently lower among currently married and sexually active unmarried women with no education and those from 
households in the least wealthy tertile. FP approval was highest among urban residents compared with rural residents, though the difference in proportion was not very huge. Approval for FP was highest, irrespective of marital status for women in Nairobi, Central, Eastern, Nyanza and Western provinces. Despite this, the percentage of currently married women who approved of FP decreased between 1993 and 2003 in all the eight provinces.

Figure 3.4: Percentage of currently married women who approved of family planning by age, KDHS 1993 to 2003 (2008/09 KDHS did not directly report on approval of FP planning and was not included in this analysis)

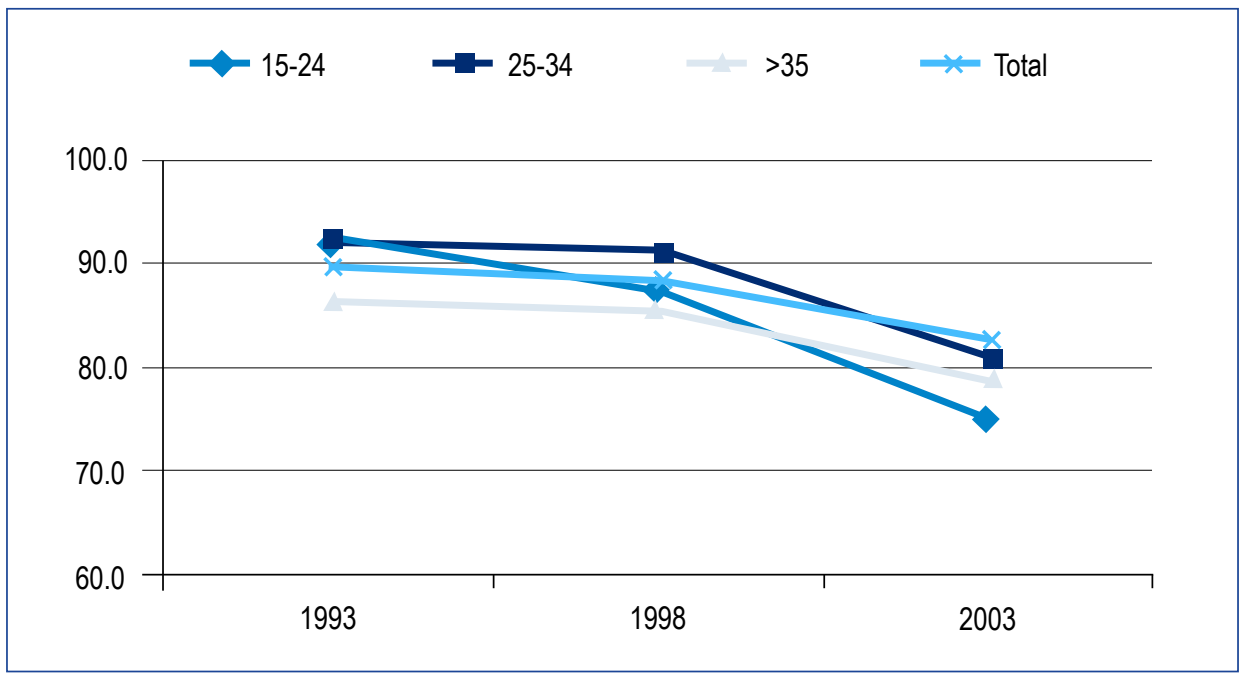

\subsubsection{Husband/Partner's knowledge of woman's use of contraception}

The extent to which couples discuss FP and women's use contraception without their partners' knowledge was assessed. Currently married women who reported knowing a contraceptive method were asked if they discussed contraceptive use with their partners. Overall, spousal communication was high, with over 89 percent of currently married women reporting that their husbands or partners were aware that they were using a contraceptive method. Table A6 in the appendix provides detailed information by background characteristics on the distribution of currently married women ages 15 to 49 who use a method and have reported to their husband/partner. A higher proportion of younger women ( 15 to 24 years) than older women stated that their husbands or partners did not know that their wives or partners were using a contraceptive method. Inter-spousal communication was also associated with level of education, with a greater proportion of women with at least secondary education reporting that they had discussed using contraceptives with their husbands or partners. Discussion of contraceptive use between partners showed marginal variation by the different provinces, though a notably higher proportion of women in Nyanza and Western Provinces reported that their partner was not aware that they were using a contraceptive. 


\subsubsection{Exposure to family planning messages}

Mass media is considered an effective way to promote contraceptive behavior. Information diffused correctly can have significant impacts on attitude change toward contraceptive behavior and its consequent practice. Table A7 in the appendix provides detailed information on the percentage distribution of women who were exposed to FP messages through various media in the months preceding the 1998 and 2008/09 surveys, by specific background characteristics. The proportion of women who had heard of FP messages via radio and TV increased between the two survey years, while the levels for exposure to FP messages via newspapers stayed consistent. Radio was the most popular medium followed by television and then newspapers.

Between 1998 and 2008/09 there was an overall increase in the percentage of women who had heard FP messages over the radio among women of all age groups, although a slightly higher percentage of older women heard the messages on radio compared with younger women. Exposure to FP messages varied by level of education and household wealth for all three forms of media, with a greater proportion of women with at least secondary education than those with less than secondary education reporting that they had been exposed to FP messages through a variety of media. While there was a notable increase in the percentage who heard FP messages on radio between 1998 and 2008/09, levels of exposure via radio actually decreased among women with no education.

With regard to household wealth, while only 38 percent of women from the least wealthy households had heard FP messages on radio in 1998, the proportion increased substantially to 53 percent by 2008/09. Similar trends were seen with the television medium and newspapers for all other household wealth groups. Variations were also observed in exposure to these three forms of media by place and area of residence. As expected, women residing in urban areas were more likely to have more exposure to FP messages compared with their rural counterparts. Women residing in Central Province had the highest exposure to FP messages through radio, while women in Eastern Province had the lowest percentage. Exposure to FP messages through television and newspapers was highest in the Nairobi province, while it was lowest among women in Western province.

\subsubsection{Use of family planning}

\subsubsection{Ever use of contraception}

Ever use of contraception is defined as the use of a contraceptive method at any time during a woman's reproductive years. Figure 3.5 shows the percentage of all women aged 15 to 49, who had ever used a contraceptive method by selected background characteristics based on the 2008/09 KDHS. With the exception of male condoms and emergency contraception, a smaller proportion of women aged 15 to 24 had ever used contraception compared with older women. A lower proportion of women with no education had ever used contraception, with the exception of female sterilization and folk methods. Women from households in the wealthiest tertile were more likely to have ever used any method (64 percent) and any modern method (61 percent) than women from households 
in the least wealthy tertiles, among whom 38 percent had ever used any method and 35 percent had ever used a modern method. Ever use of modern methods was higher among women from urban areas for most methods except female sterilization, injectables and long-acting methods (see Table A8 in the appendix for more detailed information on the distribution of all women aged 15 to 49 who had ever used any contraceptive method, by background characteristics).

Figure 3.5: Percentage of all women 15-49 who had ever used any contraceptive method or modern method by selected background characteristics, KDHS 2008/09

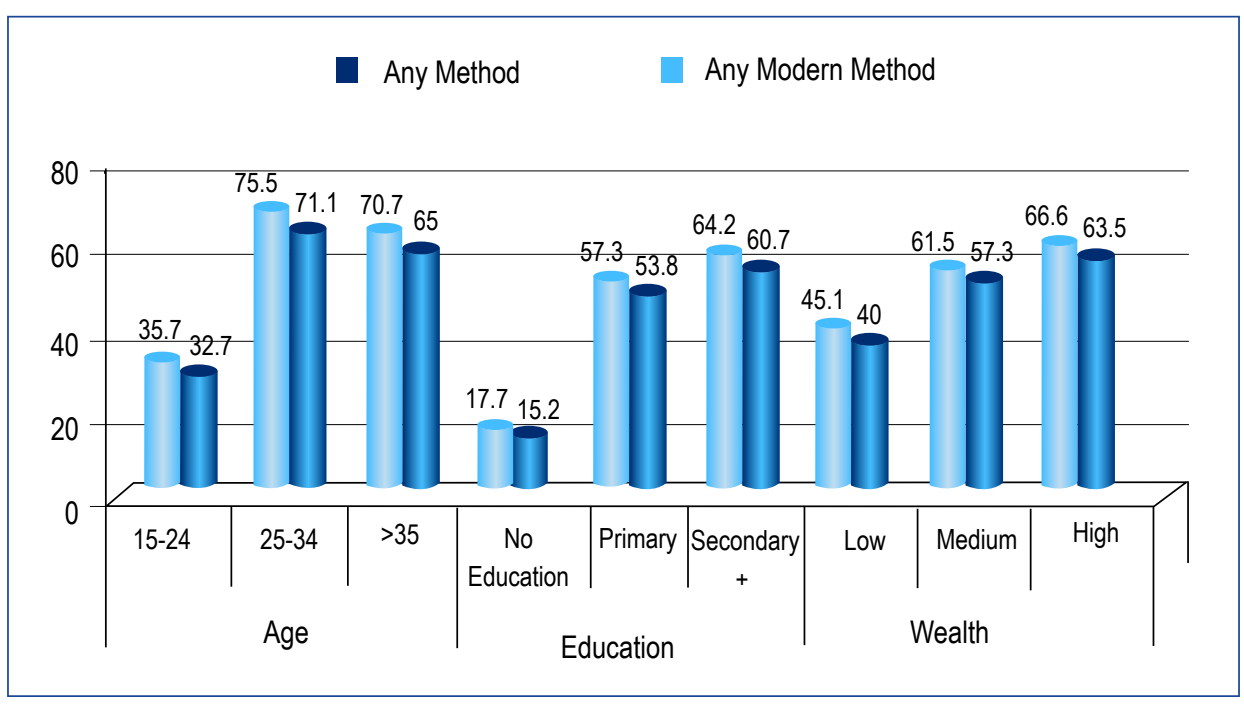

Table 3.1 shows the percentage of women who have ever used a modern method of contraception by respondents' age and marital status for survey years 1993, 1998, 2003 and 2008/09. Overall, ever use of modern contraception increased from 43 percent in 1993 to 68 percent in 2008/09. The same pattern is noted among currently unmarried women where the percentage increased from 20 percent in 1993 to 34 percent in 2008/09.

Table 3.1: Percent distribution of all currently married and currently unmarried women aged 15-49 who had ever used any modern method of contraception by age of respondent, KDHS 1993, 1998, 2003, 2008/09

\begin{tabular}{|l|c|c|c|c|c|c|c|c|}
\hline \multicolumn{3}{|c|}{ Currently Married } & \multicolumn{4}{c|}{$\begin{array}{c}\text { Currently unmarried } \\
\text { (Never married + Formerly married) }\end{array}$} \\
\hline Age & 1993 & 1998 & $\mathbf{2 0 0 3}$ & $\mathbf{2 0 0 8 / 0 9}$ & $\mathbf{1 9 9 3}$ & 1998 & $\mathbf{2 0 0 3}$ & $\mathbf{2 0 0 8 / 0 9}$ \\
\hline $15-24$ & 30.3 & 40.4 & 41.1 & 57.4 & 12.5 & 13.1 & 13.5 & 19.8 \\
\hline $25-34$ & 50.2 & 59.2 & 61.4 & 73.0 & 49.9 & 56.5 & 52.2 & 63.5 \\
\hline$>35$ & 42.8 & 56.2 & 58.7 & 68.6 & 37.8 & 48.3 & 54.4 & 56.9 \\
\hline Total & 42.6 & $\mathbf{5 3 . 4}$ & $\mathbf{5 5 . 1}$ & $\mathbf{6 7 . 8}$ & $\mathbf{2 0 . 3}$ & $\mathbf{2 4 . 5}$ & $\mathbf{2 6 . 0}$ & $\mathbf{3 3 . 7}$ \\
\hline
\end{tabular}




\subsubsection{Trends in current use of contraceptive methods by selected background characteristics}

Table 3.2 shows the trends in contraceptive prevalence rates among currently married women by selected background characteristics. The data show a 4-percentage-point increase in modern contraceptive usage between 1993 and 1998 (27 percent to 32 percent), a stall between 1998 and 2003 and a peak in 2008/09 at 39 percent. Women with more education, those living in the wealthiest households and women in urban areas had higher contraceptive prevalence rates (CPR). However, women with a primary level of education recorded a gradual increase in CPR from 26 percent in 1993 to 38 percent in 2008 , while the reverse was true for women with no education. Some regional variation was observed, with Nairobi, Central and Eastern provinces showing marked gradual increases over time. Overall, stalls and even declines were seen between 1998 and 2003 for most background characteristics with uptake than seen in 2008/09 (see Table A9 in appendix for more detailed information on the distribution of currently married and sexually active unmarried women aged 15 to 49 who were currently using any method of contraception, by background characteristics).

Table 3.2: Percent distribution of all currently married women aged 15-49 who were currently using contraception by background characteristics, KDHS 1993, 1998, $2003,2008 / 09$

\begin{tabular}{|l|c|c|c|c|c|c|c|c|}
\hline \multirow{2}{*}{$\begin{array}{l}\text { Background } \\
\text { Characteristics }\end{array}$} & \multicolumn{5}{|c|}{ Any Modern Method } & \multicolumn{5}{c|}{ Any Method } \\
\cline { 2 - 9 } Education & 1993 & 1998 & 2003 & $2008 / 09$ & 1993 & 1998 & 2003 & $2008 / 09$ \\
\hline No Education & 15.3 & 16.1 & 8.0 & 12.0 & 19.5 & 22.8 & 12.0 & 14.1 \\
\hline Primary Education & 25.6 & 28.2 & 28.8 & 38.3 & 31.1 & 34.5 & 36.6 & 44.2 \\
\hline Secondary + & 44.9 & 46.3 & 51.7 & 52.1 & 51.6 & 56.7 & 61.8 & 59.8 \\
\hline Wealth & & & & & & & & \\
\hline Low & 12.4 & 16.4 & 17.1 & 25.1 & 16.9 & 23.7 & 24.0 & 29.8 \\
\hline Medium & 30.3 & 34.1 & 36.6 & 45.6 & 35.7 & 41.3 & 45.7 & 52.1 \\
\hline High & 42.9 & 47.5 & 44.0 & 48.7 & 49.8 & 55.6 & 51.3 & 55.7 \\
\hline Residence & & & & & & & & \\
\hline Urban & 37.9 & 41.0 & 39.9 & 46.6 & 43.4 & 49.6 & 47.6 & 53.1 \\
\hline Rural & 25.4 & 29.0 & 29.2 & 37.2 & 30.9 & 36.2 & 37.0 & 43.1 \\
\hline Province & & & & & & & & \\
\hline Nairobi & 37.8 & 46.8 & 44.3 & 49.0 & 45.4 & 56.3 & 50.7 & 55.3 \\
\hline Central & 49.7 & 54.8 & 57.9 & 62.5 & 56.0 & 61.1 & 66.4 & 66.7 \\
\hline Coast & 16.6 & 20.0 & 19.1 & 29.7 & 20.2 & 22.1 & 24.1 & 34.3 \\
\hline Eastern & 30.5 & 36.0 & 38.4 & 43.8 & 38.4 & 45.6 & 50.6 & 52 \\
\hline
\end{tabular}


Table 3.2: Cont...

\begin{tabular}{|l|c|c|c|c|c|c|c|c|}
\hline \multirow{2}{*}{$\begin{array}{l}\text { Background } \\
\text { Characteristics }\end{array}$} & \multicolumn{4}{|c|}{ Any Modern Method } & \multicolumn{4}{c|}{ Any Method } \\
\cline { 2 - 10 } & 1993 & 1998 & 2003 & $2008 / 09$ & 1993 & 1998 & 2003 & $\mathbf{2 0 0 8 / 0 9}$ \\
\hline \hline Nyanza & 21.5 & 25.0 & 21.0 & 32.9 & 23.8 & 28.2 & 24.7 & 37.3 \\
\hline Rift Valley & 21.0 & 26.4 & 24.5 & 34.7 & 27.8 & 37.7 & 34.4 & 42.4 \\
\hline Western & 21.7 & 21.9 & 27.3 & 41.1 & 25.1 & 30.2 & 34.1 & 46.5 \\
\hline North Eastern & - & - & 0.2 & 3.5 & - & - & 0.2 & 3.5 \\
\hline Total & $\mathbf{2 7 . 3}$ & $\mathbf{3 1 . 5}$ & $\mathbf{3 1 . 5}$ & $\mathbf{3 9 . 4}$ & $\mathbf{3 2 . 7}$ & $\mathbf{3 9 . 0}$ & $\mathbf{3 9 . 3}$ & $\mathbf{4 5 . 5}$ \\
\hline
\end{tabular}

Figure 3.6 shows the percentage of all women who were currently using specific FP methods between 1993 and 2008/09. A slight increase in the use of female sterilization was observed between 1993 and 1998 followed by a decrease in 2003 and later an increase in 2008/09. There was a decrease between 1993 and 2008/09 in current use of the pill and the IUD. Current use of injectables, implants and male condoms steadily increased over time with use of injectables increasing from about 6 percent in 1993 to about 15 percent by 2008/09.

Figure 3.6: Trends in current use of specific modern contraceptive methods for all women 15-49, KDHS 1993, 1998, 2003, 2008/09

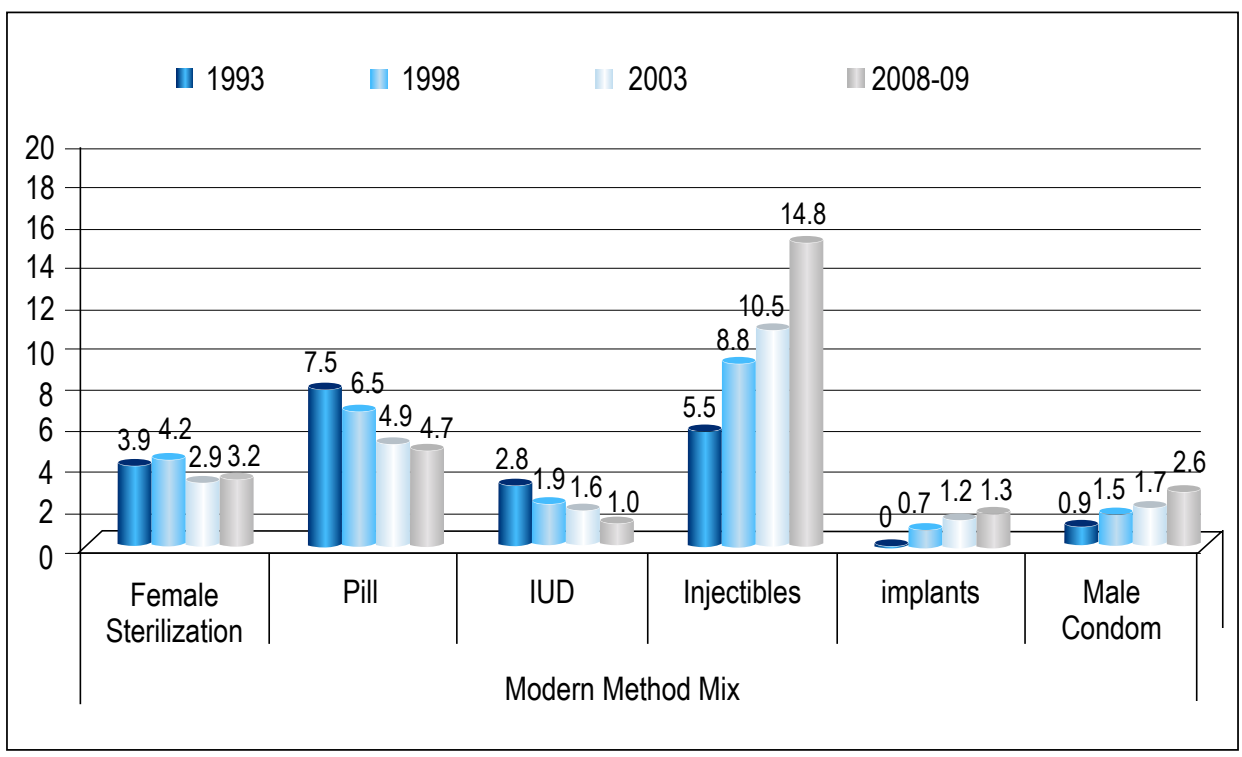

\subsubsection{Current use of contraception by women's empowerment status}

It is posited that women who are empowered to voluntarily plan their families reap social, economic and psychological benefits. ${ }^{70}$ Female empowerment in the KDHS is captured by measuring women's involvement in household decision making (a proxy for higher status within a relationship) and attitudes toward physical violence (a series of hypothetical 
scenarios in which a woman might feel wife beating was justified - proxy for low status within a relationship). Table 3.3 describes the relationship between these indicators and current contraceptive use.

Overall, there was a positive association between a woman's status and contraceptive use. For example, women who participated in all 5 household decisions presented were almost twice as likely to use any contraceptive method (50 percent) compared with women who did not participate in any household decision making (28 percent). Furthermore, women who were more likely to think wife beating was justified for all or any of the five reasons (such as neglecting children or going out without husband's permission) were more likely not to use contraception.

Table 3.3: Percent distribution of currently married women aged $15-49$ by current contraceptive method, according to selected indicators of women's status, KDHS 2008/09

\begin{tabular}{|l|c|c|c|c|c|c|c|}
\hline \multirow{2}{*}{ Empowerment Indicators } & \multicolumn{5}{|c|}{ Any Modern Method } \\
\cline { 2 - 8 } & AM & MM & FS & $\begin{array}{c}\text { Temporary } \\
\text { Modern } \\
\text { Female } \\
\text { Methods }\end{array}$ & $\begin{array}{c}\text { TM } \\
\text { Not } \\
\text { Currently } \\
\text { Using }\end{array}$ & N \\
\hline $\begin{array}{l}\text { Number of Decisions in } \\
\text { Which women Participate }\end{array}$ & & & & & & & \\
\hline 0 & 28.2 & 26.6 & 1.6 & 22.6 & 1.6 & 71.8 & 124 \\
\hline $1-2$ & 32.9 & 24.9 & 2.8 & 21.4 & 8.0 & 67.1 & 771 \\
\hline $3-4$ & 45.4 & 39.2 & 4.9 & 32.3 & 6.1 & 54.6 & 1,571 \\
\hline 5 & 50.3 & 44.8 & 5.5 & 37.3 & 5.6 & 49.7 & 2,463 \\
\hline $\begin{array}{l}\text { Number of Reasons for } \\
\text { Which Wife Beating is } \\
\text { Justified }\end{array}$ & & & & & & & \\
\hline 0 & 51.6 & 45.8 & 4.2 & 39.7 & 5.8 & 48.4 & 2,274 \\
\hline $1-2$ & 41.8 & 35.2 & 4.6 & 28.2 & 6.6 & 58.2 & 1,273 \\
\hline $3-4$ & 37.9 & 31.5 & 5.3 & 25.5 & 6.3 & 62.1 & 1,023 \\
\hline 5 & 41.3 & 36.8 & 7.6 & 26.8 & 4.5 & 58.7 & 358 \\
\hline Total & 45.5 & 39.4 & 4.8 & 32.8 & 6.0 & 54.5 & 4,928 \\
\hline
\end{tabular}

Note: If more than one method is used, only the most effective method is considered in this tabulation.

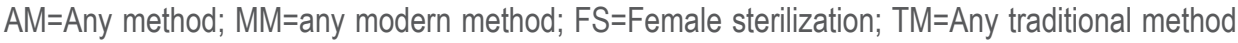
${ }^{1}$ Pill, IUD, injectables, implants, female condom, diaphragm, foam/jelly, and lactational amenorrhea method 


\subsubsection{Number of children at first use of contraception}

The use of contraception has been shown to vary by parity. ${ }^{71}$ Figure 3.7 shows the percentage distribution of women aged 15 to 49 by number of living children when they first started to use contraception over a 15-year period (1993 to 2008/09). In 2008/09 Kenyan women were more likely to initiate contraceptive use at lower parity than in the previous years. A higher proportion of younger women (15 to 24 years) used contraception before having any children compared with older cohorts ( 25 years and above). This result may reflect the fact that younger women are more likely to use contraception to delay childbearing while older women were more inclined to use contraception to space or limit births. Agreater proportion of women with at least secondary education and those from the wealthiest households initiated contraceptive use at zero parity compared with those with less than secondary education and those from the least wealthy households, respectively. Table A10 in the appendix provides detailed information on the distribution of all women aged 15 to 49 by number of children at the time of use of contraception, by background characteristics. Across all survey years, unmarried sexually active women were more likely to use contraceptives at zero parity compared with currently married or formerly married women. A greater proportion of urban women initiated contraceptive use at lower parity than their rural counterparts. Across all survey years, women in Nairobi and Central Provinces were more likely to use contraception before first birth, while women in North Eastern Province were least likely to do so.

Figure 3.7: Percent distribution of women aged $15-49$ by number of children at the time of first use of contraception, by selected background characteristics, KDHS 2008/09

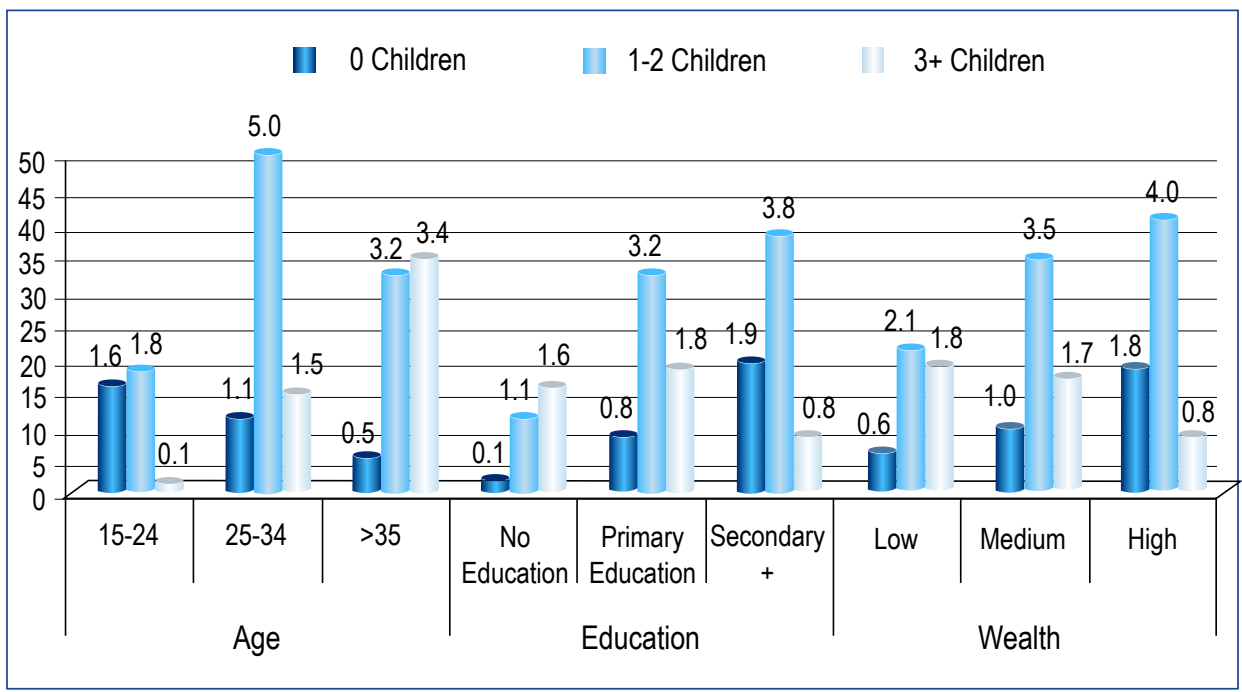

\subsubsection{Sources of contraceptives}

TableA11 in the appendix provides detailed information on the distribution of married women who were currently using a contraceptive method by their most recent source for all for 
survey years. Generally, Kenyan women were more likely to obtain contraceptives from a public source, though overall public sector provision declined between 1998 and 2003 and increased slightly in 2008/09. Older women (at least 25 years) were more likely to report public health facilities as their most recent source of supply, while younger women, aged 15 to 24 years, were more likely to report the private sector as their most recent source of contraception. Currently married women with no education and in the least wealthy households were more likely to report the public sector as their supply of contraceptives. A greater proportion of women with secondary or higher education and those from the wealthiest tertile obtained contraception from the private sector compared with those with less than secondary education and those from the least wealthy households, respectively.

\subsubsection{Contraceptive use and intention}

Figure 3.8 depicts trends in contraceptive use intentions among currently married women in Kenya between 1993 and 2008/09. Intention to use contraception declined over the years, from 55 percent in the 90 s to 40 percent in the 2008/09. Table A12 in the appendix provides detailed information on contraceptive use intention by selected background characteristics. Intention not to use contraception increased among women of all age groups between 1993 and 2008/09, especially among those 35 years and above. This might be a result of this particular age group being closer to the end of their reproductive cycle compared with the younger cohorts. The decrease in intention to use contraception was observed across all women irrespective of wealth status and area of residence (urban or rural).

Figure 3.8: Percentage distribution of currently married women aged 15-49 by intention to use contraception in future, KDHS 1993, 1998, 2003, 2008/09

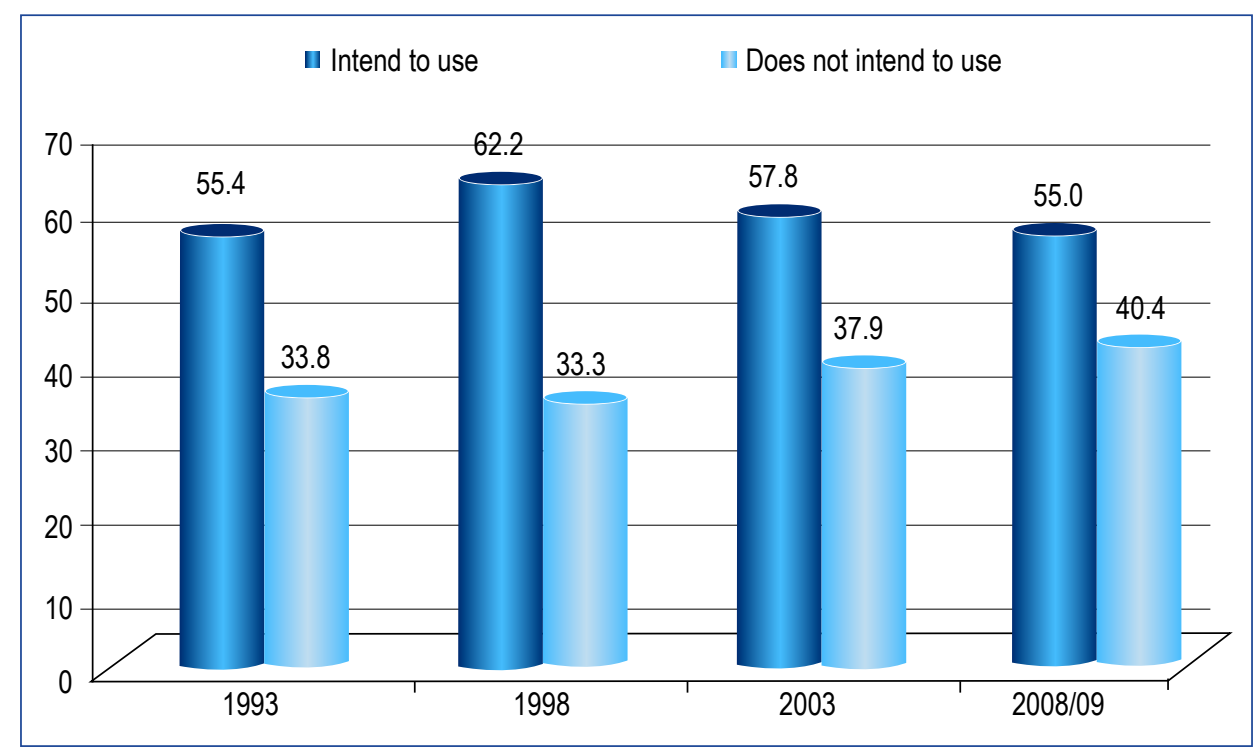




\subsubsection{Contraceptive discontinuation, switching and failure}

The dynamics (discontinuation, switching or failure) of contraceptive use after initiation are an important determinant of unintended pregnancy. According to Ali and colleagues, ${ }^{72}$ the median duration of method use was 19.1 months in 2003 for all methods combined. The median duration was lower for injectables (9.8 months) and pills (15.4 months). One in 3 couples was likely to discontinue a method within 12 months of use and with almost 64 percent discontinuing by 36 months after initiating use. ${ }^{72}$ Overall, male condom users had a high contraceptive discontinuation rate across all three survey years, with more than 71 percent discontinuing within the first 12 months of use in 2008/09 (Table 3.4).

Table 3.4: Contraceptive discontinuation at 12 months after beginning its use, KDHS 1998, 2003, 2008/09

\begin{tabular}{|l|c|c|c|}
\hline Methods & 1998 & $\mathbf{2 0 0 3}$ & $\mathbf{2 0 0 8 / 9}$ \\
\hline Pill & 34.0 & 30.9 & 38.0 \\
\hline IUD & 9.0 & 11.7 & 6.4 \\
\hline Injectables & 18.1 & 22.9 & 28.0 \\
\hline Implant & - & 17.1 & 10.5 \\
\hline Condom & 61.5 & 35.1 & 71.6 \\
\hline Natural methods & 27.0 & 29.2 & 29.9 \\
\hline All methods & $\mathbf{2 6 . 1}$ & $\mathbf{2 5 . 8}$ & $\mathbf{3 2 . 0}$ \\
\hline
\end{tabular}

Method-related dissatisfaction was the most common reason for discontinuation, with over 21 percent of women in 2003 discontinuing their method within the first year. By the third year of use, about 37 percent of women reported discontinuation. About 17 percent of women discontinued contraceptive use within the first 12 months for reasons of side effects or health concerns. Method-related dissatisfaction was highest for condom and oral pills users, indicating a susceptible group for method-related discontinuation. Desire for pregnancy was the least common reason for contraceptive discontinuation with only about 6 percent of couples in 2003 stopping the use of any contraceptive method in the first year because of the desire for another child.

Ali and colleagues ${ }^{72}$ also assessed method switching 3 months after discontinuation of any method for method-related reasons. Results from their study indicate that in 2003 about 31 percent of Kenyan women who had discontinued a method because of method-related dissatisfaction had switched to a modern reversible method of contraception within three months. However, about 51 percent remained at risk of unintended pregnancy because no method was being used 3 months after discontinuing. Overall, about 14 percent became pregnant after discontinuing a method.

Reported failure rates were relatively low across all survey years but increased substantially with increasing length of use, and ranged from 6 percent in 1998 for all methods to 7 percent in 2003. Failure rates were highest for users of male condoms and periodic abstinence and lowest for injectable users. 
The reproductive consequences of discontinuation because of method failure are grave. According to Ali and colleagues, ${ }^{72}$ over 86 percent of women reported that the pregnancies/ childbirth that resulted from contraceptive failure were unintended. Moreover, for women who discontinued a contraceptive method for method-related reasons, 23 percent reported an unintended pregnancy 12 months after discontinuing in 1998, while 20 percent reported the same in 2003.

\subsubsection{Unmet need for family planning}

A woman has an unmet need for FP when she wants to stop childbearing or space the next birth for 2 or more years, but is not using any form of contraception. The proportion of women in a country with unmet need is often a measure of the need for FP. Table 3.6 presents data on unmet need for FP, met need for FP and total demand for FP services among currently married women. Overall, 26 percent of married women interviewed in the 2008/09 KDHS had an unmet need for family planning. In 2008/09 unmet need varied by age and was highest among women aged 15 to 24 years compared with the other age cohorts. As expected, unmet need for spacing reduced with an increase in age while unmet need for limiting increased with an increase in age. The total met need and total demand for family planning increased with age. Among married women, unmet need for family planning was lower among women with secondary level education compared with those with primary or no education, and lower among women in the wealthiest tertile compared with women in the least wealthy tertile. Women in urban areas were less likely to report unmet need compared with their rural counterparts. Women in Nyanza and Rift Valley Provinces had the highest levels of unmet need at the provincial level, indicating geographical variation in unmet need for family planning. Overall, levels of unmet need for FP were lower among currently unmarried women (18 percent) compared with currently married women (26 percent).

Table 3.5: Percentage of currently married women aged 15-49 with unmet need for family planning, percentage with met need for family planning, the total demand for family planning, and the percentage for whom the demand for contraception was satisfied, KDHS 2008/09

\begin{tabular}{|l|c|c|c|c|c|c|c|c|c|c|c|}
\hline & \multicolumn{3}{|c|}{ Unmet Need } & \multicolumn{3}{c|}{ Met Need } & \multicolumn{3}{|c|}{ Total Demand for FP } & \multicolumn{2}{l|}{} \\
\cline { 2 - 14 } & $\begin{array}{c}\text { For } \\
\text { SP }\end{array}$ & $\begin{array}{c}\text { For } \\
\text { LIM }\end{array}$ & Total & $\begin{array}{c}\text { For } \\
\text { SP }\end{array}$ & $\begin{array}{c}\text { For } \\
\text { LIM }\end{array}$ & Total & $\begin{array}{c}\text { For } \\
\text { SP }\end{array}$ & $\begin{array}{c}\text { For } \\
\text { LIM }\end{array}$ & Total & $\begin{array}{c}\% \\
\text { DS }\end{array}$ & N \\
\hline Age & & & & & & & & & & & \\
\hline $15-24$ & 23.8 & 6.5 & 30.3 & 26.9 & 6.4 & 33.3 & 50.7 & 6.4 & 57.1 & 52.4 & 3511 \\
\hline $25-34$ & 13.7 & 11.1 & 24.8 & 22.9 & 26.9 & 49.8 & 36.6 & 26.9 & 63.5 & 66.7 & 2603 \\
\hline$>35$ & 3.4 & 20.1 & 23.5 & 4.7 & 44.0 & 48.7 & 8.1 & 44.0 & 52.1 & 67.5 & 2330 \\
\hline Education & & & & & & & & & & & \\
\hline No Education & 16.5 & 10.0 & 26.5 & 4.2 & 10.0 & 14.2 & 20.7 & 10.0 & 30.7 & 34.7 & 1242 \\
\hline Primary & 14.1 & 16.0 & 30.1 & 16.1 & 28.1 & 44.2 & 30.2 & 28.1 & 58.3 & 59.4 & 4404 \\
\hline Secondary + & 7.9 & 8.6 & 16.5 & 25.3 & 34.6 & 59.9 & 33.2 & 34.6 & 67.8 & 78.3 & 2798 \\
\hline
\end{tabular}


Table 3.5: Cont...

\begin{tabular}{|c|c|c|c|c|c|c|c|c|c|c|c|}
\hline & \multicolumn{3}{|c|}{ Unmet Need } & \multicolumn{3}{|c|}{ Met Need } & \multicolumn{3}{|c|}{ Total Demand for FP } & \multirow[b]{2}{*}{$\begin{array}{l}\% \\
\text { DS }\end{array}$} & \multirow[b]{2}{*}{$\mathrm{N}$} \\
\hline & $\begin{array}{l}\text { For } \\
\text { SP }\end{array}$ & $\begin{array}{l}\text { For } \\
\text { LIM }\end{array}$ & Total & $\begin{array}{l}\text { For } \\
\text { SP }\end{array}$ & $\begin{array}{l}\text { For } \\
\text { LIM }\end{array}$ & Total & $\begin{array}{l}\text { For } \\
\text { SP }\end{array}$ & $\begin{array}{l}\text { For } \\
\text { LIM }\end{array}$ & Total & & \\
\hline \multicolumn{12}{|l|}{ Wealth } \\
\hline Low & 17.6 & 18.0 & 35.6 & 10.0 & 19.8 & 29.8 & 27.6 & 19.8 & 47.4 & 45.5 & 2927 \\
\hline Medium & 10.2 & 11.6 & 21.8 & 14.5 & 37.6 & 52.1 & 24.7 & 37.6 & 62.3 & 70.5 & 2561 \\
\hline High & 9.4 & 9.3 & 18.7 & 29.1 & 26.6 & 55.7 & 38.5 & 26.6 & 65.1 & 74.9 & 2956 \\
\hline \multicolumn{12}{|l|}{ Residence } \\
\hline Urban & 10.7 & 8.9 & 19.6 & 29.5 & 23.5 & 53.0 & 40.2 & 23.5 & 63.7 & 73.0 & 2615 \\
\hline Rural & 13.1 & 14.4 & 27.5 & 13.8 & 29.3 & 43.1 & 26.9 & 29.3 & 56.2 & 61.1 & 5829 \\
\hline \multicolumn{12}{|l|}{ Province } \\
\hline Nairobi & 6.5 & 8.7 & 15.2 & 27.1 & 28.2 & 55.3 & 33.6 & 28.2 & 61.8 & 78.5 & 952 \\
\hline Central & 6.2 & 9.3 & 15.5 & 22.5 & 44.2 & 66.7 & 28.7 & 44.2 & 72.9 & 81.1 & 973 \\
\hline Coast & 15.9 & 9.3 & 25.2 & 19.3 & 15.0 & 34.3 & 35.2 & 15.0 & 50.2 & 57.7 & 1149 \\
\hline Eastern & 9.8 & 14.0 & 23.8 & 13.3 & 38.7 & 52.0 & 23.1 & 38.7 & 61.8 & 68.6 & 1127 \\
\hline Nyanza & 18.2 & 14.0 & 32.2 & 14.8 & 22.5 & 37.3 & 33.0 & 22.5 & 55.5 & 53.7 & 1318 \\
\hline Rift Valley & 13.0 & 17.6 & 30.6 & 18.4 & 24.0 & 42.4 & 31.4 & 24.0 & 55.4 & 58.1 & 1278 \\
\hline Western & 13.5 & 12.6 & 26.1 & 17.0 & 29.6 & 46.6 & 30.5 & 29.6 & 60.1 & 64.0 & 1039 \\
\hline North Eastern & 17.1 & 0.8 & 17.9 & 3.0 & 0.5 & 3.5 & 20.1 & 0.5 & 20.6 & 16.2 & 608 \\
\hline $\begin{array}{l}\text { Currently } \\
\text { Married }\end{array}$ & 12.5 & 13.1 & 25.6 & 17.5 & 28.0 & 45.5 & 30.0 & 28.0 & 58.0 & 63.9 & 8444 \\
\hline $\begin{array}{l}\text { Currently } \\
\text { unmarried }\end{array}$ & 9.1 & 8.9 & 18.0 & 13.0 & 19.0 & 32.0 & 22.1 & 19.0 & 41.1 & 64.1 & 3516 \\
\hline All Women & 4.2 & 3.0 & 7.2 & 6.8 & 6.4 & 13.2 & 11.0 & 6.4 & 17.4 & 64.8 & 4928 \\
\hline
\end{tabular}

\section{SP=Spacing, LIM=Limiting; DS=Demand Satisfied}

As shown in Figure 3.9 there was a gradual decline in unmet need from 1993 to 2008/09, with a stall observed between 1998 and 2003. Women with a primary education, in lowwealth households, living in rural areas had higher rates of reported unmet need for contraceptives, though gradual declines were seen in numbers reporting need for FP over time (see Table A13 in the appendix for trends in unmet need for Kenya for survey years 1993, 1998, 2003 and 2008/09 for currently married women according to background characteristics). 
Figure 3.9: Trends in unmet need for family planning among currently married and unmarried women aged 15 - 49, KDHS 1993, 1998, 2003, 2008/09

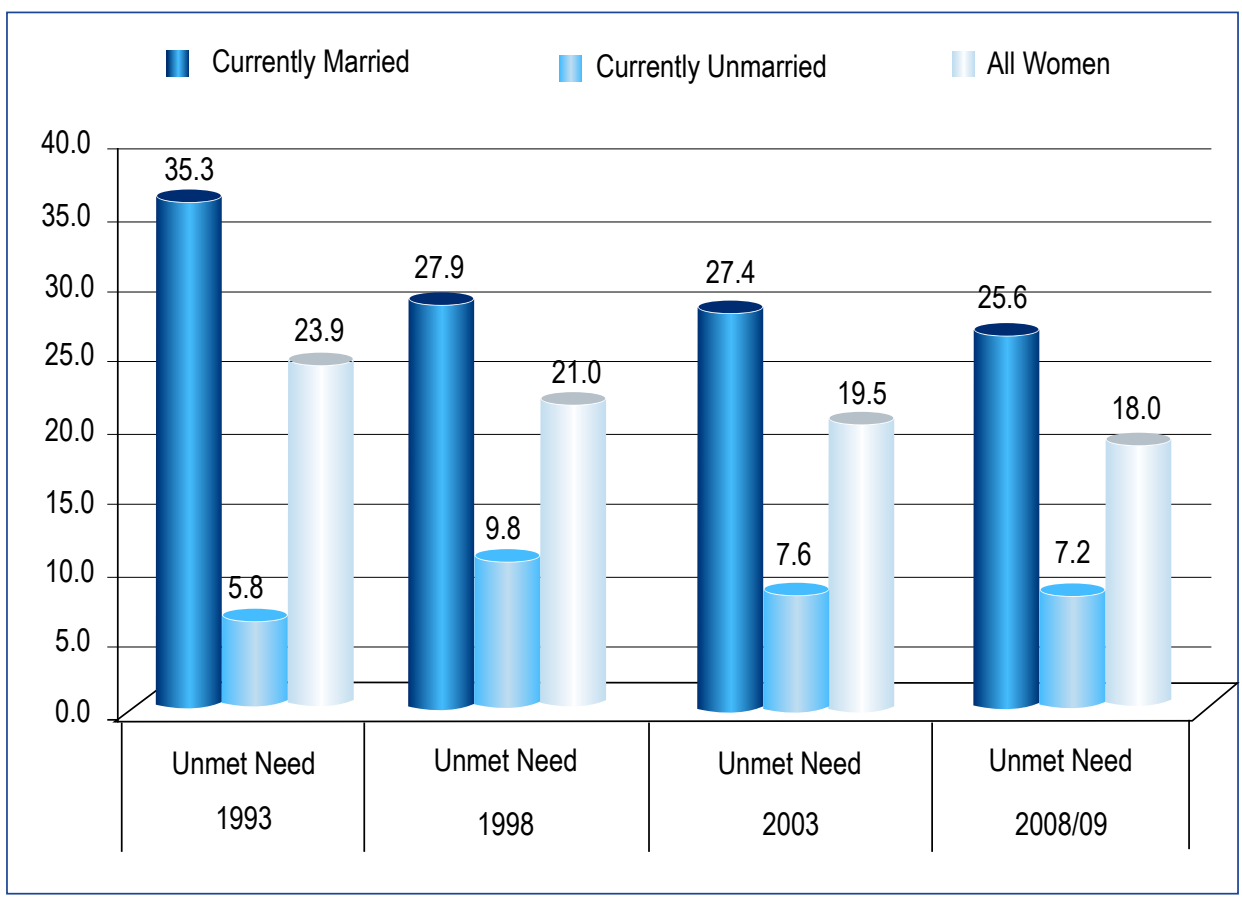

Table 3.6 shows the percentage of currently married women with an unmet need for FP by indicators of women empowerment. Overall, levels of unmet need decreased with each increase in the number of household decisions a woman participated in and increased with any increase in number of reasons a woman thought wife beating justifiable.

Table 3.6: Percentage of currently married women aged 15-49 with an unmet need for family planning by indicators of women's empowerment, KDHS 2008/09

\begin{tabular}{|l|c|c|c|c|}
\hline & \multicolumn{4}{|c|}{$\begin{array}{r}\text { Percentage of Currently Married Women with an Unmet Need for } \\
\text { Family Planning }\end{array}$} \\
\hline Empowerment Indicators & For Spacing & For Limiting & Total & Number of Women \\
\hline $\begin{array}{l}\text { Number of Decisions in } \\
\text { Which Women Participate }\end{array}$ & & & & \\
\hline 0 & 15.6 & 7.5 & 23.1 & 124 \\
\hline $1-2$ & 15.1 & 13.0 & 28.1 & 771 \\
\hline $3-4$ & 15.8 & 13.3 & 28.1 & 1,571 \\
\hline 5 & 10.8 & 12.6 & 23.4 & 2,463 \\
\hline
\end{tabular}


Table 3.6: Cont...

\begin{tabular}{|l|c|c|c|c|}
\hline & \multicolumn{4}{|c|}{ Percentage of Currently Married Women with an Unmet Need for } \\
Family Planning \\
\hline $\begin{array}{l}\text { Empowerment Indicators } \\
\text { For Spacing }\end{array}$ & For Limiting & Total & Number of Women \\
\hline $\begin{array}{l}\text { Number of Reasons for } \\
\text { Which Wife Beating is } \\
\text { Justified }\end{array}$ & & & & \\
\hline 0 & 11.0 & 10.0 & 21.0 & 2,274 \\
\hline $1-2$ & 12.9 & 14.7 & 27.7 & 1,273 \\
\hline $3-4$ & 15.6 & 15.9 & 31.5 & 1,023 \\
\hline 5 & 16.3 & 14.5 & 30.9 & 358 \\
\hline Total & 12.8 & 12.8 & 25.6 & 4,928 \\
\hline
\end{tabular}

\subsubsection{Trends in ever use of modern method by unmet need for family planning}

Figure 3.10 shows the trends in ever use of modern methods among women with unmet need for FP. Trends show a consistent gradual increase in unmet need for FP among women who had ever used a modern method. According to the 2008/09 KDHS, the majority of women with unmet need (60 percent) were ever users compared with 19 percent in 1988. This suggests that unmet need for contraception may stem from women's prior experiences with modern methods.

Figure 3.10: Trends in ever use of a modern method among women with unmet need for family planning

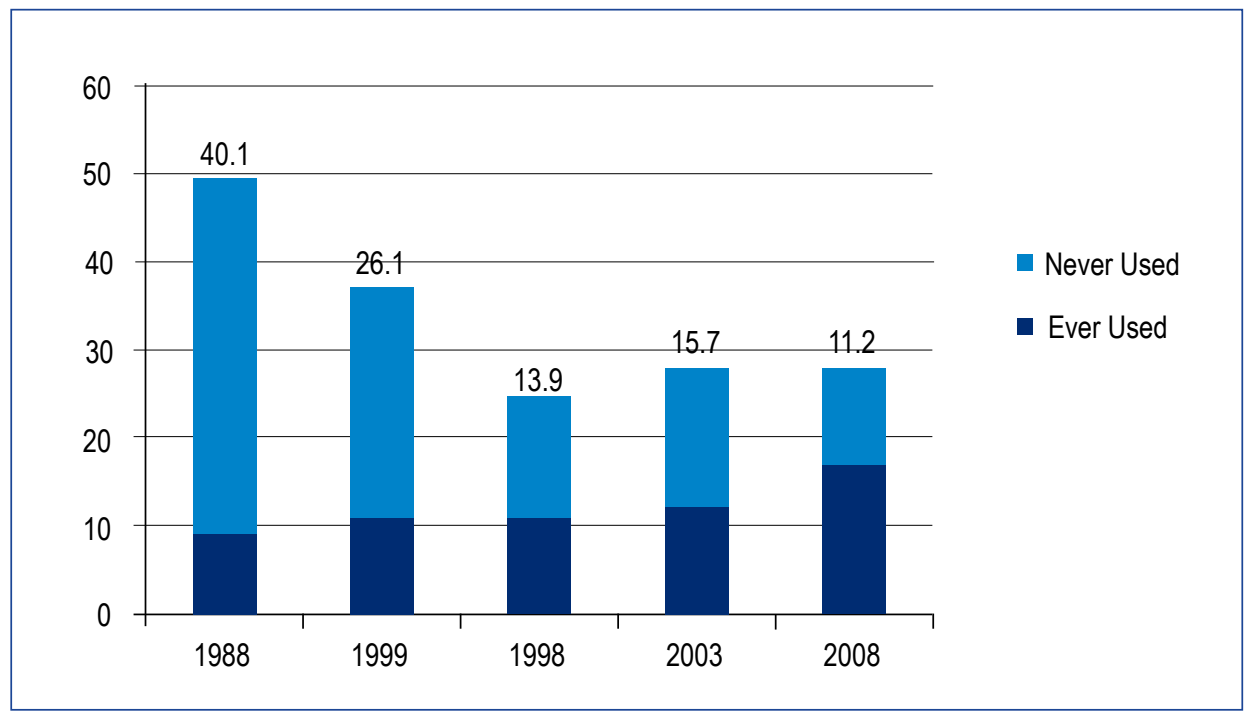

Source: Machiyama and Cleland, 2013.73 


\subsubsection{Reasons for non-use of contraception by type of unmet need for family planning}

Table 3.7 presents results for self-reported reasons for non-use of contraception by four different categories of unmet need for FP. ${ }^{73}$ Women who were categorized as having access to and a positive attitude toward contraception often reported health concerns/ side effects as major reasons for non-use (56 percent). Similarly, women with access but with a negative attitude toward use of contraception and women with negative attitude but no access to contraception were also more likely to report health concerns/side effects as a major reason for contraceptive use (58 percent and 35 percent, respectively). Lack of knowledge and partner/respondent opposition were the other major reasons reported by women with no access and a positive attitude and women who did not have access and had a negative attitude. Infrequent sex was the second major reason cited for noncontraceptive use among women with access and a positive attitude and women with access but a negative attitude.

Table 3.7: Reasons for non-use of contraception by type of unmet need, Kenya 2008

\begin{tabular}{|l|c|c|c|c|c|}
\hline \multirow{2}{*}{$\begin{array}{l}\text { Reasons for not using } \\
\text { family planning }\end{array}$} & $\begin{array}{c}\text { Unmet need for family planning } \\
\text { \&attitude }\end{array}$ & $\begin{array}{c}\text { access, but } \\
\text { not attitude }\end{array}$ & $\begin{array}{c}\text { attitude, } \\
\text { but not } \\
\text { access }\end{array}$ & $\begin{array}{c}\text { neither } \\
\text { access nor } \\
\text { attitude }\end{array}$ & Total \\
\hline Respondent's opposition & 1.1 & 6.9 & 1.4 & 17.6 & 4.2 \\
\hline Partner's/others' opposition & 8.6 & 6.6 & 12.8 & 16.9 & 8.7 \\
\hline Religion & 1.0 & 6.2 & 4.1 & 11.5 & 3.7 \\
\hline Lack of knowledge & 1.3 & 0.0 & 24.9 & 23.8 & 3.9 \\
\hline Access/cost & 6.2 & 4.2 & 5.7 & 8.5 & 5.6 \\
\hline $\begin{array}{l}\text { Health concerns/side effect/ } \\
\text { interfere with body }\end{array}$ & 52.5 & 57.9 & 34.8 & 22.1 & 51.3 \\
\hline Infrequent or no sex & 13.0 & 15.4 & 1.8 & 7.6 & 12.8 \\
\hline Breastfeeding & 8.7 & 1.6 & 2.9 & 6.5 & 5.7 \\
\hline Others/don't know & 12.5 & 11.2 & 11.9 & 6.1 & 11.6 \\
\hline Total & 348 & 231 & 45 & 42 & 666 \\
\hline
\end{tabular}

Source: Machiyama and Cleland, 2013.73

\subsection{Fertility levels, trends and differentials}

\subsubsection{Total fertility rates}

The Total Fertility Rate (TFR) is the average number of live births a woman would have in her lifetime, were she to survive her childbearing years. Figure 3.11 shows the level and trends in TFR between 1998 and 2008/09 (TRF is computed based on age-specific fertility 
rates for the three years preceding each survey). The total fertility rate dropped from 5.4 to 4.7 children per woman between 1993 and 1998 then increased to 4.9 in 2003 and dropped to 4.6 in $2008 / 09$.

Figure 3.11: Trends in fertility rates, KDHS 1993, 1998, 2003, 2008/09

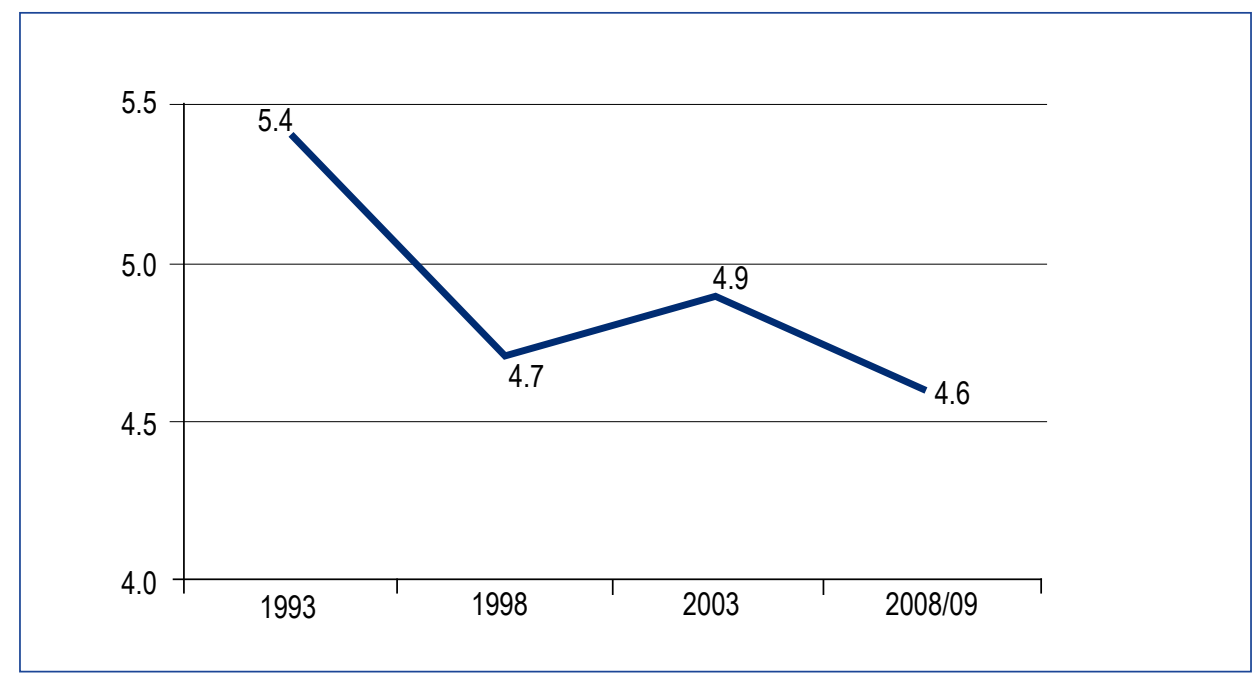

Table 3.8 summarizes the level and trends in TFR by background characteristics. Across all years, fertility was considerably higher among women with no education or primary education compared with those with secondary education or higher. Fertility was also higher among women from the least wealthy households compared with those from the wealthiest households. Women in urban areas had consistently lower fertility than those in rural areas. As noted in the $2003 \mathrm{KDHS}$ report, 10 urban-rural differences in fertility are likely driven by greater access to education and FP information, as well as later marriage in urban areas. Geographic differences in fertility rates persisted with women in Nairobi and Central Provinces having much lower fertility than women in other geographical settings.

Table 3.8: Trends in fertility rates by selected background characteristics, KDHS 1993, 1998, 2003, 2008/09

\begin{tabular}{|l|c|c|c|c|}
\hline Background Characteristics & 1993 & 1998 & 2003 & $2008 / 09$ \\
\hline Education & & & & \\
\hline No Education & 6.0 & 5.8 & 6.7 & 6.7 \\
\hline Primary & 5.7 & 5.0 & 5.4 & 5.2 \\
\hline Secondary + & 4.0 & 3.5 & 3.2 & 3.1 \\
\hline
\end{tabular}


Table 3.8: Cont...

\begin{tabular}{|l|c|c|c|c|}
\hline Background Characteristics & 1993 & 1998 & 2003 & $2008 / 09$ \\
\hline Wealth & & & & \\
\hline Low & 6.7 & 6.3 & 6.7 & 6.4 \\
\hline Medium & 5.6 & 4.7 & 4.7 & 4.5 \\
\hline High & 3.9 & 3.2 & 3.3 & 3.0 \\
\hline Residence & & & & \\
\hline Urban & 3.4 & 3.1 & 3.3 & 2.9 \\
\hline Rural & 5.8 & 5.2 & 5.4 & 5.2 \\
\hline Province & & & & \\
\hline Nairobi & 3.4 & 2.6 & 2.7 & 2.8 \\
\hline Central & 3.9 & 3.7 & 3.4 & 3.4 \\
\hline Coast & 5.3 & 5.1 & 4.9 & 4.8 \\
\hline Eastern & 5.9 & 4.7 & 4.8 & 4.4 \\
\hline Nyanza & 5.8 & 5.0 & 5.6 & 5.4 \\
\hline Rift Valley & 5.7 & 5.3 & 5.8 & 4.7 \\
\hline Western & 6.4 & 5.6 & 5.8 & 5.6 \\
\hline North Eastern & - & - & 7.0 & 5.9 \\
\hline Total TFR & $\mathbf{5 . 4}$ & 4.7 & 4.9 & 4.6 \\
\hline Number of Women & $\mathbf{7 , 5 4 0}$ & $\mathbf{7 , 8 8 1}$ & $\mathbf{8 . 1 9 5}$ & $\mathbf{8 . 4 4 4}$ \\
\hline
\end{tabular}

\subsubsection{Wanted fertility, unwanted fertility and total fertility rates}

Levels of unwanted fertility indicate the extent to which an unmet need for contraception influences a woman's inability to either delay pregnancy or stop childbearing altogether. As such, unwanted fertility is an important indicator of unintended pregnancy. Figure 3.12 illustrates the proportion of wanted and unwanted fertility rates, calculated by excluding unwanted births from TFR calculations (see Table A14 in the appendix for trends in Wanted Fertility Rates (WFR), Unwanted Fertility Rates (UWFR) and Total Fertility Rate (TFR) for the three years preceding the survey, by background characteristics, Kenya 1993 to 2008/09). Overall, if unwanted fertility were eliminated so that Kenyan women were able to achieve their desired fertility, women would have 1.4 fewer children on average. The difference between wanted fertility and actual fertility is largest for women with no education, living in low-wealth households, and from rural areas. Importantly, the data show an interesting pattern, where among women with no education an increase is observed in wanted fertility from 3.4 in 1993 to 4.7 in 2008/09 and a decrease in unwanted fertility from 2.6 to 2.0 in the same period. The net result is an overall increase in TFR from 5.8 in 1998 to 6.7 in 2008/09 among those with no education. The reverse is observed for women with at least secondary education. 
Figure 3.12: Trends in wanted fertility rates (WFR), unwanted fertility rates (UWFR) and total fertility rate (TFR) KDHS 1993, 1998, 2003, 2008/09

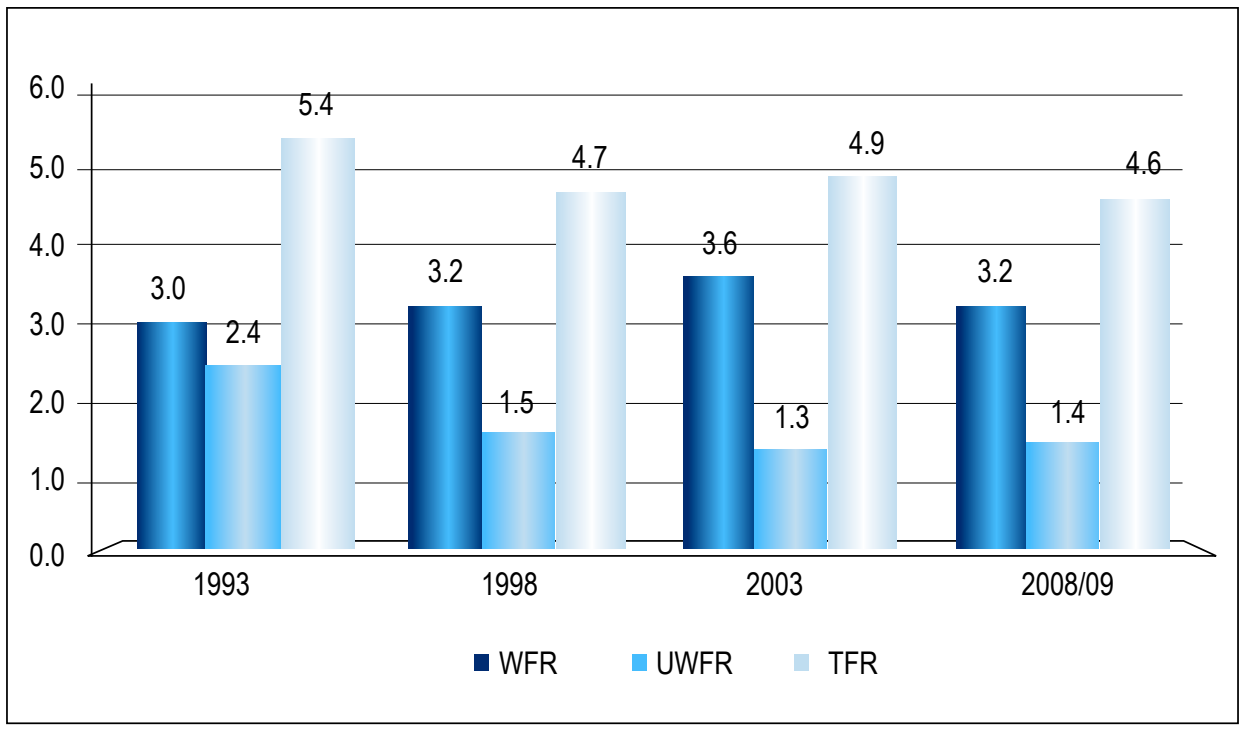

\subsection{Proximate determinants of fertility}

\subsubsection{Age at first sexual intercourse}

Age at first intercourse is considered a proximate determinant of fertility because it marks the beginning of the window of possible childbearing. In other words, the earlier sexual debut occurs, the longer the window of possible childbearing. As shown in Table 3.9, the median age for first sexual intercourse for women between the ages of 20 and 49 increased over the years from 16 in 1993 to 18 in 2008/09. Age at first sexual intercourse among women aged 20 to 24 years remained stable between 1993 and 1998 then increased in 2003 and remained constant in 2008/09. Age at first sexual intercourse among women aged 25 to 49 increased slightly over the 1993 and 2008/09 period except among women aged between 45 and 49 years where the age at first intercourse decreased from 17 years to 16 years between 1993 and 1998 then rose to 17 years again in 2003. On the basis of these results, one can infer that young people are delaying sexual activity. Age at first sexual intercourse also increases with increased level of education, among women from households with higher wealth and urban women. Women from Nyanza had the lowest age at first sexual intercourse over the entire period compared with their counterparts from other regions.

\subsubsection{Age at first marriage}

Age at first marriage is a proximate determinant of fertility because married women are more exposed to pregnancy because of regular intercourse. The median age at first marriage has risen among women over the years from 19.2 to 20.1 (Table 3.9). Women 
with secondary education enter into marriage later than those with primary or no education. In each survey year, women from wealthier households and those living in urban areas were more likely to delay entry into marriage compared with women in poorer households and in rural areas, respectively. Age at first marriage is lowest among women from Coast, Nyanza and North Eastern Provinces.

Table 3.9: Median age at first sexual intercourse and first marriage among women aged 15-49, by selected background characteristics, KDHS 1993, 1998, 2003, 2008/09

\begin{tabular}{|l|c|c|c|c|c|c|c|c|}
\hline \multirow{2}{*}{} & \multicolumn{3}{|c|}{ Age at first sexual intercourse } & \multicolumn{5}{c|}{ Age at first marriage } \\
\cline { 2 - 10 } & 1993 & 1998 & $\mathbf{2 0 0 3}$ & $\mathbf{2 0 0 8 / 0 9}$ & 1993 & 1998 & 2003 & $2008 / 09$ \\
\hline Age & & & & & & & & \\
\hline $15-19$ & $\mathrm{a}$ & $\mathrm{a}$ & $\mathrm{a}$ & $\mathrm{a}$ & $\mathrm{a}$ & $\mathrm{a}$ & $\mathrm{a}$ & $\mathrm{a}$ \\
\hline $20-24$ & 17.3 & 17.3 & 18.1 & 18.2 & $\mathrm{a}$ & $\mathrm{a}$ & $\mathrm{a}$ & $\mathrm{a}$ \\
\hline $25-29$ & 17.0 & 16.8 & 18.0 & 18.3 & 19.5 & 20.2 & 20.3 & 20.2 \\
\hline $30-34$ & 16.6 & 16.7 & 17.7 & 17.9 & 18.9 & 19.2 & 19.8 & 19.9 \\
\hline $35-39$ & 16.3 & 16.3 & 17.7 & 18.4 & 18.2 & 18.7 & 19.6 & 20.2 \\
\hline $40-44$ & 16.3 & 16.2 & 17.1 & 18.2 & 18.3 & 18.2 & 19.1 & 20.2 \\
\hline $45-49$ & 16.8 & 16.1 & 16.9 & 17.7 & 18.1 & 18.4 & 18.9 & 18.9 \\
\hline Education & & & & & & & & \\
\hline No Education & 15.7 & 15.5 & 16.4 & 17.1 & 17.0 & 16.6 & 17.3 & 17.5 \\
\hline Primary & 16.5 & 16.3 & 17.1 & 17.3 & 18.6 & 18.5 & 19.0 & 19.0 \\
\hline Secondary + & 18.8 & 18.4 & 19.6 & 20.1 & 21.5 & 21.9 & 22.7 & 22.4 \\
\hline Wealth & & & & & & & & \\
\hline Low & 15.4 & 15.4 & 16.1 & 16.3 & 17.2 & 17.3 & 17.8 & 17.7 \\
\hline Medium & 16.0 & 15.9 & 16.8 & 17.0 & 18.1 & 18.3 & 18.7 & 18.6 \\
\hline High & 17.0 & 16.9 & 17.7 & 18.2 & 18.9 & 19.6 & 19.7 & 20.0 \\
\hline Residence & & & & & & & & \\
\hline Urban & 17.9 & 17.4 & 18.6 & 19.5 & 20.6 & 21.0 & 21.4 & 22.2 \\
\hline Rural & 16.6 & 16.5 & 17.4 & 17.7 & 18.5 & 18.8 & 19.3 & 19.4 \\
\hline Province & & & & & & & & \\
\hline Nairobi & 17.9 & 17.3 & 19.2 & 20.3 & 21.0 & 21.9 & 22.1 & 24.2 \\
\hline Central & 17.8 & 16.8 & 18.4 & 18.6 & 20.1 & 20.7 & 21.1 & 20.7 \\
\hline Coast & 17.3 & 17.8 & 18.0 & 17.9 & 17.4 & 18.3 & 18.6 & 19.5 \\
\hline Eastern & 16.7 & 16.7 & 17.6 & 17.9 & 19.3 & 19.8 & 20.1 & 20.2 \\
\hline Nyanza & 15.5 & 15.6 & 15.9 & 16.7 & 17.4 & 17.5 & 17.8 & 18.9 \\
\hline Rift Valley & 17.0 & 17.0 & 18.0 & 18.5 & 18.6 & 18.7 & 19.4 & 19.7 \\
\hline
\end{tabular}


Table 3.9: Cont...

\begin{tabular}{|l|c|c|c|c|c|c|c|c|}
\hline \multirow{2}{*}{} & \multicolumn{4}{|c|}{ Age at first sexual intercourse } & \multicolumn{4}{c|}{ Age at first marriage } \\
\cline { 2 - 10 } & 1993 & 1998 & $\mathbf{2 0 0 3}$ & $\mathbf{2 0 0 8 / 0 9}$ & 1993 & 1998 & $\mathbf{2 0 0 3}$ & $\mathbf{2 0 0 8 / 0 9}$ \\
\hline Western & 16.6 & 17.5 & 17.2 & 17.5 & 18.4 & 18.9 & 19.2 & 19.2 \\
\hline North Eastern & - & - & 17.9 & 18.5 & - & - & 17.5 & 17.9 \\
\hline Median 20-49 & 16.0 & 16.0 & 17.0 & 18.0 & 19.2 & 19.4 & 19.8 & 20.1 \\
\hline $\begin{array}{l}\text { Number of } \\
\text { Women }\end{array}$ & $\mathbf{5 7 8 6}$ & $\mathbf{6 0 3 0}$ & $\mathbf{6 3 3 9}$ & $\mathbf{6 6 8 3}$ & $\mathbf{4 1 4 8}$ & $\mathbf{4 4 8 2}$ & $\mathbf{4 6 4 8}$ & $\mathbf{4 9 6 9}$ \\
\hline
\end{tabular}

$a=$ Omitted because less than 50 percent of the respondents had had intercourse for the first time or had married for the first time before reaching the age bracket

A hyphen means that data are unavailable

We also assessed the mean age difference between age at first sex and marriage (i.e., the mean duration of premarital sex, calculated as the difference between age at first marriage and age at first sex). Figure 3.13 shows that age at first intercourse and age at first marriage among Kenyan women has gradually risen over time. Furthermore, the mean duration between first sex and marriage is now 1.9 years (for the 25 to 29 cohort) vs. 1.2 years (45 to 49 cohort). The mean duration of pre-marital sex is highest for women with secondary education (2.3 years), those living in the richest households ( 2.4 years), and those from urban areas (2.7 years)

Figure 3.13: Trends in median age at first sexual intercourse among women aged 15-49, KDHS 1993, 1998, 2003, 2008/09

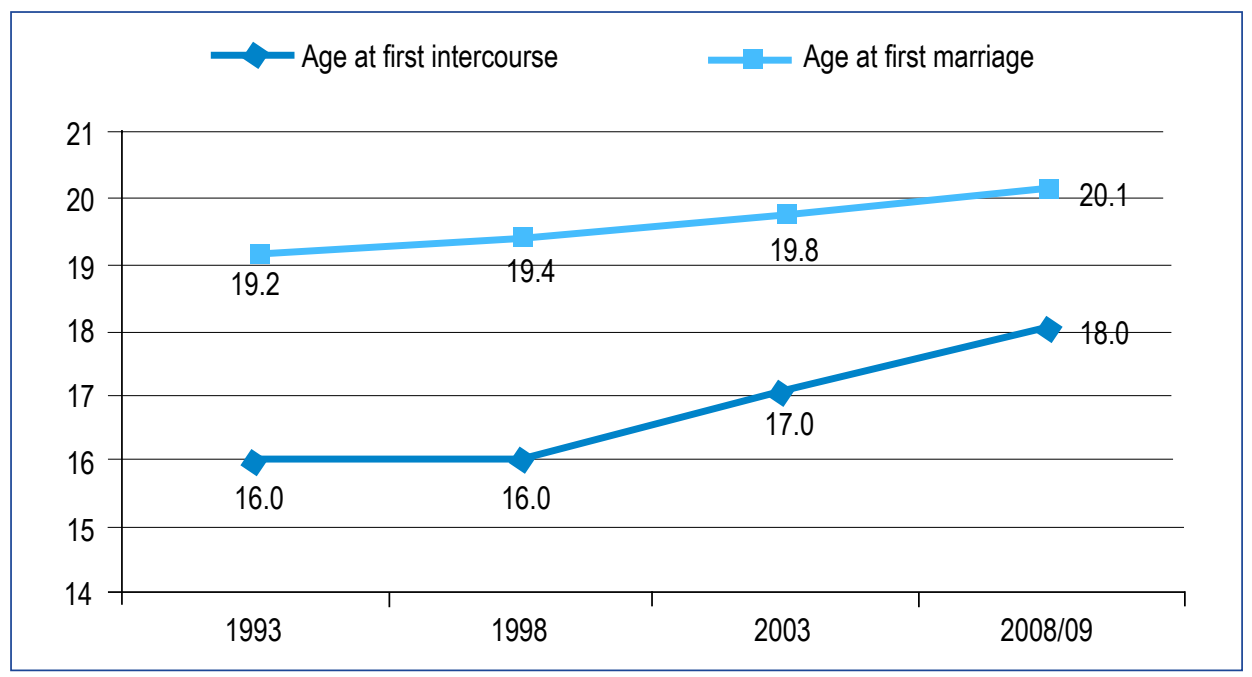

\subsubsection{Age at first birth}

The distribution of women by median age at first birth according to background characteristics over time is shown in Table 3.10. The median age at first birth increased from 19.1 years in 1993 to 19.8 years in 2008/09. 
Table 3.10: Median age at first birth among women aged 25-49 years according to background characteristics, KDHS 1993, 1998, 2003, 2008/09

\begin{tabular}{|l|c|c|c|c|}
\hline \multirow{2}{*}{ Background Characteristics } & \multicolumn{4}{|c|}{ Median age at first birth } \\
\cline { 2 - 5 } & 1993 & 1998 & 2003 & $2008 / 09$ \\
\hline Education & & & & \\
\hline No Education & 18.2 & 18.2 & 18.7 & 18.7 \\
\hline Primary & 18.9 & 18.8 & 19.1 & 19.0 \\
\hline Secondary + & 21.1 & 21.6 & 22.2 & 22.1 \\
\hline Residence & & & & \\
\hline Urban & 20.5 & 20.7 & 21.2 & 21.5 \\
\hline Rural & 18.9 & 19.1 & 19.4 & 19.4 \\
\hline Province & & & & \\
\hline Nairobi & 20.6 & 21.9 & 22.0 & 22.8 \\
\hline Central & 19.6 & 20.1 & 20.3 & 20.2 \\
\hline Coast & 19.1 & 19.9 & 19.8 & 20.1 \\
\hline Eastern & 19.2 & 19.6 & 19.9 & 19.9 \\
\hline Nyanza & 18.2 & 18.2 & 18.4 & 19.0 \\
\hline Rift Valley & 19.0 & 19.2 & 19.6 & 19.4 \\
\hline Western & 18.9 & 19.8 & 19.4 & 19.7 \\
\hline North Eastern & - & - & 19.4 & 19.4 \\
\hline Number of Women & 4,147 & 4,487 & 4,665 & 4,933 \\
\hline Total & 19.1 & 19.4 & 19.8 & 19.8 \\
\hline
\end{tabular}

A hyphen means that data are unavailable

On average, women living in urban areas had their first child at 21.5 years, about two years later than their rural counterparts (19.4 years). Age at first birth rose with level of education, although women with no education had the lowest rise over time. Marginal differences were observed in the median age at first birth across the different provinces, though Nairobi Province recorded the highest rise in median age at first birth from 20.6 to 22.9 over the four survey years under review.

\subsubsection{Adolescent fertility and motherhood}

During the period 1993 and 2003, the proportion of adolescents who had begun childbearing increased from 21 percent in 1993 to 23 percent in 2003 (Table 3.11). A significant decline (18 percent) was, however, observed in 2008/09. Interestingly, while adolescent motherhood between 1993 and 2003 was higher for women in rural areas, the reverse is seen in 2008/09. It is, however, worth noting that adolescent motherhood increased in urban areas between 1998 and 2003, from 18 percent to 22 percent, with Nairobi residents showing an even bigger increase (from 10 percent to 20 percent). 
Table 3.11: Percentage of women aged 15-19 years who are mothers or pregnant with their first child by selected background characteristics KDHS 1993, 1998, 2003, $2008 / 09$.

\begin{tabular}{|l|c|c|c|c|}
\hline Background Characteristics & 1993 & 1998 & 2003 & $2008 / 09$ \\
\hline Education & & & & \\
\hline No Education & 29.9 & 41.4 & 45.9 & 32.1 \\
\hline Primary & 22.4 & 23.7 & 24.9 & 20.6 \\
\hline Secondary + & 12.1 & 9.2 & 10.4 & 10.0 \\
\hline Wealth & & & & \\
\hline Low & 24.8 & 26.4 & 27.5 & 20.8 \\
\hline Medium & 17.6 & 22.6 & 21.8 & 13.6 \\
\hline High & 19.0 & 15.7 & 20.0 & 17.0 \\
\hline Residence & & & & \\
\hline Urban & 17.3 & 17.5 & 22.2 & 18.5 \\
\hline Rural & 21.1 & 21.8 & 23.3 & 17.5 \\
\hline Region & & & & \\
\hline Nairobi & 19.0 & 10.2 & 19.5 & 13.9 \\
\hline Central & 15.6 & 15.1 & 15.3 & 10.1 \\
\hline Coast & 17.0 & 27.8 & 29.4 & 25.7 \\
\hline Eastern & 19.8 & 15.7 & 14.8 & 13.5 \\
\hline Nyanza & 28.0 & 23.0 & 27.1 & 27.0 \\
\hline Rift Valley & 19.5 & 27.8 & 30.5 & 16.5 \\
\hline Western & 21.5 & 21.6 & 21.1 & 15.1 \\
\hline North Eastern & - & - & 29.0 & 16.2 \\
\hline Number & & 1,852 & 1,820 & 1,767 \\
\hline Total & 20.9 & 23.0 & 17.7 \\
\hline & & & & \\
\hline & & & & \\
\hline & & & & \\
\hline & & & & \\
\hline & & & & \\
\hline & & & & \\
\hline
\end{tabular}

A hyphen means that data are unavailable

Among adolescent girls with secondary or higher education, the incidence of pregnancy declined between 1993 and 1998 and leveled off at 10 percent for the two remaining survey years. A greater proportion of adolescent girls in least wealthy households had begun childbearing compared with their counterparts in wealthier households. Overall, irrespective of wealth status, the proportion of adolescents who had begun childbearing grew between 1998 and 2003, while significant declines were observed in 2008/09. 


\subsection{Fertility planning status}

\subsubsection{Trends in unintended pregnancy}

In the KDHS, women were asked to recall if the births in the 5 years preceding the survey were wanted at the time (planned), wanted later (mistimed) or not wanted at all (unwanted). Table 3.12 shows the percentage distribution of births in the 5 years preceding each survey (including current pregnancies) by fertility planning status. In Kenya overall, the proportion of births that were mistimed or unwanted stood at 51 percent in 1993, 48 percent in 1998, 45 percent in 2003 and 43 percent in 2008/09. The proportion of births that were mistimed remained higher across the years compared with unwanted births - especially in 1993 and 1998 survey years and especially among young women between the ages of 15 and 24 (see Table A15 in the appendix for more detailed information on the percentage distribution of births in the last five years preceding each survey (including current pregnancies) by fertility planning status by selected background characteristics). Young women between the ages of 15 and 24 were more likely to report a mistimed pregnancy than an unwanted pregnancy across all survey years. The data, however, show a gradual decline in levels of mistimed pregnancy from 34 percent in 1993 to 26 percent in 2008/09, indicating an 8 percentage point decline.

Table 3.12: Percent distribution of births in the five years preceding the survey by fertility planning status and by selected background characteristics, KDHS 1993, 1998, 2003, 2008/09

\begin{tabular}{|l|c|c|c|c|}
\hline & Wanted Then & Wanted Later & Wanted No More & Total Unwanted \\
\hline 1993 & 49.1 & 34.2 & 16.7 & 50.9 \\
\hline 1998 & 51.7 & 37.2 & 11.1 & 48.3 \\
\hline $\mathbf{2 0 0 3}$ & 55.5 & 24.9 & 19.6 & 44.5 \\
\hline $\mathbf{2 0 0 8 / 9}$ & 57.4 & 25.5 & 17.1 & 42.6 \\
\hline
\end{tabular}

Urban residents were more likely to report lower and decreasing incidence of mistimed births (31 percent in 1993 to 20 percent in 2008/09) compared with their rural counterparts (35 percent in 1993 to 27 percent in 2008/09). Levels of wanted pregnancy were also higher among women living in urban areas. Over the almost 20 years under review, the proportion of mistimed births was generally higher among Kenyan women with more education compared with uneducated women. Similar patterns were seen with regard to unwanted births for 2003 and 2008; while the reverse is true for 1993 and 1998 where levels of unwanted births were higher for women with no education. Levels of mistimed pregnancy showed no clear association by levels of household wealth with fluctuations observed across the survey years. Results also indicate that levels of unintended births were highest for women in Eastern and Western Provinces, while the lowest proportions were seen in the Coast and Nairobi Provinces across all survey years under review. 


\subsubsection{Fertility preferences - desire to limit childbearing}

One way of looking at fertility preferences is to assess a woman's desire to limit childbearing. In the KDHS women were asked if they would like to have another child or if they would prefer not to have any more children. Since wanting no more children is related to the number of living children, Table 3.13 shows the percentage of currently married women, with 2 to 4 children who did not want any more children by selected background characteristics for 1993, 1998, 2003 and 2008.

Table 3.13: Trends in the percentage of currently married women with two to four children who did want any more children (including those sterilized), by selected background characteristics, KDHS 1993, 1998, 2003, 2008/09

\begin{tabular}{|l|c|c|c|c|}
\hline Background Characteristics & 1993 & 1998 & 2003 & 2008 \\
\hline Age & & & & \\
\hline $15-24$ & 29.9 & 34.1 & 33.6 & 33.4 \\
\hline $25-34$ & 49.2 & 48.7 & 44.0 & 51.9 \\
\hline$>35$ & 62.0 & 73.3 & 72.8 & 75.0 \\
\hline Education & & & & \\
\hline No Education & 32.0 & 48.3 & 23.4 & 22.3 \\
\hline Primary & 44.8 & 45.5 & 45.3 & 53.8 \\
\hline Secondary+ & 53.5 & 60.1 & 62.7 & 62.4 \\
\hline Wealth & & & & \\
\hline Low & 32.3 & 37.5 & 33.1 & 43.1 \\
\hline Medium & 47.3 & 52.5 & 51.5 & 59.9 \\
\hline High & 57.8 & 61.6 & 60.0 & 57.6 \\
\hline Residence & & & & \\
\hline Urban & 56.9 & 60.5 & 57.3 & 57.0 \\
\hline Rural & 42.8 & 47.3 & 45.5 & 52.9 \\
\hline Province & & & & \\
\hline Nairobi & 65.9 & 63.3 & 57.0 & 68.5 \\
\hline Central & 62.5 & 67.8 & 66.7 & 72.6 \\
\hline Coast & 24.5 & 37.6 & 27.0 & 43.9 \\
\hline Eastern & 53.5 & 60.1 & 56.6 & 68.1 \\
\hline Nyanza & 43.2 & 43.0 & 43.5 & 44.3 \\
\hline Rift Valley & 37.6 & 43.7 & 46.6 \\
\hline Western & - & 39.5 & 50.1 \\
\hline North Eastern & & 1.5 & 2.7 \\
\hline Total & & 48.3 & 53.9 \\
\hline & & & & \\
\hline
\end{tabular}

A hyphen means that data are unavailable 


\subsubsection{Ideal number of children}

Desired family size is the number of children an individual would have regardless of actual number of children he or she already has. Table 3.14 presents the mean ideal number of children among women aged 15 to 49 years, by selected background characteristics for survey years 1993, 1998, 2003 and 2008.

In general, there has been little change observed in the mean ideal number of children desired over time (3.8 children) among currently married women in Kenya. Though urbanrural differences were marginal, urban women were more likely to want fewer children than rural women. As expected, the mean ideal number of children varied by levels of education, with the biggest difference seen between women with no education and women with secondary education across all survey years. Interestingly, women with intermediate levels of education (primary) desired the highest average number of children (above 7) across all survey years. Overall, currently married women above age 35 , with primary levels of education, in low wealth households and living in rural areas had the highest desired average number of children in Kenya.

Table 3.14: Mean ideal number of children among women (age 15-49) by selected background characteristics, KDHS 1993, 1998, 2003, 2008/09

\begin{tabular}{|l|c|c|c|c|}
\hline \multirow{2}{*}{ Background Characteristics } & \multicolumn{4}{|c|}{ Mean Ideal Number of Children } \\
\cline { 2 - 5 } & 1993 & 1998 & 2003 & $2008 / 09$ \\
\hline Age & & & & \\
\hline $25-24$ & 3.5 & 3.5 & 3.5 & 3.5 \\
\hline$>35$ & 3.8 & 3.8 & 3.9 & 3.7 \\
\hline Education & 6.4 & 7.1 & 6.9 & 6.6 \\
\hline No Education & & & & \\
\hline Primary Education & 4.9 & 5.2 & 6.7 & 6.4 \\
\hline Secondary + & 7.4 & 7.7 & 7.6 & 7.6 \\
\hline Wealth & 3.0 & 3.2 & 3.1 & 3.1 \\
\hline Low & & & & \\
\hline Medium & 4.4 & 4.3 & 4.9 & 4.5 \\
\hline High & 3.9 & 3.7 & 3.9 & 3.8 \\
\hline Residence & 3.4 & 3.3 & 3.3 & 3.2 \\
\hline Urban & & & & \\
\hline Rural & 2.9 & 3.2 & 3.4 & 3.1 \\
\hline Province & 3.9 & 4.0 & 4.1 & 4.0 \\
\hline Nairobi & & & & \\
\hline Central & 2.7 & 2.9 & 3.2 & 2.8 \\
\hline Coast & 3.1 & 3.1 & 3.1 & 3.1 \\
\hline
\end{tabular}


Table 3.14: Cont...

\begin{tabular}{|l|c|c|c|c|}
\hline \multirow{2}{*}{ Background Characteristics } & \multicolumn{4}{|c|}{ Mean Ideal Number of Children } \\
\cline { 2 - 5 } & 1993 & 1998 & 2003 & $2008 / 09$ \\
\hline Eastern & 3.5 & 3.5 & 3.5 & 3.4 \\
\hline Nyanza & 3.8 & 4.1 & 4.1 & 3.7 \\
\hline Rift Valley & 4.1 & 4.2 & 4.1 & 4.0 \\
\hline Western & 3.8 & 4.1 & 4.0 & 3.9 \\
\hline North Eastern & - & - & 11.1 & 8.8 \\
\hline Total & 3.7 & 3.8 & 3.9 & 3.8 \\
\hline Number of Women & $\mathbf{7 , 1 1 1}$ & $\mathbf{7 , 5 0 1}$ & $\mathbf{7 , 7 6 4}$ & $\mathbf{8 , 1 3 9}$ \\
\hline
\end{tabular}

Table 3.15 shows the mean ideal number of children for women 15-49 by indicators of women's empowerment based on the 2008/09 KDHS. Women who participated in all 5 household decision-making indicators wanted on average 3.8 children compared with 4.2 for women who did not participate in any household decision making. Women who agreed that wife beating was justified for all 5 scenarios (an indicator for low empowerment status) had the highest mean ideal number of children (4.4), while women who disagreed with all scenarios had the lowest mean ideal number of children desired (3.4).

Table 3.15: Mean ideal number of children for women $15-49$ by indicators of women's empowerment, KDHS 2008/09

\begin{tabular}{|l|c|c|}
\hline Empowerment Indicators & $\begin{array}{c}\text { Mean Ideal Number of } \\
\text { Children }\end{array}$ & Number of Women \\
\hline $\begin{array}{l}\text { Number of Decisions in Which women } \\
\text { Participate }\end{array}$ & & \\
\hline 0 & 4.2 & 114 \\
\hline $1-2$ & 4.7 & 701 \\
\hline $3-4$ & 4.1 & 1,525 \\
\hline 5 & 3.8 & 2,392 \\
\hline Number of Reasons for Which Wife Beating & & \\
is Justified & 3.4 & 3,843 \\
\hline 0 & 3.9 & 2,213 \\
\hline $1-2$ & 4.3 & 1,536 \\
\hline $3-4$ & 4.4 & 547 \\
\hline 5 & 3.8 & 8,139 \\
\hline Total & & \\
\hline
\end{tabular}




\subsection{Family planning among vulnerable populations}

As noted in Chapter 2, Kenya considers vulnerable members of the population to include, but not to be limited to: people with disabilities; people infected or affected by HIVIAIDS; OVC; the homeless; refugees and internally displaced people; adolescents and youth; and the poor in urban-, rural- and hard-to-reach areas. Because of their vulnerability, these populations are often marginalized and face difficulties - especially with access to education, health, and employment. Against this backdrop, this section examines: the use of reproductive health services: access to and use of contraceptives: and pregnancy and fertility desires among women living with HIV and people living with disabilities.

\subsubsection{Fertility desires and contraceptive use among women living with HIV}

Figure 3.14 shows that rates for HIV among women in Kenya slowly but consistently declined over time from 9 percent in 2003 to 8 percent in 2008/09. The percentage of HIVpositive women peaked among women aged 25 to 34 years for the 2 survey years under review, while women with primary education, living in the wealthiest households and in urban areas had the highest rates of HIV.

Figure 3.14: Percentage of women 15-49 who were HIV positive, by selected background characteristics, KDHS 2003-2008/09

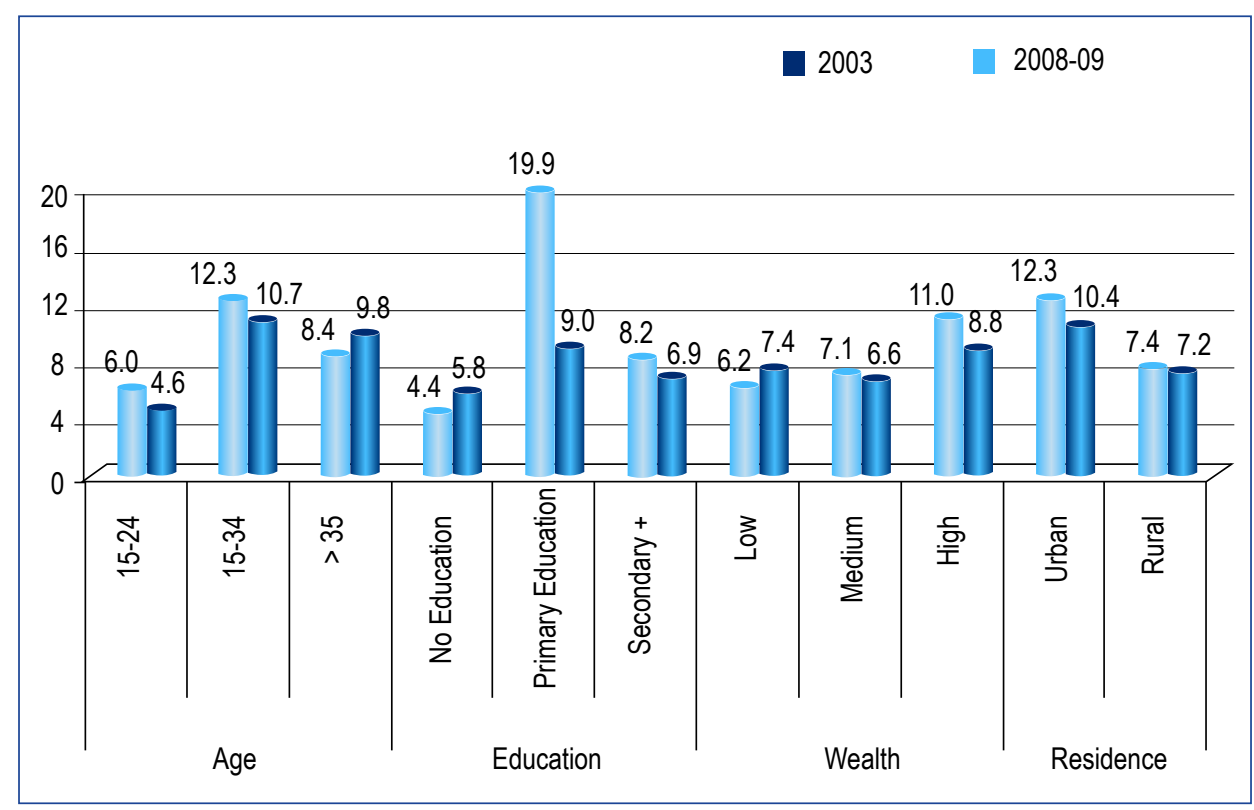


Because women of reproductive ages have the highest rates of HIV and have improved access to anti-retroviral medication and an increased life expectancy, it is imperative that efforts are made to understand their fertility preferences. Understanding their fertility preferences has implications for the extent and type of reproductive health services that are needed. The KAIS 2007 asked women who were married or cohabiting about their desires for children in the future. Table 3.16 presents the fertility desires among currently married women by self-reported HIV status. Seventy-eight percent of women who selfreported being HIV positive reported no desire to have children. Similarly, a desire for children within the subsequent 2 years was very low, with only 8 percent of currently married women who self-reported an HIV-positive status reporting a desire to have a child in these 2 years.

Table 3.16: Fertility desires among currently married women age $15-49$ by selfreported HIV status, KAIS 2007

\begin{tabular}{|l|c|c|c|c|c|}
\hline & $\begin{array}{c}\text { Want a } \\
\text { child within } \\
\text { the next 2 } \\
\text { years }\end{array}$ & $\begin{array}{c}\text { Want a } \\
\text { child, not } \\
\text { within the } \\
\text { next 2 years }\end{array}$ & $\begin{array}{c}\text { Want a } \\
\text { child, } \\
\text { time not } \\
\text { specified }\end{array}$ & $\begin{array}{c}\text { Unsure } \\
\text { if want a } \\
\text { child }\end{array}$ & $\begin{array}{c}\text { Do not want } \\
\text { child ever } \\
\text { in future }\end{array}$ \\
\hline Self-Reported HIV Status & & & & & \\
\hline Self-Reported HIV-Positive Test & 8.1 & 10.5 & 4.1 & 1.1 & 78.3 \\
\hline Self-Reported HIV-Negative Test & 19.3 & 27.1 & 2.3 & 5.8 & 45.6 \\
\hline Never tested/receive results & 20.5 & 12.1 & 2.9 & 7.0 & 57.6 \\
\hline
\end{tabular}

Table 3.17 shows the percentage distribution of contraceptive use for women who reported not wanting a child in the subsequent two years or ever on the basis of KAIS 2007, by selfreported HIV status. Overall, the results indicate that contraceptive use or non-use among currently married women who did not want to initiate childbearing in the subsequent two years was not significantly associated with a woman's self-reported HIV status. However, women who self-reported a negative-HIV status were slightly less likely to be current contraceptive users compared with self-reported HIV-positive women.

Table 3.17: Percentage distribution of contraceptive use for currently married women who did not want a child ever or in subsequent two years, by self-reported HIV Status, KAIS 2007

\begin{tabular}{|l|c|c|}
\hline & HIV Positive & HIV Negative \\
\hline Method of Contraception & $\%$ & $\%$ \\
\hline Not using contraception & 52.6 & 56.8 \\
\hline Using folkloric method & 0.0 & 0.5 \\
\hline Using traditional method & 1.1 & 1.9 \\
\hline Using modern contraception & 46.3 & 40.8 \\
\hline Total \% & 100.0 & 100.0 \\
\hline
\end{tabular}


We also assessed the effect that perceived risk of HIVIAIDS might have on contraceptive use. Table 3.18 shows the trends in use of contraception by perceived risk of getting HIV for 1998, 2003 and 2008/09. Our results show that for 1998 and 2003, the lowest use of contraception was among women with no perceived risk of getting HIV. A reversal was observed in 2008/09 where contraceptive uptake of any method was highest among women with no perceived risk of HIV and just a slightly higher uptake of modern methods.

Table 3.18: Trends in use of contraception by perceived risk of getting AIDS, KDHS $1998,2003,2008 / 9$

\begin{tabular}{|l|l|c|c|c|c|}
\hline \multirow{2}{*}{ KDHS years } & \multirow{2}{*}{ Use of FP method } & \multicolumn{4}{|c|}{ Perceived risk of getting AIDS } \\
\cline { 3 - 6 } & & None & Small & Moderate & Great \\
\hline \multirow{2}{*}{1998} & Any method & 25.3 & 31.1 & 33.8 & 31.1 \\
\cline { 2 - 6 } & Any modern method & 19.2 & 25.0 & 26.8 & 25.1 \\
\hline \multirow{2}{*}{$\mathbf{2 0 0 3}$} & Any method & 20.6 & 31.2 & 38.8 & 28.8 \\
\cline { 2 - 6 } & Any modern method & 16.1 & 25.1 & 31.1 & 23.9 \\
\hline \multirow{2}{*}{$\mathbf{2 0 0 8 / 9}$} & Any method & 40.5 & 23.3 & 38.1 & 38.8 \\
\cline { 2 - 6 } & Any modern method & 36.6 & 19.8 & 34.2 & 32.7 \\
\hline
\end{tabular}

\subsubsection{Family planning among women living with disabilities}

\subsubsection{Contraceptive use among women with disability}

People with disabilities face multiple challenges that could have implications for their sexual and reproductive health. An African Union for the Blind 2007 report $^{75}$ notes, for example, that women and girls with a disability are particularly vulnerable to physical and sexual abuse. According to the Kenya National Survey for Persons with Disabilities, about 5 percent of Kenyans in 2008 were living with some form of disability. Data for this section are drawn from the 2008 KNSPWD, which collected data for seven disability categories: hearing impairment, speech impairment, visual impairment, mental impairment, physical impairment, self-care impairment, and other.

Table 3.19 presents the percentage distribution of women 15 to 49 with a disability who are currently using any contraceptive method. The table is based on data from the subsample of women who answered questions on reproductive health indicators in the 2008 KNSPWD. 
Table 3.19: Percentage distribution of women with disabilities aged $15-49$ who were currently using contraception by method type and background characteristics, KNSPWD 2008

\begin{tabular}{|c|c|c|c|c|}
\hline $\begin{array}{l}\text { Background } \\
\text { Characteristics }\end{array}$ & $\begin{array}{l}\text { Use any type of } \\
\text { contraception }\end{array}$ & $\begin{array}{c}\text { Modern } \\
\text { contraceptive } \\
\text { methods }\end{array}$ & $\begin{array}{l}\text { Traditional } \\
\text { family } \\
\text { planning } \\
\text { methods }\end{array}$ & $\begin{array}{l}\text { Number of } \\
\text { women }\end{array}$ \\
\hline \multicolumn{5}{|l|}{ Age } \\
\hline $15-24$ & 13.2 & 11.8 & 1.3 & 76 \\
\hline $25-34$ & 15.2 & 13.6 & 1.5 & 66 \\
\hline$>35$ & 18.9 & 15.7 & 3.1 & 127 \\
\hline \multicolumn{5}{|l|}{ Education } \\
\hline No Education & 11.8 & 5.9 & 5.9 & 34 \\
\hline Primary Education & 18.6 & 16.2 & 2.4 & 167 \\
\hline Secondary + & 13.2 & 13.2 & 0.0 & 68 \\
\hline \multicolumn{5}{|l|}{ Marital Status } \\
\hline Never Married & 13.7 & 12.6 & 1.1 & 95 \\
\hline Currently Married & 16.7 & 14.4 & 2.3 & 132 \\
\hline Formerly Married & 21.4 & 16.7 & 4.8 & 42 \\
\hline \multicolumn{5}{|l|}{ Residence } \\
\hline Urban & 18.4 & 15.1 & 3.2 & 185 \\
\hline Rural & 11.9 & 11.9 & 0.0 & 84 \\
\hline \multicolumn{5}{|l|}{ Province } \\
\hline Nairobi & 11.9 & 11.9 & 0.0 & 42 \\
\hline Central & 25.9 & 25.9 & 0.0 & 27 \\
\hline Coast & 13.2 & 13.2 & 0.0 & 38 \\
\hline Eastern & 27.3 & 18.2 & 9.1 & 44 \\
\hline Nyanza & 12.9 & 12.9 & 0.0 & 70 \\
\hline Rift Valley & 0.0 & 0.0 & 0.0 & 27 \\
\hline Western & * & * & * & 16 \\
\hline North Eastern & * & * & * & 5 \\
\hline Total & 16.4 & 14.1 & 2.2 & 269 \\
\hline
\end{tabular}

Note: An asterisk denotes a figure based on fewer than 25 unweighted cases that has been suppressed

Results show that overall the contraceptive prevalence rate was 16 percent among women living with disabilities (substantially lower than the national average of 46 percent), 14 percent reported the use of a modern method, while 2 percent reported use of a traditional FP method. The contraceptive prevalence rate was highest among women aged 25 to 34 years, women with a primary education, and those living in urban areas. Formerly married women were more likely to report use of any form of contraception, while rural women had higher rates of contraceptive usage compared with their urban counterparts. 


\subsubsection{Access to FP among women with disabilities}

Table 3.20 shows the percentage of women between the ages of 12 and 49 years with disabilities who had access to FP. Survey results show that nearly all respondents (98 percent) had never been denied access to FP services. The results remained the same by the different background characteristics.

Table 3.20: Percentage distribution of women aged 12-49 years with disabilities who had access to family planning and had ever been pregnant by background characteristics, KNSPWD 2008

\begin{tabular}{|c|c|c|c|c|c|}
\hline \multirow{2}{*}{$\begin{array}{l}\text { Background } \\
\text { Characteristics }\end{array}$} & \multicolumn{2}{|c|}{$\begin{array}{l}\text { Ever been Refused/ } \\
\text { Denied Use of FP }\end{array}$} & \multicolumn{2}{|c|}{$\begin{array}{l}\text { Ever Been } \\
\text { Pregnant }\end{array}$} & \multirow{2}{*}{$\begin{array}{c}\text { Number of } \\
\text { Women }\end{array}$} \\
\hline & Yes & No & Yes & No & \\
\hline \multicolumn{6}{|l|}{ Age } \\
\hline $15-24$ & 1.3 & 98.7 & 27.6 & 72.4 & 76 \\
\hline $25-34$ & 4.5 & 95.5 & 47.0 & 53.0 & 66 \\
\hline$>35$ & 1.6 & 98.4 & 54.3 & 45.7 & 127 \\
\hline \multicolumn{6}{|l|}{ Education } \\
\hline No Education & 0.0 & 100 & 52.9 & 47.1 & 34 \\
\hline Primary Education & 2.4 & 97.6 & 47.9 & 52.1 & 167 \\
\hline Secondary + & 2.9 & 97.1 & 33.8 & 66.2 & 68 \\
\hline \multicolumn{6}{|l|}{ Marital Status } \\
\hline Never Married & 2.1 & 97.9 & 30.5 & 69.5 & 95 \\
\hline Currently Married & 2.3 & 97.7 & 37.9 & 62.1 & 132 \\
\hline Formerly Married & 2.4 & 97.6 & 100 & 0.0 & 42 \\
\hline \multicolumn{6}{|l|}{ Residence } \\
\hline Urban & 2.2 & 97.8 & 45.9 & 54.1 & 185 \\
\hline Rural & 2.4 & 97.6 & 42.9 & 57.1 & 84 \\
\hline \multicolumn{6}{|l|}{ Province } \\
\hline Nairobi & 4.8 & 95.2 & 38.1 & 61.9 & 42 \\
\hline Central & 0.0 & 100 & 37.0 & 63.0 & 27 \\
\hline Coast & 0.0 & 100 & 50.0 & 50.0 & 38 \\
\hline Eastern & 4.5 & 95.5 & 38.6 & 61.4 & 44 \\
\hline Nyanza & 1.4 & 98.6 & 60.0 & 40.0 & 70 \\
\hline Rift Valley & 0.0 & 100 & 29.6 & 70.4 & 27 \\
\hline Western & * & * & * & * & 16 \\
\hline North Eastern & * & $*$ & * & * & 5 \\
\hline Total & 2.2 & 97.8 & 45 & 55 & 269 \\
\hline
\end{tabular}

Note: An asterisk denotes a figure based on fewer than 25 unweighted cases that has been suppressed 


\subsubsection{Marital status and childbearing among women with disabilities}

Table 3.21 shows data on marital status and childbearing among women living with disabilities. Slightly more than half of the women (51 percent) aged between 15 and 49 years with disabilities were married or involved in a relationship (7 percentage points lower than the national average of 58 percent of women currently in a union). Almost 87 percent of adolescent girls compared with 31 percent of women above age 35 reported being married or in a relationship. Negligible differences were seen by residence or region, while women with no education were less likely to report being married or involved in a relationship. Results also show that 58 percent of women living with disabilities reported having children, with a greater proportion of women aged 15 to 24 years and those with secondary education having children compared with women aged 35 years and older and those with no or primary education, respectively.

Table 3.21: Percentage distribution of marital status and having children among women age 15-49 with disabilities by background characteristics, KNSPWD 2008

\begin{tabular}{|l|c|c|c|c|c|}
\hline \multirow{2}{*}{$\begin{array}{l}\text { Background } \\
\text { Characteristics }\end{array}$} & \multicolumn{2}{|c|}{$\begin{array}{c}\text { Married or Involved in a } \\
\text { Relationship }\end{array}$} & \multicolumn{2}{c|}{ Have Children } & \\
\cline { 2 - 6 } & Yes & No & Yes & No & N \\
\hline Age & & & & & \\
\hline $15-24$ & 86.8 & 13.2 & 77.6 & 22.4 & 76 \\
\hline $25-34$ & 48.5 & 51.5 & 54.5 & 45.5 & 66 \\
\hline$>35$ & 30.7 & 69.3 & 47.2 & 52.8 & 127 \\
\hline Education & & & & & \\
\hline No Education & 32.4 & 67.6 & 55.9 & 44.1 & 34 \\
\hline Primary Education & 52.7 & 47.3 & 53.9 & 46.1 & 167 \\
\hline Secondary + & 55.9 & 44.1 & 67.6 & 32.4 & 68 \\
\hline Residence & & & & & \\
\hline Urban & 47.0 & 53.0 & 56.2 & 43.8 & 185 \\
\hline Rural & 59.5 & 40.5 & 60.7 & 39.3 & 84 \\
\hline Province & & & & & \\
\hline Nairobi & $*$ & $*$ & $*$ & $*$ & 5 \\
\hline Central & 59.0 & 31.0 & 69.0 & 31.0 & 42 \\
\hline Coast & 63.0 & 37.0 & 70.4 & 29.6 & 27 \\
\hline Eastern & 39.5 & 60.5 & 52.6 & 47.4 & 38 \\
\hline Nyanza & 36.4 & 63.6 & 61.4 & 38.6 & 44 \\
\hline Rift Valley & 52.9 & 47.1 & 40.0 & 60.0 & 70 \\
\hline Western & 48.1 & 51.9 & 74.1 & 25.9 & 27 \\
\hline North Eastern & $*$ & $*$ & $*$ & 16 \\
\hline Total & & $* 9.1$ & 57.6 & 42.4 & 269 \\
\hline
\end{tabular}

Note: An asterisk denotes a figure based on fewer than 25 unweighted cases that has been suppressed 


\subsection{Trends in pregnancy termination}

Table 3.22 presents the percentage distribution of women who had ever had a terminated pregnancy by selected background characteristics in the 1998, 2003 and 2008/09 KDHS. It should be noted that KDHS data do not distinguish between induced or spontaneous abortion. Overall, the proportion of women in Kenya who had ever had a terminated pregnancy remained fairly constant over time, at around 10 percent. The percentage of women who had ever had a terminated pregnancy increased with the age of the woman. Women with no education were more likely to have ever had a termination compared with women with secondary or higher education. Rural women were slightly more likely to report having had a termination than urban women. Women in high-wealth households were less likely to report a terminated pregnancy compared with women in medium- and low-wealth households. Some regional variation was observed, as women in Western and Coastal provinces were consistently more likely to report a terminated pregnancy, while Nairobi consistently had the lowest percentage of women reporting a terminated pregnancy.

Table 3.22: Percentage distribution of women who had ever had a terminated pregnancy by selected background characteristics, KDHS 1998, 2003, 2008/09

\begin{tabular}{|c|c|c|c|c|c|c|}
\hline \multirow{2}{*}{$\begin{array}{l}\text { Background } \\
\text { Characteristics }\end{array}$} & \multicolumn{6}{|c|}{ Ever Had a Terminated Pregnancy } \\
\hline & $\begin{array}{c}1998 \\
\text { KDHS }\end{array}$ & $\begin{array}{l}\text { Number } \\
\text { of women }\end{array}$ & $\begin{array}{c}2003 \\
\text { KDHS }\end{array}$ & $\begin{array}{l}\text { Number } \\
\text { of Women }\end{array}$ & $\begin{array}{c}2008 / 09 \\
\text { KDHS }\end{array}$ & $\begin{array}{c}\text { Number of } \\
\text { Women }\end{array}$ \\
\hline \multicolumn{7}{|l|}{ Age } \\
\hline $15-24$ & 3.7 & 3,394 & 3.9 & 3,530 & 2.8 & 3,511 \\
\hline $25-34$ & 9.7 & 2,321 & 11.1 & 2,516 & 10.1 & 2,603 \\
\hline$>35$ & 14.0 & 2,166 & 20.5 & 2,149 & 17.2 & 2,330 \\
\hline \multicolumn{7}{|l|}{ Education } \\
\hline No Education & 13.8 & 1,010 & 16.2 & 1,291 & 12.1 & 1,242 \\
\hline Primary Education & 7.7 & 4,719 & 10.3 & 4,348 & 9.9 & 4,404 \\
\hline Secondary + & 7.3 & 2,152 & 8.4 & 2,556 & 6.7 & 2,798 \\
\hline \multicolumn{7}{|l|}{ Wealth } \\
\hline Low & 10.1 & 2747 & 11.5 & 2,594 & 10.3 & 2,927 \\
\hline Medium & 7.9 & 2745 & 10.6 & 2,487 & 9.6 & 2,561 \\
\hline High & 6.9 & 2389 & 9.4 & 3,114 & 7.2 & 2,956 \\
\hline \multicolumn{7}{|l|}{ Residence } \\
\hline Urban & 7.1 & 1,466 & 9.4 & 2,751 & 6.6 & 2,615 \\
\hline Rural & 8.7 & 6,415 & 10.8 & 5,444 & 9.9 & 5,829 \\
\hline \multicolumn{7}{|l|}{ Province } \\
\hline Nairobi & 6.2 & 419 & 8.6 & 1,169 & 5.0 & 952 \\
\hline Central & 4.6 & 787 & 9.6 & 1,314 & 9.2 & 973 \\
\hline Coast & 10.9 & 1,226 & 14.5 & 938 & 13.7 & 1,149 \\
\hline
\end{tabular}


Table 3.22: Cont...

\begin{tabular}{|c|c|c|c|c|c|c|}
\hline \multirow{2}{*}{$\begin{array}{l}\text { Background } \\
\text { Characteristics }\end{array}$} & \multicolumn{6}{|c|}{ Ever Had a Terminated Pregnancy } \\
\hline & $\begin{array}{c}1998 \\
\text { KDHS }\end{array}$ & $\begin{array}{l}\text { Number } \\
\text { of women }\end{array}$ & $\begin{array}{c}2003 \\
\text { KDHS }\end{array}$ & $\begin{array}{l}\text { Number } \\
\text { of Women }\end{array}$ & $\begin{array}{c}2008 / 09 \\
\text { KDHS }\end{array}$ & $\begin{array}{c}\text { Number of } \\
\text { Women }\end{array}$ \\
\hline Eastern & 8.6 & 1,186 & 8.6 & 993 & 9.6 & 1,127 \\
\hline Nyanza & 7.8 & 1,390 & 12.3 & 1,025 & 8.9 & 1,318 \\
\hline Rift Valley & 7.2 & 1,977 & 9.3 & 1,328 & 7.9 & 1,278 \\
\hline Western & 14.4 & 896 & 13.6 & 991 & 11.0 & 1,039 \\
\hline North Eastern & - & - & 7.5 & 437 & 8.9 & 608 \\
\hline Total & 8.3 & 7,881 & 10.5 & 8,195 & 9.0 & 8,444 \\
\hline
\end{tabular}

\subsubsection{Abortion incidence}

The incidence of abortion in a particular community often reflects the magnitude of unintended pregnancies. Unsafe abortion is a significant contributor to maternal mortality and morbidity in Kenya, partly because recourse to safe abortion is restricted and the availability of trained staff, supplies and equipment is limited. The extent of unsafe induced abortion in Kenya is documented in a recently released national study Incidence and Complications of Unsafe Abortion in Kenya undertaken in 2012 and conducted by the APHRC in collaboration with the Ministry of Health and other partners to assess the annual number of abortions in Kenya. ${ }^{74}$ Data from this national study show that almost 464,690 abortions were procured in 2012 among women of reproductive age (15 to 49 years) in Kenya (see Table 3.23).

Table 3.23: Estimated number of cases of induced abortion complications and overall induced abortions by region, Kenya 2012

\begin{tabular}{|c|c|c|c|c|}
\hline \multirow[b]{2}{*}{ Region } & \multirow{2}{*}{$\begin{array}{c}\text { No. of cases of induced } \\
\text { abortions treated at } \\
\text { health facilities }\end{array}$} & \multicolumn{3}{|c|}{ Number of all induced abortions } \\
\hline & & Low estimate & $\begin{array}{l}\text { Medium } \\
\text { estimate }\end{array}$ & $\begin{array}{l}\text { High } \\
\text { estimate }\end{array}$ \\
\hline Central \& Nairobi & 20,676 & 49,828 & 70,504 & 91,180 \\
\hline Coast and North Eastern & 16,649 & 49,616 & 66,265 & 82,914 \\
\hline Eastern & 7,057 & 21,030 & 28,087 & 35,144 \\
\hline Nyanza \& Western & 36,842 & 109,789 & 146,631 & 183,473 \\
\hline Rift Valley & 38,687 & 115,289 & 153,976 & 192,664 \\
\hline Total & 119,912 & 344,778 & 464,690 & 584,601 \\
\hline
\end{tabular}

Source: APHRC, MOH, Ipas, and Guttmacher Institute, 2013.74 
According to the 2012 incidence report, the estimated rate of induced abortion was 48 per 1000 women. As shown in Table 3.24, regional disparities existed, with abortion rates highest for Nyanza and Western (63 per 1000) and Rift Valley Provinces (64 per 1000), with abortion ratios the highest in both regions.

Table 3.24: National and regional induced abortion rates and ratio, Kenya 2012

\begin{tabular}{|l|c|c|c|}
\hline Region & $\begin{array}{c}\text { Number of Women (in } \\
\text { 000's) of reproductive } \\
\text { age (15-49) }\end{array}$ & $\begin{array}{c}\text { Induced Abortion Rate } \\
\text { per 1,000 women of } \\
\text { reproductive age }\end{array}$ & $\begin{array}{c}\text { Induced Abortion } \\
\text { Ratio per 100 live } \\
\text { births }\end{array}$ \\
\hline Central and Nairobi & 2186 & 32 & 20 \\
\hline Coast and North Eastern & 1298 & 51 & 32 \\
\hline Eastern & 1382 & 20 & 13 \\
\hline Nyanza and Western & 2329 & 63 & 39 \\
\hline Rift Valley & 2404 & 64 & 40 \\
\hline Total & 9600 & 48 & 30 \\
\hline
\end{tabular}

Source: APHRC, MOH, Ipas, and Guttmacher Institute, 2013.74

The incidence study also assessed the characteristics of women seeking post-abortion care $(\mathrm{PAC})$ for abortion-related complications in both public and private facilities across Kenya. Table 3.25 presents the socio-demographic characteristics of women seeking PAC in health facilities over a 30-day period. Analyses show that about 17 percent of patients were below age 19; 32 percent were between 20 and 24 years and 51 percent were above age 25. The majority of women seeking PAC were married or in unions (64 percent), had a primary education (40 percent), lived in rural areas (59 percent), and were unemployed or housewives (42 percent).

Table 3.25: Socio-demographic characteristics of women seeking PAC in health facilities over a 30-day period, Kenya 2012

\begin{tabular}{|l|c|c|}
\hline Background Characteristics & $\%$ & N \\
\hline Age & & 335 \\
\hline $10-19$ Years & 16.5 & 810 \\
\hline $20-24$ Years & 31.5 & 1478 \\
\hline $25+$ Years & 51.3 & \\
\hline Residence & & 1386 \\
\hline Urban & 40.9 & 1238 \\
\hline Rural & 58.7 & \\
\hline
\end{tabular}


Table 3.25: Cont...

\begin{tabular}{|l|c|c|}
\hline Background Characteristics & $\%$ & N \\
\hline Marital Status & & 761 \\
\hline Never Married & 27.8 & 1700 \\
\hline Married/Living together & 64.4 & 162 \\
\hline Divorced & 7.5 & \\
\hline Education & & 158 \\
\hline No education & 9.3 & 963 \\
\hline Primary & 40.1 & 952 \\
\hline Secondary & 35.5 & 543 \\
\hline Post-secondary & 14.8 & \\
\hline Occupation & & 589 \\
\hline Farmer/unskilled & 24.9 & 684 \\
\hline Skilled/clerical & 20.2 & 384 \\
\hline Student & 13.0 & 965 \\
\hline Unemployed/housewife & 41.7 & 2631 \\
\hline Religion & & 606 \\
\hline Catholic & 24.3 & 1767 \\
\hline Other Christians & 64.4 & 216 \\
\hline Muslims & 8.5 & 30 \\
\hline Others & 2.3 & \\
\hline Total & 100 & \\
\hline
\end{tabular}

The data from the incidence study further indicate that 37 percent of the women presented with severe complications, 40 percent with moderately severe complications, and 23 percent with minor complications. Most of the severe complications were among women who reported an interference with the pregnancy prior to visiting a provider (58 percent). ${ }^{74}$ Severity of complications was associated with delays in seeking health care, as women who delayed for more than one week before seeking medical care had the most severe complications (54 percent). Adolescents accounted for 45 percent of the severe abortionrelated-complication cases that presented for PAC, and 43 percent were among women with gestational age above 12 weeks. About 85 women died from abortion-related complications in the sampled facilities, indicating a case fatality rate of 266 deaths per 100,000 unsafe abortions. 


\subsection{Chapter summary}

According to the 2008/09 KDHS, overall rates of unintended pregnancy remained quite high, with about 43 percent of women in Kenya reporting an unintended pregnancy. Very little change was observed in relation to previous KDHS surveys.

- The total fertility rate dropped from 5.4 to 4.7 children per woman between 1993 and 1998 then increased to 4.9 in 2003 and dropped to 4.6 in 2008/09. Fertility rates were highest among women with low and medium education and those living in low wealth households.

- Use of contraception varied by socioeconomic status, with more educated women and women from the richest households being more likely to be current contraceptive users. Overall, the current rate of contraceptive usage (especially use of modern contraceptive) modestly increased over the 15 years examined, with women above age 24 being more likely to report contraceptive use.

- The levels of unmet need for FP declined over time among currently married women (35 percent in 1993 to 26 percent in 2008/09).

- Actual fertility rates were higher than desired fertility: If Kenyan women were to achieve their desired fertility, on average women would have 1.4 less children.

- Overall, levels of unintended pregnancy among Kenyan women changed substantially between 1993 and 2008/09 (from 51 percent to 43 percent). However, little change was observed between 2003 and 2008/09 (45 percent in 2003 to 43 percent in 2008/09). The proportion of births that were reported as mistimed consistently stayed higher than unwanted births.

- The uptake of long-acting methods (implants and IUDs) remained very low and use declined over time.

- Among women with unmet need for FP, access and cost were not of major concern, rather, health concerns and side effects were the most commonly cited reasons for non-use of contraception.

- Contraceptive discontinuation rates remained quite high with 1 in 3 couple discontinuing a method in the first $12-24$ months of use, and almost 64 percent discontinuing by 36 months. Primary reasons for discontinuation included health concerns and method-related dissatisfaction. This implies a need for improved quality services with counseling about side effects and alternative methods to facilitate easy switching between methods if the need arises.

- Age at first sexual intercourse and first marriage among Kenyan women increased between the survey years. However, the mean difference between age at sexual initiation and age at first marriage widened, indicating an increase in premarital sexual activity and the risk of pregnancy before marriage.

- The proportion of females ages 15 to 24 years who had ever been pregnant or had a child largely remained unchanged between 1993 and 2008/09. Although contraceptive use among 15 to 24 year olds increased modestly, about 47 percent of pregnancies among female youth were unintended. Although levels of modern contraception among sexually active unmarried females aged 15 to 24 years slightly increased over 
time, only 1 in 5 sexually active unmarried female youth was currently using a modern method of contraceptive.

- Trends in termination of pregnancy remained consistent over time although numbers in the KDHS are likely underestimates. Findings from the recently completed abortion incidence study ${ }^{74}$ suggest much higher numbers. The report indicates that about 464,690 induced abortions were procured in 2012 among women of reproductive ages (15 to 49 years) in Kenya, indicating an annual abortion rate of 48 per 1000 women.

- Overall, reproductive health indicators were poorer among women with no education, from low wealth households and living in rural areas. 


\section{CHAPTER 4}

\section{Availability, Cost and Quality of Family Planning - and Abortion-Related Services}

\subsection{Availability of family planning services}

The 1999, 2004 and 2010 Kenya Service ProvisionAssessments Surveys (KSPA) assessed the availability of FP services in health facilities (hospitals, health centers, maternity facilities, clinics and dispensaries) in Kenya ${ }^{44,76,77}$ For a facility to be considered a source of FP, it must provide, prescribe, or counsel clients on any of the following: contraceptive pills, injectables, implants, intrauterine devices (IUDs), male condoms or female condoms. The 2010 KSPA indicated that 85 percent of 690 facilities assessed offered any modern methods of contraception, an increase from 75 percent of the facilities (430) in 2004. At the same time, 89 percent of all health facilities offered some type of temporary modern methods of FP. Only 26 percent offered male or female sterilization services and 8 percent provided male or female sterilization (Table 4.1). Virtually all government facilities offer FP, as do a high proportion of NGOs and private facilities. However, less than half of facilities managed by faith-based organizations (FBOs) offer FP and this proportion has decreased over time (Table 4.1).

The 2010 KSPA shows regional variations: facilities in Nairobi and North Eastern Provinces (68 percent and 67 percent, respectively) were least likely to offer FP services, in contrast with facilities in Rift Valley, Nyanza, and Western Provinces (at 92 percent to 93 percent). Over half of all health facilities offered counseling services in natural methods and 24 percent of health facilities offered natural methods only.

Table 4.1: Percentage of all facilities offering temporary methods of family planning and sterilization, by background characteristics, KSPA 2004 and 2010

\begin{tabular}{|c|c|c|c|c|c|c|c|c|c|c|}
\hline \multirow{3}{*}{$\begin{array}{l}\text { Background } \\
\text { Characteristics }\end{array}$} & \multicolumn{2}{|c|}{$\begin{array}{c}\% \text { offering } \\
\text { any modern } \\
\text { method of FP }\end{array}$} & \multicolumn{2}{|c|}{$\begin{array}{c}\% \text { offering } \\
\text { counseling on } \\
\text { natural method }\end{array}$} & \multicolumn{2}{|c|}{$\begin{array}{l}\% \text { offering any } \\
\text { temporary } \\
\text { method of FP }\end{array}$} & \multicolumn{2}{|c|}{$\begin{array}{c}\% \text { offering } \\
\text { male or female } \\
\text { sterilization }\end{array}$} & \multicolumn{2}{|c|}{$\begin{array}{l}\% \text { providing } \\
\text { male or } \\
\text { female } \\
\text { sterilization }\end{array}$} \\
\hline & 2004 & 2010 & 2004 & 2010 & 2004 & 2010 & 2004 & 2010 & 2004 & 2010 \\
\hline & $\%$ & $\%$ & $\%$ & $\%$ & $\%$ & $\%$ & $\%$ & $\%$ & $\%$ & $\%$ \\
\hline \multicolumn{11}{|l|}{ Type of facility } \\
\hline Hospital & 83 & 85 & 48 & 75 & - & 91 & 46 & 67 & - & 46 \\
\hline Health center & 85 & 83 & 50 & 64 & - & 86 & 3 & 33 & - & 20 \\
\hline Maternity & 87 & 88 & 40 & 63 & - & 88 & 17 & 47 & - & 31 \\
\hline Clinic & 66 & 80 & 37 & 44 & - & 81 & 3 & 18 & - & 3 \\
\hline Dispensary & 68 & 89 & 31 & 59 & - & 94 & 0 & 22 & - & 2 \\
\hline
\end{tabular}


Table 4.1: Cont...

\begin{tabular}{|c|c|c|c|c|c|c|c|c|c|c|}
\hline \multirow{3}{*}{$\begin{array}{l}\text { Background } \\
\text { Characteristics }\end{array}$} & \multicolumn{2}{|c|}{$\begin{array}{c}\% \text { offering } \\
\text { any modern } \\
\text { method of FP }\end{array}$} & \multicolumn{2}{|c|}{$\begin{array}{c}\% \text { offering } \\
\text { counseling on } \\
\text { natural method }\end{array}$} & \multicolumn{2}{|c|}{$\begin{array}{l}\% \text { offering any } \\
\text { temporary } \\
\text { method of FP }\end{array}$} & \multicolumn{2}{|c|}{$\begin{array}{c}\% \text { offering } \\
\text { male or female } \\
\text { sterilization }\end{array}$} & \multicolumn{2}{|c|}{$\begin{array}{l}\% \text { providing } \\
\text { male or } \\
\text { female } \\
\text { sterilization }\end{array}$} \\
\hline & 2004 & 2010 & 2004 & 2010 & 2004 & 2010 & 2004 & 2010 & 2004 & 2010 \\
\hline & $\%$ & $\%$ & $\%$ & $\%$ & $\%$ & $\%$ & $\%$ & $\%$ & $\%$ & $\%$ \\
\hline \multicolumn{11}{|l|}{$\begin{array}{l}\text { Managing } \\
\text { Authority }\end{array}$} \\
\hline Government & 85 & 96 & 42 & 64 & - & 97 & 5 & 33 & - & 11 \\
\hline NGO & 88 & 89 & 85 & 36 & - & 89 & 5 & 24 & - & 7 \\
\hline $\begin{array}{l}\text { Private (for } \\
\text { profit) }\end{array}$ & 59 & 84 & 33 & 46 & - & 84 & 11 & 21 & - & 7 \\
\hline $\begin{array}{l}\text { Faith-based } \\
\text { organization }\end{array}$ & 58 & 44 & 27 & 58 & - & 69 & 2 & 12 & - & 3 \\
\hline \multicolumn{11}{|l|}{ Province } \\
\hline Nairobi & 49 & 68 & 33 & 43 & - & 68 & 6 & 29 & - & 11 \\
\hline Central & 83 & 89 & 53 & 33 & - & 90 & 4 & 9 & - & 6 \\
\hline Coast & 73 & 75 & 45 & 72 & - & 83 & 10 & 26 & - & 7 \\
\hline Eastern & 77 & 79 & 39 & 44 & - & 87 & 3 & 12 & - & 5 \\
\hline North Eastern & 68 & 67 & 37 & 67 & - & 67 & 0 & 65 & - & 1 \\
\hline Nyanza & 91 & 93 & 31 & 79 & - & 96 & 4 & 42 & - & 14 \\
\hline Rift Valley & 72 & 92 & 33 & 64 & - & 95 & 4 & 27 & - & 8 \\
\hline Western & 78 & 93 & 47 & 60 & - & 94 & 8 & 47 & - & 18 \\
\hline Total & 75 & 85 & 38 & 56 & - & 89 & 5 & 26 & - & 8 \\
\hline
\end{tabular}

The 1999 KSPA is not comparable to the later KPSA surveys (2004 \& 2010) A hyphen means that data are unavailable

\subsubsection{Frequency of availability of family planning services}

In 2010, most facilities (88 percent) offered FP services five or more days per week. Government and private health facilities were more likely than NGOs or faith-based health facilities to offer FP service 5 or more day per week. Health facilities in North Eastern, Central, Western and Nairobi Provinces were more likely than those in Nyanza, Eastern, Coast and Rift Valley Provinces to offer FP services five or more days per week. ${ }^{44,77}$

\subsubsection{Method availability}

According to the $2010 \mathrm{KSPA}$, a wide range of methods was available in most health facilities. The most commonly available temporary modern methods were combined oral contraceptives, the 2- or 3-month progestin-only injectables and male condoms (Table 4.2). 
Table 4.2: Among facilities offering family planning services, percentage that provided clients with specific FP methods, by type of facility, KSPA 2010

\begin{tabular}{|l|c|c|c|c|c|c|}
\hline \multirow{2}{*}{ Method Provided } & \multicolumn{5}{|c|}{ Type of facility } & Total \\
\cline { 2 - 7 } & Hospital & $\begin{array}{c}\text { Health } \\
\text { Center }\end{array}$ & Maternity & Clinic & Dispensary & $\%$ \\
\hline Combined oral contraceptive & 92 & 91 & 96 & 85 & 94 & 91 \\
\hline Progestin-only oral pill & 89 & 82 & 73 & 56 & 85 & 77 \\
\hline Progestin-only injectable (3- month) & 90 & 90 & 93 & 91 & 93 & 92 \\
\hline Progestin-only injectable (2- month) & 5 & 3 & 3 & 1 & 2 & 2 \\
\hline Progestin-only injectable (2/month) & 91 & 90 & 95 & 92 & 93 & 92 \\
\hline Combined injectable (1-month) & 3 & 0 & 5 & 1 & 1 & 1 \\
\hline Male condom & 92 & 91 & 89 & 79 & 93 & 89 \\
\hline Female condom & 55 & 39 & 51 & 28 & 33 & 34 \\
\hline Intrauterine contraceptive device & 74 & 66 & 76 & 34 & 23 & 36 \\
\hline Implant & 67 & 53 & 72 & 34 & 18 & 31 \\
\hline Counseling on natural method & 29 & 19 & 34 & 23 & 26 & 25 \\
\hline Moon beads for standard days & 12 & 9 & 5 & 2 & 1 & 3 \\
\hline Female sterilization & 50 & 23 & 35 & 3 & 2 & 9 \\
\hline Male sterilization & 33 & 13 & 17 & 1 & 1 & 5 \\
\hline $\begin{array}{l}\text { At least two temporary modern } \\
\text { methods* }\end{array}$ & 93 & 92 & 98 & 90 & 95 & 93 \\
\hline $\begin{array}{l}\text { At least four temporary modern } \\
\text { methods* }\end{array}$ & 90 & 85 & 94 & 62 & 87 & 80 \\
\hline Emergency contraceptive pill & 79 & 81 & 73 & 48 & 82 & 72 \\
\hline $\begin{array}{l}\text { Number of facilities offering } \\
\text { temporary methods of family } \\
\text { planning }\end{array}$ & 46 & 68 & 15 & 164 & 319 & 612 \\
\hline Total number of facilities & 51 & 80 & 17 & 203 & 340 & 690 \\
\hline & & & & & & \\
\hline
\end{tabular}

\section{* Does not include emergency contraceptive pills}

Most temporary methods were found in all types of health facilities while male and female sterilization were provided primarily in hospitals, health centers and maternity homes. Female sterilization was provided in only 9 percent of all facilities and male sterilization in only 5 percent of the facilities.

\subsection{Cost of family planning services}

Direct and indirect costs of FP can affect the use of FP in different societies. ${ }^{27,78,79}$ Indirect costs may include the cost of travelling to the nearest facility to obtain FP services. FP services in government facilities are supposed to be provided free of charge and there 
should be no charge for any government supplied-commodities, whether provided in a government- or non-government facility. However, recent KSPA reports and KDHS reports indicated that most facilities charge some user fees (Tables 4.3 and 4.4). The increase over time in the proportion of facilities charging user fees occurred in all types of health facilities, although hospitals and dispensaries were less likely to charge user fees. Facilities in Nairobi and Central Provinces were most likely to charge user fees for FP. It is worth noting that the user fees charged were not for the commodities themselves but, rather, were fees levied by the facility to cover other costs, including client registration and supplies used (e.g., gloves, cotton wool, needles, and syringes).

Table 4.3: Percentage of facilities offering FP that charged user fees by background characteristics, KSPA 1999, 2004, 2010

\begin{tabular}{|c|c|c|c|}
\hline & KSPA 1999 & KSPA 2004 & KSPA 2010 \\
\hline Background Characteristics & $\begin{array}{c}\text { \% } \\
\text { with user fees } \\
\text { for family } \\
\text { planning } \\
\text { services }\end{array}$ & $\begin{array}{c}\% \\
\text { with user fees } \\
\text { for family } \\
\text { planning } \\
\text { services }\end{array}$ & $\begin{array}{c}\% \\
\text { with user fees } \\
\text { for family } \\
\text { planning } \\
\text { services }\end{array}$ \\
\hline \multicolumn{4}{|l|}{ Type of facility } \\
\hline Hospital & 32 & 60 & 70 \\
\hline Health center & 31 & 44 & 79 \\
\hline Maternity & 89 & 94 & 95 \\
\hline Clinic & 82 & 93 & 93 \\
\hline Dispensary & 32 & 49 & 66 \\
\hline \multicolumn{4}{|l|}{ Managing Authority } \\
\hline Government & 25 & 42 & 68 \\
\hline NGO & - & 31 & 65 \\
\hline Private(for profit) & 80 & 95 & 94 \\
\hline Faith-based organization & 56 & 62 & 58 \\
\hline \multicolumn{4}{|l|}{ Province } \\
\hline Nairobi & 53 & 72 & 92 \\
\hline Central & 45 & 57 & 97 \\
\hline Coast & 36 & 54 & 68 \\
\hline Eastern & 57 & 58 & 70 \\
\hline North Eastern & - & 11 & 1 \\
\hline Nyanza & 33 & 57 & 70 \\
\hline Rift Valley & 35 & 44 & 76 \\
\hline Western & 59 & 28 & 71 \\
\hline Total & 44 & 51 & 76 \\
\hline
\end{tabular}


The user fees charged were relatively modest and varied by type of method. As indicated in Table 4.3, user fees were higher for female sterilization and lower for oral contraceptive pills. The 2008/09 KDHS indicated, however, that one-fifth of all the current users of female sterilization, pills, injectables and implants received the services free of charge (Table 4.4.) Government (public sector) facilities were more likely to provide free FP services.

Table 4.4: Median cost of contraception and percentage of current users of contraception aged 15-49 who did not pay for contraception or who did not know the cost of the method, by source of current method, KDHS 2008/09

\begin{tabular}{|l|c|c|c|c|c|}
\hline Source of Methods/cost & $\begin{array}{c}\text { Female } \\
\text { sterilization }\end{array}$ & Pill & Injectables & Implants & Total \\
\hline Public sector & & & & & \\
\hline Percentage free & 54.1 & 30.8 & 16.4 & 35.6 & 27.7 \\
\hline Do not know cost & 10.4 & 0.0 & 0.4 & 0.0 & 2.4 \\
\hline Median cost [in Kshs.] & 2495 & 18.0 & 30.0 & 196.0 & 29.0 \\
\hline Number of women & 179 & 169 & 813 & 85 & 1,334 \\
\hline Private medical sector/other & & & & & \\
\hline Percentage free & 28.0 & 3.5 & 5.0 & 6.4 & 8.1 \\
\hline Do not know cost & 17.1 & 3.7 & 0.3 & 0.0 & 10.2 \\
\hline Median cost [in Kshs.] & 2497 & 23.0 & 90.0 & 996.0 & 60.0 \\
\hline Number of women & 90 & 229 & 433 & 24 & 995 \\
\hline Total & & & & & \\
\hline Percentage free & 45.4 & 15.1 & 12.5 & 29.1 & 19.3 \\
\hline Do not know cost & 12.6 & 2.1 & 0.4 & 0.0 & 5.7 \\
\hline Median cost [in Kshs.] & 2495 & 20.0 & 45.0 & 384.0 & 43.0 \\
\hline Number of women & 269 & 398 & 1246 & 110 & 2,329 \\
\hline
\end{tabular}

\section{Source: 2008/09 KDHS}

\subsection{Infrastructure and resources to support family planning provision}

In order to provide quality FP services, health facilities must have adequate infrastructure and resources to enable them to provide quality counseling, and when needed, physical examinations. These resources include, among other things, room or space that provides sufficient privacy for counseling and physical examination, visual aids for client education, and guidelines and protocols for FP. ${ }^{44}$ Health facilities should also have equipment and supplies needed to provide each FP method offered. ${ }^{77}$ Moreover, facilities should provide treatment for STIs, HIV counseling and testing services, infection control and anti-retroviral therapy (ART) services to those who need them. As shown in Table 4.5, in 2010, only 25 
percent of the facilities offering temporary methods had all necessary items (including a private room or a visual barrier, individual client cards, written guidelines for FP and visual aids for FP) to support quality counseling.

Physical examinations might be necessary when FP services are provided. It is therefore essential that health facilities have adequate capacity for infection control (e.g., availability of soap, running water, hand disinfectant, disposable latex gloves, disinfecting solution, and a sharps box). In 2004, only 41 percent of the facilities had all of these items; this improved in 2010 to 55 percent (Table 4.5).

Table 4.5: Percentage of facilities offering temporary family planning methods that have the infrastructure and resources to support quality counseling, infection control, pelvic examinations, and STI treatment by background characteristics, KSPA

\begin{tabular}{|c|c|c|c|c|c|}
\hline $\begin{array}{l}\text { Background } \\
\text { Characteristics }\end{array}$ & $\begin{array}{c}\text { All items } \\
\text { to support } \\
\text { quality } \\
\text { counseling }\end{array}$ & $\begin{array}{c}\text { All items } \\
\text { for infection } \\
\text { control }\end{array}$ & $\begin{array}{l}\text { Conditions } \\
\text { for quality } \\
\text { pelvic } \\
\text { examination }\end{array}$ & \begin{tabular}{c}
\multicolumn{1}{c}{ FP } \\
providers \\
routinely \\
test STls
\end{tabular} & $\begin{array}{c}\text { Number of } \\
\text { facilities } \\
\text { offering } \\
\text { temporary FP }\end{array}$ \\
\hline \multicolumn{6}{|l|}{ KSPA 2004} \\
\hline \multicolumn{6}{|l|}{ Type of facility } \\
\hline Hospital & 30 & 48 & 30 & 29 & 24 \\
\hline Health center & 21 & 31 & 10 & 62 & 107 \\
\hline Maternity & 16 & 32 & 20 & 55 & 18 \\
\hline Clinic & 28 & 42 & 23 & 88 & 5 \\
\hline Dispensary & 23 & 48 & 2 & 74 & 169 \\
\hline \multicolumn{6}{|c|}{ Managing Authority } \\
\hline Government & 22 & 47 & 8 & 65 & 209 \\
\hline NGO & 18 & 5 & 3 & 61 & 14 \\
\hline Private (for profit) & 19 & 32 & 25 & 68 & 36 \\
\hline $\begin{array}{l}\text { Faith-based } \\
\text { organization }\end{array}$ & 26 & 35 & 1 & 69 & 63 \\
\hline \multicolumn{6}{|l|}{ Province } \\
\hline Nairobi & 41 & 40 & 27 & 44 & 18 \\
\hline Central & 3 & 50 & 8 & 59 & 42 \\
\hline Coast & 57 & 50 & 11 & 58 & 35 \\
\hline Eastern & 15 & 69 & 1 & 63 & 62 \\
\hline North Eastern & 2 & 2 & 2 & 61 & 6 \\
\hline Nyanza & 18 & 39 & 11 & 71 & 49 \\
\hline Rift Valley & 23 & 20 & 6 & 70 & 89 \\
\hline Western & 20 & 33 & 9 & 91 & 22 \\
\hline Total & 22 & 41 & 8 & 66 & 322 \\
\hline
\end{tabular}


Table 4.5: Cont...

\begin{tabular}{|c|c|c|c|c|c|}
\hline $\begin{array}{l}\text { Background } \\
\text { Characteristics }\end{array}$ & $\begin{array}{l}\text { All items } \\
\text { to support } \\
\text { quality } \\
\text { counseling }\end{array}$ & $\begin{array}{c}\text { All items } \\
\text { for infection } \\
\text { control }\end{array}$ & $\begin{array}{l}\text { Conditions } \\
\text { for quality } \\
\text { pelvic } \\
\text { examination }\end{array}$ & $\begin{array}{c}\text { FP } \\
\text { providers } \\
\text { routinely } \\
\text { test STls }\end{array}$ & $\begin{array}{c}\text { Number of } \\
\text { facilities } \\
\text { offering } \\
\text { temporary FP }\end{array}$ \\
\hline \multicolumn{6}{|l|}{ KSPA 2010} \\
\hline \multicolumn{6}{|l|}{ Type of facility } \\
\hline Hospital & 40 & 66 & 43 & 46 & 46 \\
\hline Health center & 34 & 53 & 24 & 63 & 68 \\
\hline Maternity & 27 & 52 & 51 & 70 & 15 \\
\hline Clinic & 19 & 59 & 21 & 82 & 164 \\
\hline Dispensary & 25 & 52 & 6 & 93 & 319 \\
\hline \multicolumn{6}{|c|}{ Managing Authority } \\
\hline Government & 31 & 53 & 10 & 85 & 334 \\
\hline NGO & 42 & 36 & 8 & 70 & 19 \\
\hline Private(for profit) & 20 & 59 & 29 & 80 & 198 \\
\hline $\begin{array}{l}\text { Faith-based } \\
\text { organization }\end{array}$ & 6 & 54 & 10 & 88 & 61 \\
\hline \multicolumn{6}{|l|}{ Province } \\
\hline Nairobi & 39 & 52 & 39 & 56 & 28 \\
\hline Central & 29 & 65 & 26 & 83 & 113 \\
\hline Coast & 42 & 73 & 22 & 86 & 67 \\
\hline Eastern & 23 & 37 & 5 & 89 & 102 \\
\hline North Eastern & 1 & 24 & 1 & 91 & 16 \\
\hline Nyanza & 21 & 60 & 14 & 78 & 79 \\
\hline Rift Valley & 17 & 54 & 13 & 84 & 167 \\
\hline Western & 38 & 51 & 14 & 83 & 41 \\
\hline Total & 25 & 55 & 16 & 83 & 612 \\
\hline
\end{tabular}

Only 8 percent of the facilities in 2004 and 16 percent in 2010 had the required conditions for providing quality pelvic examinations needed for provision of the IUD (including private room offering visual and auditory privacy, an examination bed, examination light, and vaginal speculum). Hospitals and maternity homes were most likely to have all the required items. Facilities in Nairobi were most likely to have required conditions for quality pelvic examinations.

Table 4.6 provides further evidence that by 2010 most health facilities had not met recommended counseling conditions. A review of individual client history cards shows that conditions for quality FP counseling were met only for 34 percent of female FP clients. 
Table 4.6: Among observed female family planning clients, percentage whose consultations included components that contribute to quality counseling by type of facility, KSPA 2010

\begin{tabular}{|l|c|c|c|c|c|c|}
\hline \multirow{2}{*}{ Components of Consultation } & \multicolumn{6}{|c|}{ Type of facility } \\
\cline { 2 - 7 } & Hospital & $\begin{array}{c}\text { Health } \\
\text { Center }\end{array}$ & Maternity & Clinic & Dispensary & Total \\
\hline Visual privacy assured & 92 & 87 & 90 & 100 & 90 & 91 \\
\hline Auditory privacy assured & 89 & 79 & 90 & 100 & 73 & 83 \\
\hline Client assured of confidentiality & 50 & 39 & 43 & 49 & 49 & 47 \\
\hline $\begin{array}{l}\text { Client asked her concerns about } \\
\text { methods discussed or used }\end{array}$ & 80 & 83 & 93 & 84 & 75 & 80 \\
\hline All counseling conditions met & 39 & 28 & 43 & 42 & 28 & 34 \\
\hline $\begin{array}{l}\text { Individual client card reviewed } \\
\text { during consultation }\end{array}$ & 83 & 78 & 78 & 69 & 74 & 78 \\
\hline $\begin{array}{l}\text { Individual client card written on } \\
\text { after consultation }\end{array}$ & 94 & 94 & 96 & 92 & 96 & 95 \\
\hline Return visit discussed & 97 & 98 & 92 & 93 & 97 & 97 \\
\hline $\begin{array}{l}\text { Number of observed female } \\
\text { family planning clients }\end{array}$ & 351 & 251 & 11 & 95 & 301 & 1,010 \\
\hline
\end{tabular}

In most health facilities, FP providers routinely treat STIs. In 2010, 83 percent of facilities provided treatment for STIs compared with 66 percent in 2004. However, in Nairobi Province and in most of the hospitals country wide, FP providers were less likely to routinely treat STIs (Table 4.7).

Table 4.7: Percentage of facilities offering temporary family planning (TFP) methods where FP providers routinely treat sexually transmitted infections and, among these percentage with specific medicines available with at least one treatment for each of the four common STIs, by type of facility, KSPA 2010

\begin{tabular}{|l|c|c|c|c|c|c|}
\hline \multirow{2}{*}{} & \multicolumn{6}{|c|}{ Type of facility } \\
\cline { 2 - 7 } & Hospital & $\begin{array}{c}\text { Health } \\
\text { Center }\end{array}$ & Maternity & Clinic & Dispensary & Total \\
\hline Item & $\%$ & $\%$ & $\%$ & $\%$ & $\%$ & $\%$ \\
\hline FP Providers routinely treat STIs & 46 & 63 & 70 & 82 & 93 & 83 \\
\hline National STI guidelines & 25 & 34 & 31 & 18 & 21 & 22 \\
\hline STI guidelines & 42 & 46 & 36 & 33 & 41 & 39 \\
\hline Visual aids for STIs & 81 & 72 & 66 & 51 & 60 & 60 \\
\hline
\end{tabular}


Table 4.7: Cont...

\begin{tabular}{|l|c|c|c|c|c|c|}
\hline & \multicolumn{5}{|c|}{ Type of facility } \\
\cline { 2 - 7 } & Hospital & $\begin{array}{c}\text { Health } \\
\text { Center }\end{array}$ & Maternity & Clinic & Dispensary & Total \\
\hline Item & $\%$ & $\%$ & $\%$ & $\%$ & $\%$ & $\%$ \\
\hline $\begin{array}{l}\text { Availability of medicine for } \\
\text { treating: }\end{array}$ & & & & & & \\
\hline Trichomoniasis & 83 & 55 & 84 & 86 & 53 & 64 \\
\hline Gonorrhoea & 84 & 48 & 81 & 78 & 52 & 60 \\
\hline Chlamydia & 95 & 75 & 88 & 93 & 81 & 85 \\
\hline Syphilis & 97 & 100 & 88 & 81 & 94 & 91 \\
\hline All four STIs & 69 & 31 & 74 & 67 & 31 & 43 \\
\hline $\begin{array}{l}\text { Number of facilities offering TFP } \\
\text { where providers routinely treat }\end{array}$ & & & & & & \\
STIs & 21 & 43 & 10 & 134 & 298 & 508 \\
\hline Number of facilities offering TFP & 46 & 68 & 15 & 164 & 319 & 612 \\
\hline
\end{tabular}

\subsection{Management practices to support quality family planning}

Updated FP records, training of staff and supportive supervision are critical management practices required to support provision of quality FP services. This section summarizes data on the numbers of facilities keeping updated client registers as well as the provision of training and supervision of FP service providers.

\subsubsection{Client records}

Table 4.8 shows that a large proportion of facilities assessed in the 2004 and 2010 KSPA surveys kept up to date FP client registers. Overall, there was an increase in the number of facilities with up-to-date client registers with a marked improvement for hospitals, maternity facilities and dispensaries. Government and NGO facilities were most likely to have upto-date client registers. Although there was an increase in the proportion of facilities with up-to-date client registers in most provinces, a marked decline was observed in North Eastern Province where in 2010 only 15 percent of facilities had up-to-date client records compared with 49 percent in 2004. 
Table 4.8: Percentage of facilities offering temporary family planning (TFP) methods that have an up-to-date client register and that charge user fees for FP services and percentage of such facilities where interviewed FP service providers report routine training and supervision by background characteristics, KSPA 2004 and 2010

\begin{tabular}{|c|c|c|c|c|c|c|}
\hline \multirow{3}{*}{$\begin{array}{l}\text { Background } \\
\text { Characteristics }\end{array}$} & \multicolumn{3}{|c|}{ KSPA 2004} & \multicolumn{3}{|c|}{ KSPA 2010} \\
\hline & \multicolumn{2}{|c|}{$\begin{array}{l}\text { Percentage of facilities } \\
\text { that offer temporary FP } \\
\text { methods with: }\end{array}$} & \multirow{2}{*}{$\begin{array}{l}\text { Number of } \\
\text { facilities } \\
\text { offering } \\
\text { temporary } \\
\text { FP }\end{array}$} & \multicolumn{2}{|c|}{$\begin{array}{l}\text { Percentage of facilities } \\
\text { that offer temporary FP } \\
\text { methods with: }\end{array}$} & \multirow{2}{*}{$\begin{array}{l}\text { Number of } \\
\text { facilities } \\
\text { offering } \\
\text { temporary } \\
\text { FP }\end{array}$} \\
\hline & $\begin{array}{l}\text { Observed } \\
\text { up-to-date } \\
\text { client } \\
\text { register }\end{array}$ & $\begin{array}{l}\text { User fees } \\
\text { for FP } \\
\text { services }\end{array}$ & & $\begin{array}{l}\text { Observed } \\
\text { up-to-date } \\
\text { client } \\
\text { register }\end{array}$ & $\begin{array}{l}\text { User fees } \\
\text { for FP } \\
\text { services }\end{array}$ & \\
\hline \multicolumn{7}{|l|}{ Type of facility } \\
\hline Hospital & 72 & 60 & 24 & 86 & 70 & 46 \\
\hline Health center & 85 & 44 & 107 & 90 & 79 & 68 \\
\hline Maternity & 57 & 94 & 18 & 75 & 95 & 15 \\
\hline Clinic & 56 & 93 & 5 & 59 & 93 & 164 \\
\hline Dispensary & 73 & 49 & 169 & 86 & 66 & 319 \\
\hline \multicolumn{7}{|l|}{$\begin{array}{l}\text { Managing } \\
\text { Authority }\end{array}$} \\
\hline Government & 88 & 42 & 209 & 91 & 68 & 334 \\
\hline NGO & 98 & 31 & 14 & 100 & 65 & 19 \\
\hline Private(for profit) & 38 & 95 & 36 & 63 & 94 & 198 \\
\hline $\begin{array}{l}\text { Faith-based } \\
\text { organization }\end{array}$ & 52 & 62 & 63 & 57 & 58 & 61 \\
\hline \multicolumn{7}{|l|}{ Province } \\
\hline Nairobi & 84 & 72 & 18 & 86 & 92 & 28 \\
\hline Central & 81 & 57 & 42 & 74 & 97 & 113 \\
\hline Coast & 71 & 54 & 35 & 66 & 68 & 67 \\
\hline Eastern & 64 & 58 & 62 & 77 & 70 & 102 \\
\hline North Eastern & 49 & 11 & 6 & 15 & 1 & 16 \\
\hline Nyanza & 82 & 57 & 49 & 90 & 70 & 79 \\
\hline Rift Valley & 78 & 44 & 89 & 84 & 76 & 167 \\
\hline Western & 85 & 28 & 22 & 93 & 71 & 41 \\
\hline Total & 76 & 51 & 322 & 79 & 76 & 612 \\
\hline
\end{tabular}




\subsubsection{Training of staff}

Health service providers must receive regular training to ensure that they develop technical skills as well as are exposed to new information relevant to the services that they provide. The KSPA assesses whether health service providers have participated in any formal or structured pre-service or in-service training related to the services they offer in the 12 months preceding each survey. Overall, the proportion of facilities where staff report routine training is low (Table 4.9) and there was little difference by type of facility, with the exception of maternities in which 50 percent reported routine training. A greater proportion of private (for profit) and faith-based facilities than government-owned or NGO-run facilities reported routine training and a greater proportion of facilities in Nairobi Provinces reported routine training compared with all other regions.

Table 4.9: Percentage of facilities offering temporary family planning (TFP) methods where interviewed FP service providers reported routine training and supervision by background characteristics, KSPA 2004 and 2010

\begin{tabular}{|c|c|c|c|c|c|c|}
\hline \multirow{3}{*}{$\begin{array}{l}\text { Background } \\
\text { Characteristics }\end{array}$} & \multicolumn{3}{|c|}{ KSPA 2004} & \multicolumn{3}{|c|}{ KSPA 2010} \\
\hline & \multicolumn{2}{|c|}{$\begin{array}{l}\text { Percentage of } \\
\text { facilities where staff } \\
\text { report receiving } \\
\text { routine: }\end{array}$} & \multirow[t]{2}{*}{$\begin{array}{l}\text { Facilities with } \\
\text { interviewed } \\
\text { FP service } \\
\text { providers (n) }\end{array}$} & \multicolumn{2}{|c|}{$\begin{array}{l}\text { Percentage of facilities } \\
\text { where staff report } \\
\text { receiving routine: }\end{array}$} & \multirow{2}{*}{$\begin{array}{l}\text { Number of } \\
\text { facilities } \\
\text { with } \\
\text { interviewed } \\
\text { FP service } \\
\text { providers }\end{array}$} \\
\hline & Training & $\begin{array}{l}\text { Personal } \\
\text { Supervision }\end{array}$ & & Training & $\begin{array}{l}\text { Personal } \\
\text { Supervision }\end{array}$ & \\
\hline \multicolumn{7}{|l|}{ Type of facility } \\
\hline Hospital & 29 & 70 & 23 & 26 & 88 & 45 \\
\hline Health center & 32 & 84 & 107 & 25 & 94 & 68 \\
\hline Maternity & 36 & 78 & 16 & 50 & 75 & 15 \\
\hline Clinic & 37 & 64 & 5 & 26 & 62 & 160 \\
\hline Dispensary & 35 & 93 & 157 & 16 & 88 & 297 \\
\hline \multicolumn{7}{|c|}{ Managing Authority } \\
\hline Government & 29 & 88 & 201 & 17 & 92 & 314 \\
\hline NGO & 18 & 99 & 14 & 14 & 88 & 19 \\
\hline Private (for profit) & 42 & 76 & 34 & 32 & 65 & 192 \\
\hline FBO & 49 & 85 & 59 & 18 & 76 & 59 \\
\hline \multicolumn{7}{|l|}{ Province } \\
\hline Nairobi & 54 & 89 & 18 & 46 & 77 & 28 \\
\hline Central & 38 & 80 & 41 & 17 & 63 & 105 \\
\hline Coast & 43 & 69 & 35 & 36 & 83 & 64 \\
\hline Eastern & 23 & 97 & 58 & 14 & 93 & 99 \\
\hline North Eastern & 24 & 68 & 5 & 8 & 87 & 10 \\
\hline Nyanza & 31 & 95 & 48 & 25 & 92 & 79 \\
\hline Rift Valley & 33 & 83 & 80 & 20 & 79 & 161 \\
\hline Western & 30 & 98 & 22 & 17 & 86 & 39 \\
\hline Total & 34 & 87 & 308 & 22 & 81 & 584 \\
\hline
\end{tabular}


Table 4.10 provides the results of the $2010 \mathrm{KSPA}$ on staff training related to FP work. The results show that only 23 percent of the interviewed FP service providers reported receiving any FP-related training during the 12 months preceding the survey. In addition, 17 percent of the interviewed FP service providers reported having undertaken training related to FP work between 13 and 35 months preceding the survey. Taken together, the results reflect the small percentage of facilities that ensured that staff receive regular training related to FP service provision.

Table 4.10: Among interviewed family planning service providers, percentage that received training related to their work during specific time periods, by background characteristics, KSPA 2010

\begin{tabular}{|c|c|c|c|}
\hline \multirow[b]{2}{*}{$\begin{array}{l}\text { Background } \\
\text { Characteristics }\end{array}$} & \multicolumn{3}{|c|}{ Percentage of interviewed service providers who received: } \\
\hline & $\begin{array}{l}\text { FP related training } \\
\text { during the } 12 \\
\text { months preceding } \\
\text { the survey }\end{array}$ & $\begin{array}{l}\text { Most recent training } \\
\text { in the } 13-35 \text { months } \\
\text { preceding the survey }\end{array}$ & $\begin{array}{c}\text { Number of } \\
\text { interviewed FP } \\
\text { service providers }\end{array}$ \\
\hline \multicolumn{4}{|l|}{ Type of facility } \\
\hline Hospital & 27 & 20 & 418 \\
\hline Health center & 26 & 21 & 263 \\
\hline Maternity & 36 & 21 & 58 \\
\hline Clinic & 24 & 20 & 252 \\
\hline Dispensary & 15 & 11 & 521 \\
\hline \multicolumn{4}{|l|}{ Managing Authority } \\
\hline Government & 21 & 15 & 944 \\
\hline NGO & 18 & 41 & 49 \\
\hline Private(for profit) & 29 & 22 & 348 \\
\hline Faith-based organization & 20 & 15 & 172 \\
\hline \multicolumn{4}{|l|}{ Province } \\
\hline Nairobi & 33 & 30 & 111 \\
\hline Central & 15 & 18 & 194 \\
\hline Coast & 29 & 10 & 172 \\
\hline Eastern & 19 & 20 & 271 \\
\hline North Eastern & 12 & 25 & 22 \\
\hline Nyanza & 27 & 20 & 221 \\
\hline Rift Valley & 20 & 13 & 385 \\
\hline Western & 26 & 14 & 137 \\
\hline Total & 23 & 17 & 1,513 \\
\hline
\end{tabular}




\subsubsection{Supervision}

Regular supervision is a critical quality-assurance practice that ensures that facilities and staff follow standards and protocols. During the 2004 and 2010 KSPA, a facility was considered to have routine staff supervision if at least half of the FP service providers at the facility reported having been personally supervised during the 6 months preceding the survey. Table 4.11 shows that supervision was common in all facilities, with 81 percent reporting having routine supervision, a slight decline from 87 percent in 2004. Health centers were more likely to have staff supervision than other types of facilities. Government facilities and facilities in Eastern and Nyanza Provinces were among those that were the most likely to have routine staff-supervision activities.

Table 4.11: Among FP providers who were personally supervised in the 6 months before the survey, median number of times they were supervised and percentage reporting specific supervisory activities during the last visit, by background characteristics, KSPA 2004 and 2010

\begin{tabular}{|c|c|c|c|c|c|c|c|c|}
\hline \multirow{2}{*}{$\begin{array}{l}\text { Background } \\
\text { Characteristics }\end{array}$} & \multirow{2}{*}{$\begin{array}{l}\text { Median } \\
\text { number of } \\
\text { times staff } \\
\text { supervised }\end{array}$} & \multicolumn{6}{|c|}{$\begin{array}{c}\text { Percentage of providers reporting that, during the last } \\
\text { supervisory visit: }\end{array}$} & \multirow{2}{*}{$\begin{array}{l}\text { Number of } \\
\text { FP service } \\
\text { providers } \\
\text { supervised }\end{array}$} \\
\hline & & $\begin{array}{l}\text { Checked } \\
\text { records }\end{array}$ & $\begin{array}{c}\text { Observed } \\
\text { work }\end{array}$ & $\begin{array}{l}\text { Provided } \\
\text { feedback }\end{array}$ & $\begin{array}{l}\text { Provided } \\
\text { updates }\end{array}$ & $\begin{array}{l}\text { Discussed } \\
\text { problems }\end{array}$ & $\begin{array}{l}\text { Deliver } \\
\text { supplies }\end{array}$ & \\
\hline \multicolumn{9}{|l|}{2004} \\
\hline \multicolumn{9}{|l|}{ Type of facility } \\
\hline Hospital & - & 91 & 89 & 92 & 66 & 86 & 47 & 189 \\
\hline Health center & - & 99 & 90 & 74 & 73 & 89 & 51 & 202 \\
\hline Maternity & - & 97 & 95 & 72 & 83 & 96 & 55 & 44 \\
\hline Clinic & - & 92 & 86 & 85 & 71 & 80 & 42 & 5 \\
\hline Dispensary & - & 96 & 94 & 89 & 78 & 95 & 75 & 127 \\
\hline \multicolumn{9}{|c|}{ Managing Authority } \\
\hline Government & - & 95 & 89 & 87 & 66 & 88 & 59 & 379 \\
\hline NGO & - & 97 & 95 & 96 & 65 & 97 & 55 & 16 \\
\hline $\begin{array}{l}\text { Private(for } \\
\text { profit) }\end{array}$ & - & 97 & 96 & 61 & 90 & 96 & 33 & 103 \\
\hline FBO & - & 95 & 94 & 91 & 88 & 90 & 69 & 69 \\
\hline \multicolumn{9}{|l|}{ Province } \\
\hline Nairobi & - & 94 & 92 & 83 & 73 & 93 & 49 & 79 \\
\hline Central & - & 94 & 92 & 93 & 52 & 86 & 64 & 53 \\
\hline Coast & - & 98 & 91 & 53 & 92 & 95 & 38 & 94 \\
\hline Eastern & - & 99 & 91 & 96 & 76 & 98 & 67 & 86 \\
\hline North Eastern & - & 92 & 75 & 87 & 60 & 93 & 70 & 4 \\
\hline Nyanza & - & 87 & 92 & 85 & 76 & 85 & 56 & 66 \\
\hline Rift Valley & - & 97 & 92 & 89 & 65 & 82 & 59 & 124 \\
\hline Western & - & 97 & 88 & 90 & 70 & 89 & 58 & 62 \\
\hline Total & & 96 & 91 & 83 & 73 & 90 & 55 & 567 \\
\hline
\end{tabular}


Table 4.11: Cont...

\begin{tabular}{|c|c|c|c|c|c|c|c|c|}
\hline \multirow{2}{*}{$\begin{array}{l}\text { Background } \\
\text { Characteristics }\end{array}$} & \multirow{2}{*}{$\begin{array}{l}\text { Median } \\
\text { number of } \\
\text { times staff } \\
\text { supervised }\end{array}$} & \multicolumn{6}{|c|}{$\begin{array}{c}\text { Percentage of providers reporting that, during the last } \\
\text { supervisory visit: }\end{array}$} & \multirow{2}{*}{$\begin{array}{l}\text { Number of } \\
\text { FP service } \\
\text { providers } \\
\text { supervised }\end{array}$} \\
\hline & & $\begin{array}{l}\text { Checked } \\
\text { records }\end{array}$ & $\begin{array}{c}\text { Observed } \\
\text { work }\end{array}$ & $\begin{array}{l}\text { Provided } \\
\text { feedback }\end{array}$ & $\begin{array}{l}\text { Provided } \\
\text { updates }\end{array}$ & $\begin{array}{l}\text { Discussed } \\
\text { problems }\end{array}$ & $\begin{array}{l}\text { Deliver } \\
\text { supplies }\end{array}$ & \\
\hline \multicolumn{9}{|l|}{2010} \\
\hline \multicolumn{9}{|l|}{ Type of facility } \\
\hline Hospital & 3 & 97 & 91 & 91 & 77 & 91 & 49 & 319 \\
\hline Health center & 3 & 97 & 94 & 91 & 81 & 93 & 62 & 228 \\
\hline Maternity & 2 & 94 & 88 & 92 & 75 & 83 & 45 & 34 \\
\hline Clinic & 3 & 94 & 89 & 88 & 71 & 87 & 37 & 164 \\
\hline Dispensary & 3 & 98 & 90 & 78 & 72 & 93 & 54 & 438 \\
\hline \multicolumn{9}{|l|}{2004} \\
\hline Government & 3 & 97 & 91 & 83 & 75 & 93 & 55 & 800 \\
\hline NGO & 3 & 98 & 97 & 100 & 79 & 100 & 63 & 38 \\
\hline $\begin{array}{l}\text { Private(for } \\
\text { profit) }\end{array}$ & 3 & 96 & 30 & 90 & 74 & 86 & 35 & 219 \\
\hline FBO & 3 & 97 & 93 & 94 & 72 & 89 & 59 & 126 \\
\hline \multicolumn{9}{|l|}{ Province } \\
\hline Nairobi & 3 & 98 & 92 & 89 & 81 & 94 & 52 & 77 \\
\hline Central & 3 & 100 & 94 & 97 & 79 & 88 & 39 & 128 \\
\hline Coast & 3 & 95 & 84 & 81 & 84 & 93 & 60 & 134 \\
\hline Eastern & 3 & 97 & 90 & 89 & 61 & 93 & 53 & 214 \\
\hline North Eastern & 3 & 98 & 99 & 66 & 58 & 88 & 45 & 20 \\
\hline Nyanza & 3 & 95 & 90 & 92 & 84 & 94 & 69 & 185 \\
\hline Rift Valley & 2 & 98 & 93 & 76 & 73 & 89 & 50 & 304 \\
\hline Western & 3 & 97 & 92 & 90 & 76 & 90 & 33 & 121 \\
\hline Total & 3 & 97 & 91 & 86 & 75 & 91 & 52 & 1,183 \\
\hline
\end{tabular}

NB: No data on median number of times staff were supervised in the 6 months before the survey for 2004; FBO=faithbased organization

\subsection{Abortion and post-abortion care service provision}

Kenya's Constitution, while maintaining a restrictive stance, provides opportunities for enhancing the reproductive health and rights of a woman and allows for legal abortion if "in the opinion of a trained health professional, there is need for emergency treatment, or the life or health of the mother is in danger, or if permitted by any other written law". ${ }^{81}$ Though essential strides have been made in relation to reducing mortality and morbidity from unsafe abortion, Kenyan women needing abortion and PAC services still face certain barriers, including negative provider attitudes, biases and conscientious objection, 
lack of knowledge of the law, failure to apply the law, lack of awareness about facilities providing safe abortion services; lack of awareness (among women) of need to report early in pregnancy. ${ }^{83}$ Recognizing the significant contribution that unsafe abortion makes to high maternal mortality in Kenya, in 2012, the Ministry of Health launched the Standards and Guidelines for Reducing Morbidity and Mortality from Unsafe Abortion in Kenya. The document outlines the laws and policies that guide services as well as standards to be adhered to in dealing with prevention, management of risky unplanned pregnancies including abortion within the confines of the Kenyan law - and the provision of PAC.

\subsubsection{Abortion service provision}

The 2012guidelines indicate that pregnancies can only be terminated by health professionals who are trained and skilled in pregnancy termination. With appropriate training doctors, nurses, midwives and clinical officers can provide first-trimester termination of pregnancy; while termination of pregnancy during the second trimester should only be performed by a skilled medical officer in consultation with a gynecologist. Moreover, pregnancies should only be terminated in a health facility with appropriate equipment.

Medical abortion which is gaining some ground in Kenya is a simple process, involving the use of pills rather than invasive surgical instruments, and has been shown to be safe and up to 98 percent effective for early pregnancy termination and management of post-partum hemorrhage. ${ }^{82}$ In Kenya, Misoprostol has been registered since 2008 for the prevention and treatment of gastric ulcers. In 2010, Misoprostol was registered for obstetric and gynecological indications and was included in the Kenya Essential Medicines List (KEML) and National Clinical Guidelines, which was a key step toward sustainable supply of this medication. Recently, Mifepristone was introduced into the National Clinical Guidelines and is listed for use in combination with Misoprostol for legal termination of pregnancy. However, the use of these drugs for obstetric and gynecological indications is only now increasing. In a 2008 mystery clients' study of pharmacies in Nairobi, Kenya, it was found that although 42 percent of pharmacies had Misoprostol available for sale, only 12 percent of pharmacists agreed to dispense Misoprostol to mystery clients for pregnancy termination. ${ }^{84}$

\subsubsection{Post-abortion care}

Post-abortion care (PAC) is regarded as a way to improve services provided to women with complications from spontaneous or induced abortions with the goal of reducing maternal morbidity and mortality. According to government standards, PAC services should be provided by a trained and skilled health professional in the management of incomplete abortion and related complications and should consist of 6 components: a) counseling, b) evacuation of the uterus, c) management of complications, d) post-abortion FP and contraception, e) infection prevention, and f) community involvement.

The uterine evacuation method used during post-abortion care can be used to assess the quality of care. ${ }^{74}$ According to guidelines from the WHO, medical abortion, Manual Vacuum 
Aspiration (MVA) and Electric Vacuum Aspiration (EVA) are appropriate for pregnancies within 12 to 14 weeks of gestation. Dilation and Curettage (D\&C) and digital evaluation are considered less safe. Table 4.12 shows the technology used for uterine evacuation among PAC client by facility level and type, cadre of health worker and region based on findings from the 2012 Incidence and Complications of Unsafe Abortion in Kenya study. ${ }^{74}$ Results showed that most abortion complications were treated with MVA/EVA (65 percent) followed by digital evacuation (12 percent) and medical abortion and D\&C (8 percent each). MVA/EVA was performed in over 90 percent of Level VI facilities but only 43 percent of Level II facilities, which have a higher annual PAC caseload. ${ }^{74}$ Substantial variations in uterine evacuation methods were also observed by facility ownership, cadre of health workers, and region. Overall, the results highlight disparities in the quality of post-abortion care service provision and underscore the need to support lower-level facilities and midlevel providers in providing quality post-abortion care services.

Table 4.12: Technology used for uterine evacuation among PAC clients by facility level, cadre of health worker, facility ownership, and region, Kenya, $2012(n=2,188)$

\begin{tabular}{|l|c|c|c|c|c|}
\hline & $\begin{array}{c}\text { MVA/EVA } \\
(\%)\end{array}$ & $\begin{array}{c}\text { Medical } \\
\text { abortion } \\
(\%)\end{array}$ & D\&C (\%) & $\begin{array}{c}\text { Digital } \\
\text { Evacuation } \\
(\%)\end{array}$ & Other (\%) \\
\hline Level of facility & 43.1 & 14.4 & 4.0 & 19.4 & 19.0 \\
\hline Level II & 71.2 & 6.2 & 4.4 & 14.6 & 3.7 \\
\hline Level III & 69.9 & 5.5 & 14.6 & 6.6 & 3.5 \\
\hline Level IV & 81.6 & 3.7 & 5.3 & 7.9 & 1.5 \\
\hline Level V & 94.0 & 1.2 & 3.6 & 1.2 & 0.0 \\
\hline Level VI & & & & & 1.9 \\
\hline Health facility ownership & 64.4 & 4.1 & 5.9 & 15.5 & 10.1 \\
\hline Public & 80.1 & 6.8 & 7.3 & 3.9 & 1.8 \\
\hline Private-for-profit & 49.7 & 21.1 & 15.9 & 11.4 & 2.0 \\
\hline Private-not-for-profit & & & & & \\
\hline Cadre of health worker & 61.0 & 4.9 & 31.4 & 1.6 & 1.3 \\
\hline Obstetric/Gynecologist & 53.7 & 7.3 & 32.6 & 4.8 & 1.6 \\
\hline Medical officer & 82.1 & 6.5 & 3.0 & 5.8 & 2.5 \\
\hline Clinical officer & 54.6 & 5.2 & 2.2 & 22.4 & 15.6 \\
\hline Nurse & 36.2 & 38.1 & 0.0 & 23.9 & 1.8 \\
\hline Trained midwife & 82.6 & 6.4 & 3.4 & 5.7 & 2.0 \\
\hline Region & 64.3 & 6.7 & 2.8 & 13.2 & 13.0 \\
\hline Central \& Nairobi & & & & \\
\hline Coast \& North Eastern & & & & \\
\hline
\end{tabular}


Table 4.12: Cont...

\begin{tabular}{|l|c|c|c|c|c|}
\hline & $\begin{array}{c}\text { MVA/EVA } \\
(\%)\end{array}$ & $\begin{array}{c}\text { Medical } \\
\text { abortion } \\
(\%)\end{array}$ & D\&C (\%) & $\begin{array}{c}\text { Digital } \\
\text { Evacuation } \\
(\%)\end{array}$ & Other (\%) \\
\hline Eastern & 48.3 & 1.5 & 18.7 & 25.5 & 6.1 \\
\hline Nyanza & 61.7 & 11.3 & 3.1 & 17.3 & 6.5 \\
\hline Rift Valley & 55.9 & 5.7 & 21.2 & 7.3 & 9.9 \\
\hline Total & $\mathbf{6 5 . 4}$ & $\mathbf{7 . 6}$ & $\mathbf{7 . 9}$ & $\mathbf{1 2 . 2}$ & $\mathbf{6 . 9}$ \\
\hline
\end{tabular}

Source: APHRC, MOH, Ipas, and Guttmacher Institute, 2013. ${ }^{74}$

\subsection{Chapter summary}

- Although regional variations exist, about 85 percent of facilities assessed in Kenya in 2010 provided modern FP.

- Short-acting methods were available in most facilities while long-acting methods were available in about one-third of facilities and permanent methods in less than 10 percent of facilities.

- User fees were still being charged, though there should be no charge for any government-supplied commodity; however, government facilities were more likely to provide free FP services.

- In 2010 , only 25 percent of the facilities offering temporary methods of FP had all necessary items (including a private room or a visual barrier, individual client cards, written guidelines for FP provision and visual aids to support quality FP counseling.

- Proportion of facilities where staff report routine training in FP service provision was low, with only 23 percent of facilities reporting any training of staff in the previous 12 months.

- Kenya's new Constitution, while maintaining a restrictive stance, provides opportunities for enhancing the reproductive health and rights of a woman and allows for legal abortion if sanctioned by the opinion of a trained health professional, for emergency treatment, if the life or health of the mother is in danger, or if permitted by any other written law.

- The Standards and Guidelines for Reducing Morbidity and Mortality from Unsafe Abortion in Kenya (currently under review to become Policies, Standards and Guidelines for the Reduction of Maternal Morbidity and Mortality in Kenya), stipulates that all Kenyans should have equitable access to SRH information and services. The Standards and Guidelines also outline the use of safe technologies for abortion and PAC such as medical abortion (including Mifepristone and Misoprostol combination) and MVA or EVA.

- Though essential strides have been made in relation to reducing mortality and morbidity from unsafe abortion, Kenyan women needing such services still face legal restrictions, provider biases, and lack of public information about the law. 
- Access to medical abortion using Mifepristone and Misoprostol remained problematic and these drugs were not widely used by either practitioners or providers nor known by the women needing these services.

- There are substantial disparities in the quality of PAC service provision by region, type of facility and cadre of health care provides. Lower-level facilities and mid-level providers should be supported to provide quality PAC services. 


\section{CHAPTER 5}

\section{Financing and Delivery Mechanisms}

\subsection{Overview of family planning- and reproductive-health programs in Kenya}

In 1967 Kenya adopted and incorporated FP into the country's overall development policy in an effort to reduce the high population growth, which was then estimated at 3 percent per year. However, it was not until 1980 that government's involvement in contraceptive service provision fully began. ${ }^{86}$ The program was designed to have a close link with the national health program, and was to be wholly voluntary, with full respect for the wishes and religious beliefs of the individual parents. ${ }^{87}$ During the second Government Development Plan 1970/74, the government established an integrated Maternal and Child Health / Family Planning (MCH/FP) program, which was initiated in 1975. Subsequently, a comprehensive Integrated Rural Health and Family Planning Program (IRH/FP) was established to enhance cooperation with NGOs and introduce new strategies, such as Primary Health Care (PHC), and demand creation ${ }^{87}$ The 1980s and early 1990s, therefore, saw considerable commitment to FP by the Kenyan government with the development of national policies and guidelines and the establishment of the National Council for Population and Development (NCPD) in the office of the Vice President, whose members were drawn from the public sector, private institutions, as well as civil society and religious organizations.

During this period the government also supported the increased distribution of contraceptive through public and private facilities, and extensive information, education and communication (IEC) campaigns. The impact of these campaigns, programs, and expanded service provision was an increase in the contraceptive prevalence rate in Kenya from 7 percent in 1980 to 27 percent by 1989,86 and the reduction in Kenya's fertility rate from 8.1 in the 1970 s to 4.7 in the late $1990 \mathrm{~s}^{88}$ External funding played a significant role in the funding of all contraceptive commodities and IEC campaigns, as donors covered all associated costs.$^{88}$ In the later part of the 1990s, international aid allocations declined due in part to donor fatigue and the shift in focus to HIVIAIDS. ${ }^{89}$ Dwindling international aid, poor government response to this shift and mismanagement saw the weakening of government- and voluntary-sector contraceptive services.

In the early 2000s some clinics suffered commodity stock outs and lack of method choice, while others were shut down. ${ }^{86}$ With evidence of worsening FP indicators from the KDHS and KSPA, advocacy initiatives culminated in government funds being allocated to contraceptives for the first time in Kenya, with a line item for contraceptive commodities included in the 2005 national budget, allocating 200 million shillings, or US\$2.62 million. This government funding was increased to 300 shillings (US $\$ 4.17$ million) in the 2006/07 budget. It should, however, be noted that this allocation only meets a third of the public sector provision cost for FP commodities in Kenya ${ }^{86}$ and there is the continued need for advocacy to increase government funding for FP programs. 


\subsection{Delivery mechanisms}

FP services in Kenya are delivered through a multi-sectoral approach involving many implementing partners under the coordination and supervisory role of the Division of Reproductive Health of the Ministry of Public Health and Sanitation. ${ }^{32}$ There are two major delivery mechanisms; clinic based and non-clinic based, including community-based delivery. ${ }^{90}$ The major provider of FP services in Kenya is the government through the Ministry of Public Health and Sanitation, which serves more than half (57 percent) of current FP users, while 36 percent are supplied through private facilities and 6 percent are supplied through other sources. ${ }^{1}$

\subsubsection{Clinic-based delivery of family-planning- and reproductive-health services}

Clinic-based programs offer a wider range of contraceptive methods than other servicedelivery mechanisms because they provide methods that can be administered only by clinical personnel (male and female sterilization, IUDs and implants), as well as the nonclinical methods (e.g., oral contraceptives, injectables, condoms, spermicides, diaphragms and natural methods). ${ }^{90}$ In this delivery system the personnel serving the public receive clinical training as medical doctors, nurses, clinical officers or midwives and are capable of doing clinical examinations. They are also trained on FP during pre-service training and many receive in-service training to upgrade their knowledge and skills. ${ }^{77,91}$

Despite the expansion in the number of health facilities that provide FP services, challenges exist:

- Although 75 percent of facilities offer FP services, they are not evenly distributed and most facilities are concentrated in urban areas.

- Very few health facilities offer youth-friendly FP services. According to 2010 KSPA, only 7 percent of health facilities offered youth-friendly services.

- Lower-level health facilities usually do not provide long-acting methods and permanent methods.

- Frequent contraceptive stock-outs occur in health facilities because of continued reliance on donor financing of commodity procurement and the weak logistics of the distribution system. ${ }^{86}$

\subsubsection{Community-based delivery (CBD)}

Community-based delivery systems (CBDs) encompass community-based organizations, structures, and institutions and include the use of non-professional health workers to provide FP information and a limited range of methods. ${ }^{31,92,93}$ The adoption of CBD programs in Kenya in the 1980s was driven by the need to rapidly expand access and was informed by the success of CBD programs in Asia and in Zimbabwe. ${ }^{78,93,94} \mathrm{As}$ in other countries, the CBD strategy was based on the premise that making contraceptives available at convenient locations would increase their acceptability and availability. ${ }^{78,93}$ The 
Family Planning Association of Kenya (FPAK), Maendeleo ya Wanawake Organization (MYWO) and Chogoria Community Based Program were the pioneers in establishing CBD programs in Kenya. These were followed by Mkomani Health Clinic (MHC) in Mombasa, the Christian Health Association of Kenya (CHAK) and other NGOs and FBOs. ${ }^{78,93}$

$\mathrm{CBD}$ programs were implemented through various models, including home visits, fixed and mobile CBD posts; workplace-based outlets, as well as one-on-one and group education meetings at which FP commodities were often distributed to continuing and new clients. The services most commonly offered through CBDs include distribution of contraceptives (oral pills, foaming tablets, and condoms), health education, provision of IEC materials, and referrals for clinic-based services. Some of the first CBD programs were integrated with existing health infrastructure, and services were provided by incumbent health program staff members as a means of maintaining efficient service delivery. ${ }^{31,78,95}$

The CBD programs varied in the strategies they applied, their geographical coverage, the number of agents involved, the catchment areas served by their CBD agents, the links to clinics, their requirements for a medical examination for new pill clients, the range of services provided by the agents, and the status, remuneration, recruitment and supervision of the agents. ${ }^{31,78,94,95}$ The CBD initiatives were financially supported primarily by USAID, UNFPA and the German Government and were coordinated by the NCPD. $31,95,96$

In the mid-1980s and early 1990s Kenya's CBD program, consisting of over 25 different initiatives, was rated as being strong ${ }^{31}$ and was considered to have contributed to the increase in FP use. ${ }^{78,95}$ However, the CBD programs began to decline in the mid-1990s due to decreasing funding for FP programs. The decline has been so dramatic that the 2008/09 KDHS indicated that less than one percent of current users obtained their services through CBD. ${ }^{1}$

Recently, as a strategy to improve RH indicators in the country, Kenya is increasingly involving communities, especially community health workers (CHWs) in the delivery of FP information and services. ${ }^{97}$ Currently Kenya's use of $\mathrm{CHWs}$ is limited to the provision of FP information, counseling and the provision of selected services such as condoms, pills, lactational amenorrhea method and the Standard Days Method. Under the current guidelines, CHWs are not allowed to provide popular methods such as injectables to their clients. On the basis of success stories from countries such as Uganda and Ethiopia, where $\mathrm{CHWs}$ were successfully trained and administered injectables, an advocacy campaign was launched in 2006, which cumulated in a pilot project (called CBA21) to assess the safety, feasibility, and acceptability of community-based distribution of injectables by CHWs in Kenya. ${ }^{97}$ Results from the pilot study showed that not only were the $\mathrm{CHWs}$ able to safely provide injectables, most clients also found the provision of their services acceptable. Implemented by the District Health Management Team (DHMT), which put together all support and monitoring systems, the feasibility of the project was also ascertained. Results from the pilot project indicated that 68 percent of women continued use of the method 12 months after initiation, indicating the effectiveness of $\mathrm{CHWs}$ in following up with their clients. This mode of CBD not only has the potential to reduce the burden on an 
already overworked clinical practitioner, but their specialized clinical skills could be used for other important services. Owing to the success of the project and continued advocacy, the Kenyan government in 2012 issued a new policy allowing trained CHWs to provide injectables to hard-to-reach areas. The scale up of this project though approved by the DHMT is yet, however, to take place.

\subsubsection{Social marketing and social franchising (not-for profit and NGOs)}

Not-for profit entities are private sector providers usually comprising mission facilities and affiliates of international organizations. Social marketing activities comprise the bulk of the retail contraceptive services in many settings and tend to be highly subsidized by government and donors. Not-for-profit entities own about 16 percent of all health facilities - consisting mostly of dispensaries and health centers - and provide about 10 percent of FP services. ${ }^{98}$

\subsubsection{Social marketing of family planning commodities}

The social marketing of FP is another approach to increasing access to and availability of FP commodities through market-based outlets such as retail shops and supermarkets. ${ }^{99}$ The prices of the commodities are usually controlled and subsidized. The major objectives of social franchise marketing are to: a) expand the range of FP choices for women of reproductive age; $b$ ) engage the private sector to increase access to quality FP and other health services; and c) increase the demand for FP while also addressing supply.

In Kenya, social marketing of FP commodities started in the late 1980s, with the creation of Population Services International (PSI) Kenya to implement a general social marketing program to support the government of Kenya's efforts to increase access to and use of condoms and oral contraceptives. This was done by creating an affordable brand, establishing a distribution system and generating demand through media campaigns. A key goal was to increase access to low-cost condoms by getting more retail outlets in rural and urban areas to sell condoms at a set rate of ten Kenyan Shillings. The program also focused on reduction of HIV and STIs, prevention of pregnancy; and minimizing embarrassment associated with condom purchase.

After a decade of condom social marketing in Kenya, condoms were more readily available in a variety of retail outlets as a result of increased distribution. In 2000 PSI Kenya expanded its social franchise marketing to include FEMIPLAN - a range of FP products that included combined oral contraceptives, progestin-only injectables and male condoms. FEMIPLAN has been promoted through: mass media campaigns on radio, TV and in print; continuous medical education for pharmacy technicians and assistants and distribution of information, education and communication materials to women through pharmacies and private clinics. 


\subsubsection{Clinic social franchising / marketing}

There are currently 4 major clinic social franchises operating in Kenya: Tunza Family Health Network (by PSI), Gold Star Network (fhi360), Child and Family Wellness (The Healthstore Foundation), and AMUA (Maries Stopes Kenya). All of these social franchises have FP components within their service-delivery detail; however, the Tunza Family Health Network franchise by PSI and AMUA by MSK have as their major mandates the provision of FP services and tackling the unmet need for FP.

In December 2008, PSI Kenya launched the Tunza program, a clinic-based social franchise aimed at engaging private health providers and empowering low-income Kenyan women to avoid unplanned pregnancies through access to high-quality FP services. ${ }^{99}$ The Tunza Family Health Network is composed of over 250 private health clinics and practitioners. PSI employs a double-pronged approach, which includes a supply side (the providers) that guarantees high-quality FP services by a qualified provider with emphasis on providing the long-term reversible method of IUD and sub-dermal implants and robust demand creation by a dedicated marketing team that assists in the uptake of these services. These FP commodities are provided at highly subsidized prices to the providers, who are then required to offer affordable and quality services to their clients. As of September 2010, the franchise had already achieved a cumulative 169,642 couple years of protection (CYP) through 27,680 IUDs and 4972 implant insertions. ${ }^{99}$

The second fractional social franchise dedicated to FP is AMUA, which is implemented on behalf of the government of Kenya by Marie Stopes Kenya (MSK) with funds from the German Development Corporation (KfW). AMUA consist of over 250 privately owned and operated clinics in both urban and rural areas and is found in zones identified by the KDHS as having higher fertility and unmet need for FP. ${ }^{100}$ The majority of the franchises within this network are small, stand alone, owned and operated by licensed nurses, and staffed by a small number of health workers. These clinics provide a range of services and long-term- and short-term FP commodities. According to MSK, as of 2010 the franchise had generated 152,235 CYPs, which was 90 percent of their target. The biggest challenge faced is funding as well as incentivizing CHWs for demand creation.

\subsubsection{Commercial sector provision of FP services (for profit)}

Commercial sector FP includes retailers, private health professionals and facilities, employers and health insurance arrangements that provide or finance FP services on a for-profit basis. In Kenya, most clinical methods are usually obtained from government facilities and other commercial and non-commercial providers, while methods such as oral contraceptives can be obtained from commercial pharmacies. ${ }^{101}$ The commercial sector including pharmacies/chemists, private hospitals and shops provide about 35 percent of FP services in Kenya, ${ }^{102,103}$ meaning that one third of couples get their FP methods from the private commercial sector. As reported in Chapter 4, wealthy women are more likely to use FP services from the private sector, with the poor patronizing public health facilities to meet their FP needs, though a large proportion of women from high-wealth households also use public facilities. 


\subsection{Financing mechanisms}

The majority of FP delivery costs are borne by the government, households and donors. Donors fund nearly all the procurement costs of all contraceptive commodities except condoms, including all contraceptives provided by NGOs. However, 75 percent to 80 percent of the total FP service-delivery-related costs are met by the government through the provision of personnel, facilities, and other infrastructure and support activities. ${ }^{104}$ In the recent past, the government has increased its financial obligation to FP through the inclusion of a specific budget item in the annual budget. In this section we review the financing mechanism for the FP and reproductive sector in Kenya.

\subsubsection{Government funding of health}

Before 2008, only one ministry was responsible for health in Kenya - the MOH. Table 5.1 shows the budget allocations from the 2003/04 to 2007/08 fiscal years under the $\mathrm{MOH}$. Although the total gross health budget increased during this period, the $\mathrm{MOH}$ share of the government's budget has fluctuated and remained below the recommended Abuja Accord Goal of 15 percent. ${ }^{105}$

Table 5.1: Trends in Kenya's health budget, 2003/04-2007/08 fiscal years

\begin{tabular}{|l|r|r|r|c|c|}
\hline Item & $2003 / 04$ & $2004 / 05$ & $2005 / 06$ & $2006 / 07$ & $2007 / 08$ \\
\hline $\begin{array}{l}\text { Total gross health budget } \\
\text { (constant 2007/08 us \$million) }\end{array}$ & 317 & 332 & 385 & 437 & 543 \\
\hline $\begin{array}{l}\text { MOH health share of government's budget } \\
\text { (percent) }\end{array}$ & 7.0 & 6.1 & 5.7 & 7.6 & 6.4 \\
\hline $\begin{array}{l}\text { MOH health expenditure per capita } \\
\text { (constant 2007/08 US\$ ) }\end{array}$ & 9.4 & 9.6 & 10.8 & 11.9 & 15.6 \\
\hline $\begin{array}{l}\text { Preventive/promotive health } \\
\text { (FP/RH) }\end{array}$ & 5 & 9 & 8 & 10 & 20 \\
\hline $\begin{array}{l}\text { Recurrent expenditure's share of the health } \\
\text { budget (percent) }\end{array}$ & 94 & 91 & 86 & 78 & 70 \\
\hline
\end{tabular}

\section{Source: Cieza and Holm, 2010105}

\subsubsection{Government funding of reproductive health and family planning}

In 2008, the MOH was split into two separate ministries - the Ministry of Medical Services (MOMS) and the Ministry of Public Health and Sanitation (MOPHS). The MOPHS handled the FP/RH portfolio. Reproductive health financing from the government receives low priority. In 2000, only 51.6 million Kenyan Shillings was dedicated to $\mathrm{RH}$ out of a total budget of 30 billion Kenyan Shillings. This indicates that the total health budget was 
581 times the total amount allocated for RH. However, during the 2009/10 FY 1.2 billion Kenyan Shillings was allocated to FP/RH. ${ }^{106}$ The low priority given to $\mathrm{RH}$ is also reflected in the government of Kenya's per citizen commitments. Per citizen, the government of Kenya committed 1.5 Kenyan Shillings in 2005 , though this number significantly increased in 2009 to 30.5 Kenyan Shillings. The RH health portion of the country's budget stood at 3 percent as of 2009/09 compared to 0.2 percent in 2005/06 (Table 5.2). It worth noting that maternal and child health is included in the budget allocation for FP/RH; most of the budget allocation is, however, earmarked for FP. ${ }^{106}$

Table 5.2: Reproductive health commitments per capita

\begin{tabular}{|l|c|c|c|c|c|}
\hline & $\mathbf{2 0 0 5 / 0 6}$ & $\mathbf{2 0 0 6 / 0 7}$ & $\mathbf{2 0 0 7 / 0 8}$ & $\mathbf{2 0 0 8 / 0 9}$ & $\mathbf{2 0 0 9 / 1 0}$ \\
\hline $\begin{array}{l}\text { Total RH commitments per capita in } \\
\text { Kenyan Shillings }\end{array}$ & 1.5 & 1.4 & 1.9 & 53.2 & 30.5 \\
\hline $\begin{array}{l}\text { Total RH as a \% of total health } \\
\text { (commitments) }\end{array}$ & 0.2 & 0.2 & 0.2 & 5.9 & 2.6 \\
\hline
\end{tabular}

Source: Nyakundi et al, 2011106

From this analysis, it is clear that the public expenditure on FP and RP services as a percentage of total public expenditure on health is relatively low, particularly considering that maternity costs are likely to be included under reproductive health. For example, in 2009/10 the total expenditure on RH services amounted to 17 billion Kenyan Shillings (\$225 million). The total expenditure on reproductive health services accounted for 14 percent of total expenditure on health and 0.8 percent of GDP in 2009/10. Specifically, FP accounted for 24 percent of $\mathrm{RH}$ spending in 2005/06, though it declined to 22 percent of RH expenditure by 2009/10. ${ }^{107}$ The National Health Accounts (NHA) for 2009/10 show that the public and private sectors (including households) were the primary sources of $\mathrm{RH}$ financing in 2009/10, contributing 40 percent and 38 percent respectively; while private firms contributed 8 percent of the total spending on $\mathrm{RH}$ in 2009/10. ${ }^{107}$ The relative contribution of the public sector increased from 34 percent in 2005/06 to 40 percent in $2009 / 10$. The donors contributed 22 percent of the financing in 2009/2010 compared to 24 percent during the 2005/2006 fiscal year.

\subsubsection{Donor funding}

Development partners have been supporting the provision of FP services since independence. Historically, development partners have provided funds for the procurement of all contraceptive commodities in Kenya and financially supported the CBD programs in the country. However, in 2005, the government of Kenya incorporated contraceptive programs into the national budget and allocated a line item for contraceptive commodities. Development partners remain a key funding source for RH/FP in Kenya. For instance, the 2008/2009 fiscal year estimates that the combined ministries of health were to receive 
about 7 billion Kenyan Shillings from development partners. Approximately 3.2 billion Kenyan Shillings allocated to the MOPHS was aimed at upgrading and strengthening rural health centers and dispensaries, as well as supporting environmental, FP and maternal and child care programs. ${ }^{105}$ Overall, according to a NIDI and APHRC report, donor funding has slightly decreased from 24 percent in 2005/06 to 22 percent of total $\mathrm{RH}$ funding in 2009/10. ${ }^{107}$

\subsubsection{Out-of-pocket spending on reproductive health and family planning}

Household expenditure on $\mathrm{RH}$ is an important funding source. Household out-of pocket expenditure comprised 29 percent of the total RH spending in 2009/10. The NHA reports that in 2005/06 households' out-of-pocket expenditure on RH was mostly at health facilities. Public hospitals accounted for 37 percent of the total household spending on $\mathrm{RH}$, while private facilities accounted for 38 percent of household resources. With regard to what was purchased, 42 percent of household resources on $\mathrm{RH}$ were used to buy FP services.

\subsubsection{Spending on contraceptives}

According to the NHA, resources going to the purchase of FP commodities have increased from 13 million Kenyan Shillings in 2005/06 to 171 million Kenyan Shillings in 2009/10, an increase of about 122 percent. According to a recent report, however, these estimates might be underestimates of the volume of resources actually going to FP commodities, as the estimates rely mainly on distributional factors/ratios of apportion expenditures on $\mathrm{RH}$ by activities. ${ }^{107}$

\subsubsection{Cost sharing}

As part of the response to declining public sector resources since the 1980s, the government has been implementing a "cost-sharing" program in the health sector, under which fees are charged to service recipients to cover part of the costs. In its new National Condom Policy and Strategy, ${ }_{108}^{108}$ for instance, the government has made the long-term commitment to gradually introduce fees for all public sector health services, including FP, in an effort to shore up the health system and expand access. At the same time, the government is committed to the effective application of a system of waivers and exemptions from fees for poor clients and other designated groups (e.g., youth, people living with HIVIAIDS). A waiver is an exemption from payment based on financial hardship. Clients are expected to request for a waiver and judgment is made on a case-by-case basis. Exemption, on the other hand, is an automatic excuse from payment based on $\mathrm{MOH}$ guidelines. Overall, the waiver and exemption system has had limited impact because of lack of awareness of the system. ${ }^{103}$ 
According to the $\mathrm{MOH}$ fee guidelines, $\mathrm{MCH} / \mathrm{FP}$ and antenatal and postnatal services are to be provided free. In practice, however, public health facilities have put in place an "access fee" under the direction of the District Health Management Boards (DHMBs). Typically, these are as follows: 20 to 100 Kenyan Shillings at the registration desk to gain access to all services; a "commodity fee" of about 50 Kenyan Shillings per visit, usually dependent on the client's method choice; and a "supplies fee," dependent on the availability of items such as paraffin, gloves, cotton wool, needles, and syringes. In July 2003, a new policy for user fees at the PHC facilities was declared. The policy stated that all services rendered would cost only 10 Kenyan Shillings at the dispensary level and 20 Kenyan Shillings at the health center.

Nyakundi et al. ${ }^{106}$ indicate that the waiver and exemption system's effectiveness has been hampered by the inability of the service providers to accurately identify poor clients and by the absence of attractive incentives for facility managers to offer exemptions and waivers. Analyses carried out the Health Policy Initiative ${ }^{103}$ and Nyakundi et al. ${ }^{106}$ show that, in addition to limiting poor people's access to health care, the cost-sharing policy has worsened existing inequalities in access to health services, including FP and RH services, by preventing vulnerable groups from seeking affordable health care.

The 2008/09 KDHS indicates that about 20 percent of women using a modern contraceptive method received the method free of charge. The $2008 / 09 \mathrm{KDHS}$ data also indicate that 28 percent of the women who obtained their contraceptive methods from the public sector (government health facilities) did not pay for the method. This figure compares with 8 percent who obtained their methods in the private sector. ${ }^{1}$

\subsubsection{Results or output-based financing programs}

Results Based Financing (RFB) is a strategy for using explicit results or performancebased subsidies to support the delivery of basic services where policy concerns would justify public funding to complement or replace user fees. The core of this approach is contracting out service delivery to a third party, where payment of public funds is tied to the actual delivery of these services. ${ }^{109}$ In FP, results or output-based financing programs address supply- and demand-side challenges that limit the use of FP services by incentivizing quality service provision while removing access barriers faced by women. Incentives include subsidies or fees paid to clinics or vouchers sold to women. ${ }^{110}$

In Kenya, the RBF program began in 2005 when the Government of Kenya and the Federal Republic of Germany (through KfW banking Group) entered into an agreement to fund safe motherhood, FP, and gender violence recovery using a voucher system. The project was initially implemented on a pilot basis for 3 years and targeted economically disadvantaged people in 3 rural districts (Kisumu, Kiambu, and Kitui) and 2 urban slums in Nairobi (Korogocho and Viwandani) but in 2012 the project was scaled up to include Uasin Gishu District. The project up until 2011 was led by the National Coordinating Agency for Population and Development (NCAPD), but it is currently being led by the MOPHS. ${ }^{111}$ 
The reproductive health voucher system represents a new approach to provide skilled medical care to pregnant women to help them overcome barriers (such as high out-ofpocket fees, poorly staffed and equipped facilities, and costly transportation) that may prevent them from getting appropriate care. Eligible women receive a voucher that can be used as a coupon for prenatal and delivery services from approved private and public health care providers, as well as an FP voucher for long-acting- and permanent methods of contraception. In Kenya, utilization of assisted deliveries and FP increased at contracted clinics after the voucher program was implemented in 2006. Between 2006 and 2011, 96,000 deliveries were performed in the contracted clinics and 27,000 long-term FP users were serviced at the same clinics..$^{12}$ By the end of 2012, more than 120,000 deliveries and 40, 000 long-term contraceptive methods had been provided. ${ }^{112}$

A review of the FP voucher in phase I (2006 to 2010) shows that uptake was rather slow with only 48 percent of the vouchers sold in the first 2 years having been utilized by the end of the 3 rd year. ${ }^{113}$ Barriers to utilization include but are not limited to clients reluctance to access FP, inadequate counseling by service providers, supply stock-outs, long queues and misconceptions that IUDs will encourage multiple sexual partnerships. ${ }^{113}$ However, a substantial increase in the use of FP vouchers was observed in phase II (2010 to 2012) from about 350 clients monthly to more than 1000 clients.

According to a recent study, the $\mathrm{RH}$ voucher program is associated with reduced likelihood of out-of-pocket payments for RH services at the facility level, increased utilization of assisted deliveries, and FP visits at the contracted facilities. ${ }^{114} \mathrm{Importantly}$, in communities that were exposed to the program, voucher clients are poorer than non-voucher clients, indicating vouchers are reaching the intended audience. ${ }^{115}$

There are two primary cost components to voucher programs: the costs of the goods and services provided; and the administrative costs of setting up and running the program. Owing to the high uptake of safe motherhood vouchers, a majority of the costs associated with services in Kenya has been for the safe motherhood program, which makes up 75 percent of the total service costs. During phase II of the Kenyan program (2010 to 2012), the average cost per client was $\$ 119$ for safe motherhood services, $\$ 24$ for FP and $\$ 103$ per client overall. ${ }^{112}$

Uptake of the voucher program is impeded by a variety of factors. Transportation costs are not covered by the vouchers and about 40 percent of eligible voucher holders do not use them for of this reason. Therefore, though the program is designed to reach the poorest and disadvantaged, reaching the poorest and most remote individuals remains a challenge. ${ }^{112}$ According to a USAID report, though there is some buy in and ownership of the voucher program in Kenya and it is part of the national health financing strategy, increased ownership is still needed for it to remain a long-term financing mechanism and meet its long-term goals. ${ }^{112}$ Perhaps Kenya's FP 2020 commitment to scaling up the RH voucher program at the $2012 \mathrm{FP}$ London summit was an indication of more ownership of the program and could go a long way to sustain the program.

Considering that 56 percent of women still deliver at home and 1 in 4 have an unmet need for FP, the voucher program remains a vital mechanism that empowers women who 
otherwise have access to health care but cannot afford it. The voucher program also gives these women choices in terms of facilities that can properly attend to them as well as demand proper services at a facility of their choice. ${ }^{113}$

\subsubsection{Health insurance schemes}

The health insurance sector in Kenya remains limited both in terms of the number of people being covered and the resources controlled. ${ }^{107}$ The National Health Insurance Fund (NHIF - public health insurance) and private health insurance schemes are important agents in $\mathrm{FP} / \mathrm{RH}$ financing. Kenyans who are formally employed and whose income exceeds a set threshold participate in NHIF. By the early 1990s there were an estimated 1.3 million workers and 8 million dependents covered by the NHIF. Since NHIF covers mainly those employed in the formal sector, it does not cover the health needs including FP/RH of the poor who are employed in the non-formal sector. ${ }^{116}$

Private health insurance coverage in Kenya is still relatively small (about 2 percent of the total population). Analysis carried out jointly by the APHRC and Netherlands Interdisciplinary Demographic Institute (NIDI) indicates that the private health insurance and NHIF controlled slightly over 9 and 6 percent respectively of the total FP/RH expenditures in 2005/06 fiscal year and the respective percentage rose to 13 and 9 in the 2008/09 fiscal year. ${ }^{107}$ Overall, health insurance accounted for 21 percent of resources mobilized for $\mathrm{RH}$ in 2009/10, an increase from 16 percent in 2005/06 (Figure 5.1).

Figure 5.1: Spending by Health Insurance in Kenya 2005-2010

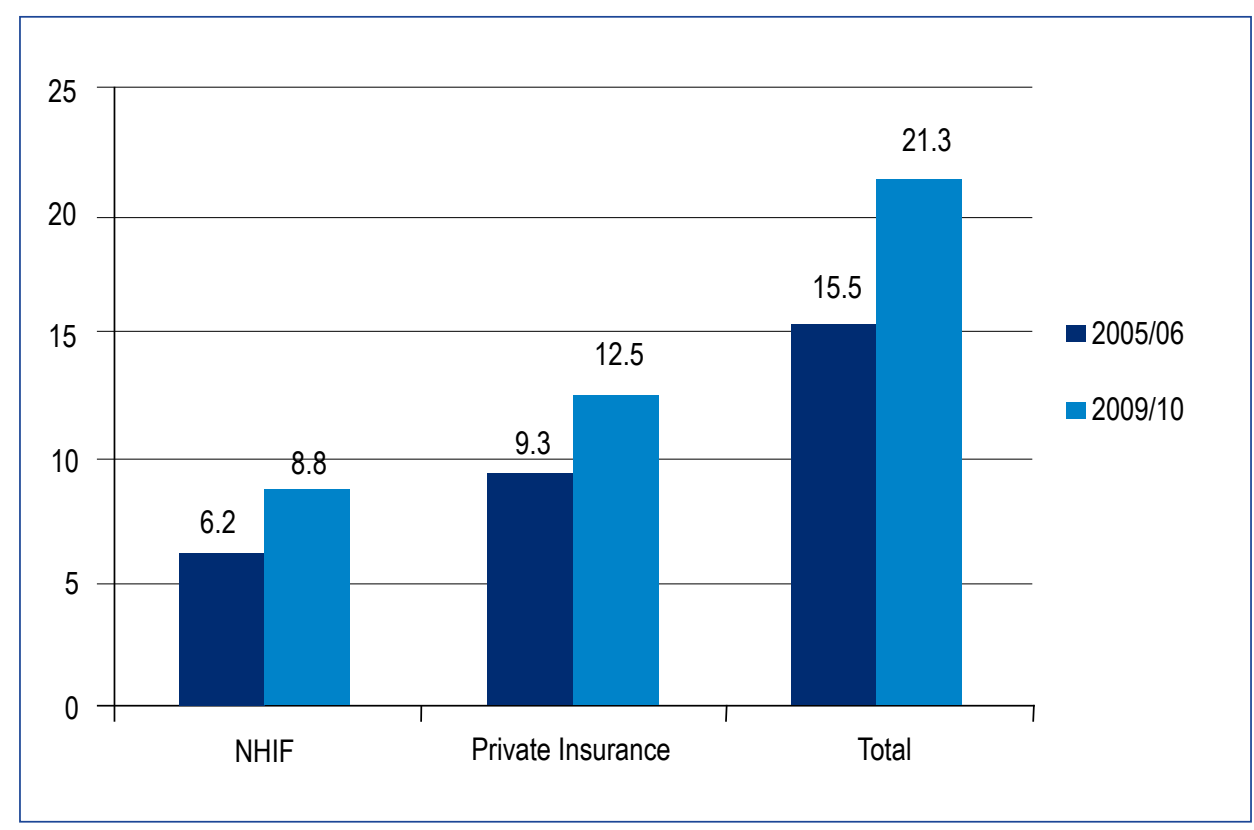

Source: NIDI and APHRC. 2012107 


\subsection{Chapter summary}

- Seventy-five to eighty percent of the total FP/RH service-delivery-related costs are met by the government through provision of personnel, facilities, and other infrastructure and support activities. Frequent contraceptive stock-outs continue to occur, however, because of continued reliance on donor financing of commodity procurement and weak logistics system and distribution system. There is, therefore, continued need for advocacy to increase government funding for FP programs in general and commodity procurement and distribution in particular.

- In the mid-1980s and early 1990s Kenya's CBD program was rated as being strong, and was considered to have contributed to the increase in FP use; however, less than 1 percent of current users in the 2008/09 KDHS obtained their services through $\mathrm{CBD}$, as there have been dramatic declines in these programs. Efforts to revitalize community-based FP programs may improve FP uptake among marginalized and vulnerable populations.

- There is an increasing role of the commercial sector in provision of FP services, as it currently provides about 35 percent of FP services in Kenya.

- The RH voucher system is a potentially vital financing mechanism and a safety net for low-income populations and a financial incentive to health facilities to properly attend to low-income women; at present, however, it covers a minute proportion of the national population.

- The NHIF is an important agent in FP/RH financing, as it provides subsidized services to those employed in the non-formal sector and its coverage should be enhanced. 


\section{CHAPTER 6}

\section{Policy Context and Recommendations}

In Kenya, childbearing carries with it a significant risk of complications, including child and maternal mortality and morbidity. Yet, an estimated 2 in 5 pregnancies among women in Kenya are unintended. The high levels of unintended pregnancies can be attributed to comparatively high levels of unmet need for contraception - it is estimated that about 1 in every 4 women who want to space or stop childbearing in the next two years is not using any contraception in Kenya. ${ }^{1}$ One consequence of high unmet need is the large number of unsafe abortions procured by women and girls. It is estimated that in 2012, about 465, 000 unsafe abortions were procured in Kenya. ${ }^{74}$ Existing evidence shows that the total burden of obstetric complications can be reduced significantly through the prevention of unintended pregnancies. Tsui and Creanga ${ }^{117}$ show, for example, that the use of contraceptives in the preceding birth interval can reduce the mortality risk for the new born by 31 percent and by 68 percent if contraceptive use overlaps with breastfeeding. Ahmed and colleagues ${ }^{118}$ have projected that Kenya's current contraceptive prevalence rate of 44 percent (all methods) prevented about 6,172 deaths, implying that the proportion of maternal deaths reduced with the use of contraceptive was 52 percent. Meeting the unmet need for contraception in Kenya is therefore an important avenue for improving maternal and child health. Meeting the unmet need for contraception also has implications for demographic trends as unintended pregnancies contribute significantly to higher fertility rates and population growth. With Kenya's fertility rate not declining at the expected pace, meeting the unmet need for contraception is therefore pertinent for both health and development goals.

In this chapter, we summarize 6 policy and programmatic recommendations and 3 research priorities arising from the review of data and literature on unintended pregnancies and abortion in Kenya. These recommendations and research priorities draw on a validation process of the findings with a wide range of key stakeholders. The policy, programmatic and research recommendations were developed as part of the validation deliberations and represent those most clearly supported by the evidence presented in this report. These recommendations take into account the policy context in Kenya, which as described in Chapter 2, is rapidly evolving with the ongoing devolution process, and increased global interest around SRH and FP following the 2012 London Summit on Family Planning. The Kenyan government has committed to improving access to contraception and other sexual and reproductive health services as part of its FP2020 commitments. This creates an enabling environment for the implementation of initiatives to address unintended pregnancies and unsafe abortions. 


\subsection{Policy and programmatic recommendations to address unintended pregnancies and abortions}

The recommendations address the overall significant SRH challenges highlighted throughout the report. For each recommendation, a description of the relevant contextual issues is provided. Overall, it is expected that recommendations outlined provide approaches to: 1) reduce unintended pregnancy; and 2) prevent unsafe abortion.

\subsubsection{Accelerate the implementation of the relevant policies and guidelines (such as} the National School Health Policy, the Adolescent Reproductive Health and Development Policy, and the 2005 National Guidelines for Provision of Youth Friendly Services in Kenya) to reach youth with comprehensive sexual and reproductive health information and services

Although the Kenyan government has made significant strides in addressing the SRH needs of young people, numerous challenges continue to be faced. For instance, the 2008/09 KDHS estimates that 47 percent of the births to young people aged 15 to 19 and 40 percent of the births to young people aged 20 to 24 in Kenya are unplanned. ${ }^{1}$ Part of the challenge of reaching young people is the wide range of experiences and vulnerabilities associated with differing age, education, and marital status. As such, targeted programs are needed to reach young people with SRH information and services based on their diverse needs.

To reach in-school youth, the MOE and the MOH (Division of Child and Adolescent Health, Division of Reproductive Health) should:

a) Accelerate the implementation of the 2009 National School Health Policy by including innovative approaches to reach in-school youth with comprehensive SRH information and services.

\section{SUGGESTION: An innovative approach to comprehensive sex education for in-school youth}

One idea for an alternative model to reach in-school youth is the use of health care professionals such as nurses and counselors and or specially trained $\mathrm{CHWs}$ who are assigned and/or placed in schools to provide SRH classes and ad-hoc counseling. This approach would relieve teachers from having to take on SRH education, a concern that they have raised and would place the responsibility of sexual education on properly trained experts.

b) The planned revision of the 2009 National School Health Policy should outline specific approaches to raise financial resources to support the implementation of a comprehensive school health program to address youth SRH and broader health needs at county and national level. 
According to the 2010 Kenya Service Provision Assessment, only 7 percent of health facilities offer youth-friendly services. To reach out-of-school youth, the $\mathrm{MOH}$ and county departments of health should accelerate the implementation of the 2005 National Guidelines for Provision of Youth Friendly Services in Kenya by allocating adequate financial and human resources to enable health facilities to provide appropriate SRH services to youth. These efforts will also enable the Kenyan government to meet its FP2020 commitment to increase the number of youth-friendly centers in the nation.

\subsubsection{Develop comprehensive communication and sensitization approaches that address local context-specific concerns about the use of contraception}

The county departments of health and the newly appointed county NCPD representatives should develop comprehensive communication and sensitization approaches (strategies and tactics) and draw on work from ongoing development partners and the $\mathrm{MOH}$ to address local context-specific concerns about contraceptive methods, including religiousand age-specific concerns. These agencies should also monitor, evaluate and document the impact of these communication strategies and tactics on contraceptive uptake and reduced contraceptive discontinuation. Better communication and sensitization approaches will debunk myths and misconceptions and ensure that critical information reaches the intended recipients and informs personal choices around contraceptive use.

Success Story: In 2012, UNFPA implemented a collaborative intervention with religious leaders to address contraceptive uptake among Islamic communities in Kenya. This project was informed by evidence showing low levels of contraceptive use among Muslims in Kenya. To raise awareness of FP and contraceptive use, a 3-day national dialogue with religious leaders was held to discuss the relationship between FP and Islam. The national dialogue aimed at increasing religious leaders' understanding of population issues as they pertain to development, to address the myths about FP within the context of Islam, and to agree on context-appropriate and culturally-sensitive messages to increase demand for contraceptives and $\mathrm{RH}$ services. Following this meeting, the religious leaders developed key advocacy messages for use in their communities.

United Nations Population Fund Annual Report, 2012 http://countryoffice.unfpa. org/kenya/drive/UNFPAAnnualReport2012.pdf

Way forward: county departments of health - in addition to other contextually important players such as relevant government departments, development partners, research institutions, faith-based organizations, and civil society - should coordinate a health task force to develop this plan, acquire funding, and meet with all relevant stakeholders. We feel that county-level RH departments should be the focal points that will take an active leadership role in addressing the context-specific concerns around contraceptive use. 


\subsubsection{Coordinate comprehensive awareness campaigns to expand communication on laws, policies, and reproductive health services and rights that are allowed under the Constitution}

The high incidence of unsafe abortion suggests that women lack access to or do not understand the current Constitutional provisions on abortion. The National Partnership for the Prevention of Maternal Mortality and associated organizations such as the Reproductive Health Alliance should coordinate all comprehensive awareness campaigns to expand communication on laws, policies, and reproductive health services and rights that are allowed under the Constitution and available to women in Kenya. At minimum, a comprehensive awareness campaign will ensure that women know what options are available to them under the Kenyan law and Constitution and will be empowered to seek and demand those services.

SUGGESTION: Even with full knowledge of the law and policies about abortion services by potential users, effective use of these services will require that providers are fully sensitized and have access to digital and/or physical copies of the Standards and Guidelines for Reducing Maternal Morbidity and Mortality from Unsafe Abortion in Kenya (currently under review to become Policies, Standards and Guidelines for the Reduction of Maternal Morbidity and Mortality in Kenya). Providers will also require access to appropriate medical equipment and treatment supplies to be able to safely and skillfully provide the services. The provision of both the guidelines and the equipment and supplies will need to take into account the devolution process currently taking place in Kenya.

\subsubsection{Expand the maternal health care package to include family planning}

Currently, Kenya's free maternal health service policy covers only the expenses associated with delivery; therefore the DRH in collaboration with county governments should expand the free maternal health care package of services to incorporate short- and long-acting FP methods during the postpartum period so that new mothers can effectively space or limit further births as a continuation of the care received during pregnancy and delivery. In order to ensure resources go farther, DRH should determine a model to better identify/target the key beneficiaries of free or subsidized health care (poor and vulnerable women). Special attention should be paid to the most vulnerable groups including adolescents and young people, street children, refugees, people living with HIVIAIDS and people with special needs. 
SUGGESTION: Today 56 percent of Kenyan women deliver at home and 1 in 4 have an unmet need for FP, as a result the RH Voucher Program remains a vital mechanism to provide women from low-income households with access to more affordable health care, include delivery facilities and/ or skilled birth attendants. Kenya's FP2020 commitment to scaling up the RH Voucher Program is a commendable effort towards more country ownership and sustainability of the voucher program. However, there is a need to expand the package to cover additional expenses that can impede service utilization such as transportation costs (it is estimated that 40 percent of eligible voucher holders do not use their vouchers because they are unable to pay for transportation to health facilities).

Way forward: Although Kenya's free maternal health care program has changed the way mothers can access services, the failure of this program to include access to FP services means that it does not currently address some of the root causes of maternal morbidity and mortality, including high unmet need for contraception. Until this program is updated to include free access to crucial FP services and commodities during the postpartum period, the Reproductive Health Voucher Program should remain an active program targeting Kenya's poorest women because it helps to guarantee access to maternal health services at a reduced rate while at the same time providing much-needed FP access.

\subsubsection{Assess the feasibility of Public-Private Partnerships (PPPs) as an avenue to deliver quality sexual and reproductive health services}

Kenya's new devolution process also presents an opportunity for increased PublicPrivate-Partnerships (PPP), which can be instrumental in helping county governments maximize their resources to effectively deliver quality SRH services to the poorest while taking advantage of or facilitating the growth of private health sector providers as preferred suppliers for those who can afford them. The County Reproductive Health Interagency Coordinating Committee should take the lead in assessing the needs for PPP for SRH, based on successful existing partnerships in each county and other replicable success stories from other counties. This assessment should be followed by establishing a sustainable coordination mechanism at county level to serve as a platform for designing, implementing and monitoring PPP for SRH. 
SUGGESTION: An example of a mechanism through which the public and private sector can work together to provide quality and sustainable $\mathrm{RH}$ services could be taken from the Total Market Approach. Because public and private entities go in different directions and have different mandates, the total market approach identifies specific roles for the public and private sectors so that they can collaboratively work in meeting the family planning needs of users. The Total Market Approach adopts several steps: 1) engaging the relevant key stakeholders (both government and private); 2) market segmentation analysis (using existing data), which includes identification of vulnerable groups and the mapping and prioritization of key gaps in commodity needs and provision; 3) providing the capacity-building needs of both private and public sector providers; 4) assessing budgets dedicated to FP and RH at county level; and 5) monitoring and evaluation to assess impact. The Total Market Approach, if well implemented, can hold counties accountable and empower them to use available resources to provide quality services and commodities to their respective constituents.

Way forward: The NCPD should carry out a mapping exercise that documents all existing public and private $\mathrm{RH}$ programs in order to maximize resources and reach. It is also imperative that results from a Total Market mapping study be shared with all stakeholders within each county for policy and programming adjustments. It should be noted that the Kenya Bureau of Statistics health expenditure and utilization survey is in the process of being completed and could be a valuable resource toward this effort.

\subsubsection{Improve access to post-abortion care services, reduce financial barriers and improve the quality of post-abortion care}

Unsafe abortion is a significant contributor to maternal mortality and morbidity in Kenya, partly because of limited availability of trained staff, supplies and equipment. There is therefore a need to improve the quality of comprehensive post-abortion care in both the public and private sectors in order to reduce the incidence of severe complications from unsafe abortion. As a result, it is critical that the $\mathrm{MOH}$ and the Reproductive Health Network and National Partnership for the Prevention of MMR work to improve access to quality post-abortion care services and to reduce financial barriers to PAC.

The MOH and the DRH should:

a) Monitor the PAC guidelines to ensure implementation of not only the treatment but also other critical components required by the guidelines such as post-abortion contraception and counseling;

b) Continue efforts in training providers in post-abortion counseling and provision of contraceptive methods, with a focus on long-acting methods; and 
c) Accelerate the provision of and guidance on the national standardized training curriculum for prevention of causes of maternal morbidity and mortality - including the management of unintended, risky and unplanned pregnancies by disseminating the curriculum and training county health officials and service providers.

The Reproductive Health Network and National Partnership for the Prevention of MMR should:

a) Develop a mechanism/system to ensure private providers are closely following the $\mathrm{WHO} / \mathrm{MOH}$ standards and guidelines for provision of comprehensive abortion care;

b) Provide training and supportive supervision for private abortion care service providers

c) Monitor the quality of care for comprehensive abortion services in the private sector, by developing or updating a comprehensive quality-assurance guide on abortion services for use in private facilities where comprehensive abortion care is ongoing to ensure a minimum set of services.

Way forward: In early 2014, the MOH was still in the process of producing guidelines on abortion and post-abortion care services; however, the $\mathrm{MOH}$ had yet to disseminate the documents to health care providers across the country. To ensure that there are enough resources for the guidelines to reach down to the county providers, stakeholders involved in the provision of the related services (pharmaceutical companies and private sector, NGOs and others) should be involved in printing and disseminating the final guidelines and ensuring there is adequate private sector sensitization and training.

\section{2. Critical research priorities}

The evidence provided in this Country Profile Report underscores the need for additional research on SRH among vulnerable groups. In addition, further research is needed to understand women's concerns about the range of FP methods. Three specific research priorities are highlighted:

1. The need to expand research on education that demystifies comprehensive sexuality education and finds innovative ways and delivery models through which this information can be brought to schools;

2. The need to collect more data on people living with disabilities because the volume and quality of the data that exists limits our ability to assess adequately the extent to which the dynamics of FP / RH indicators improve among people with disabilities; and

3. The need to expand research on traditional contraceptive methods (the DHS leaves out traditional methods in the matrix calculation for unmet need) and to expand research on a wider range of FP methods, with a focus on non-hormonal methods and to explore the cost-effectiveness of these newer FP methods. 


\section{3. Chapter summary}

The available data and literature suggest that there is an urgent need to improve access to FP and RH services to the majority of people in Kenya, particularly to hard-to-reach populations and communities, including young people. This calls for the expansion and strengthening of existing delivery approaches to ensure that SRH services reach the people who need them most and to ensure that the country meets its national health and development goals. Multiple avenues for achieving improved SRH outcomes exist and in this report we highlight six potential actions that national stakeholders can take to achieve improved health. These include the following:

- Accelerate implementation of the relevant policies and guidelines (such as the National School Health Policy, the Adolescent Reproductive Health and Development Policy, and the 2005 National Guidelines for Provision of Youth Friendly Services in Kenya) to reach youth with comprehensive SRH information and services;

- Develop comprehensive communication and sensitization approaches that address local context-specific concerns about the use of contraception;

- Coordinate comprehensive awareness campaigns to expand communication on laws, policies, and RH services and rights that are allowed under the Constitution;

- Expand the maternal health care package to include FP;

- Assess the feasibility of PPPs as an avenue to deliver quality SRH services; and

- Improve access to post-abortion care services, reduce financial barriers and improve the quality of post-abortion care.

Since 2000, Kenya has passed several new SRH-and population-related policies, including a new population and development policy that addresses rapid population growth, among other population-related policies. Owing to Kenya's dynamic policy context, all relevant policies not only need to be mapped out, but the implementation status of these policies must also be assessed and accelerated, as relevant bodies and key stakeholders work to actualize the Country Profile Report policy recommendations. Results of the this country profile also highlight the need for further research on: 1) innovative ways through which SRH information can be brought to schools; 2) FP/SRH indicators in people living with disabilities; and 3) traditional and non-hormonal methods of contraception. 


\section{REFERENCES}

1. Kenya National Bureau of Statistics (KNBS), ICF Macro. Kenya Demographic and Health Survey 2008-09. Calverton, Maryland: KNBS and ICF Macro; 2010.

2. Oisebe C. Population Stabilization: Kenyan Case. Nairobi, Kenya: National Council for Population and Development; 2011.

3. Center for Reproductive Rights. In Harm's Way: The Impact of Kenya's Restrictive Abortion Law. New York: Center for Reproductive Rights; 2010.

4. Hussain R. Abortion and unintended pregnancy in Kenya. In Brief, No 2 (Alan Guttmacher Institute). New York: Guttmacher Institute; 2012.

5. Population Reference Bureau (PRB). 2011 World Population Data Sheet. Washington, DC: PRB; 2011.

6. Population Reference Bureau (PRB). 2012 World Population Data Sheet. Washington, DC: PRB; 2012.

7. World Health Organization. Atlas of Health Statistics of the African Region-2012. Brazzaville, Congo: WHO Regional Office for Africa; 2012.

8. World Health Organization. International Statistical Classification of Diseases and Related Health Problems. Tenth Revision. Instruction Manual 2nd ed. Geneva: World Health Organization; 2004.

9. World Health Organization (WHO), United Nations Children's Fund (UNICEF), United Nations Population Fund (UNFPA), World Bank. Trends in Maternal Mortality: 19902010: WHO, UNICEF, UNFPA and The World Bank estimates. Geneva: World Health Organization; 2012.

10. Central Bureau of Statistics (CBS) [Kenya], Ministry of Health (MOH) [Kenya], ORC Marco. Kenya Demographic and Health Survey 2003. Calverton, Maryland: CBS, $\mathrm{MOH}$, and ORC Marco; 2004.

11. Marston C, Cleland J. The Effects of Contraception on Obstetric Outcomes. Geneva: Department of Reproductive Health, World Health Organization; 2004.

12. National Coordinating Agency for Population \& Development (NCAPD). Maternal Deaths on the Rise in Kenya: A Call to Save Women's Lives. NCAPD Policy Brief No. 9. Nairobi: NCAPD; 2010.

13. Ziraba A, Madise N, Mills $S$, Kyobutungi $C$, Ezeh A. Maternal mortality in the informal settlements of Nairobi city: what do we know? Reproductive Health. 2009;6(1):6.

14. Marston C, Cleland J. Do unintended pregnancies carried to term lead to adverse outcomes for mother and child? An assessment of five developing countries. Population Studies. 2003;57(1):77-93.

15. Magadi MA, Nyovani JM, Rodrigues RN. Frequency and timing of antenatal care in Kenya: Explaining the variations between women of different communities. Social Science and Medicine. 2000;51(4):551-561

16. Fotso J, Ezeh A, Madise N, Ziraba A, Ogollah R. What does access to maternal care mean among the urban poor? Factors associated with use of appropriate maternal health services in the slum settlements of Nairobi, Kenya. Maternal and Child Health Journal. 2009;13(1):130-137. 
17. Campbell J, Fauveau V, Hoope-Bender Pt, Matthews Z, McManus J. The State of the World's Midwifery 2011: delivering health, saving lives. New York, US: United Nations Population Fund; 2011.

18. Sciarra JJ. Global issues in women's health. International Journal of Gynaecology and Obstetrics. 2009;104(1):77-79.

19. Levine R, Langer A, Birdsall N, Matheny G, Wright M, Bayer A. Contraception. In: Jamison DT, Breman JG, Measham AR, et al., eds. Disease Control Priorities in Developing Countries. Washington, DC: World Bank; 2006:1075-1095.

20. Tsui AO, McDonald-Mosley R, Burke AE. Family planning and the burden of unintended pregnancies. Epidemiologic Reviews. April 1, 2010;32(1):152-174.

21. World Health Organization. Disease and Injury Country Estimates: Burden of Disease. Geneva: World Health Organization; 2004.

22. Biddlecom A. Unsafe abortion in Kenya. In Brief (Alan Guttmacher Institute). 2008;(4):1-4.

23. The Alan Guttmacher Institute. Sharing Responsibility: Women, Society and Abortion Worldwide. New York: The Alan Guttmacher Institute; 1999.

24. Izugbara C, Ochako R, Saliku T, Ikamari L. Unintended Pregnancy, Contraceptive use, and Pregnancy Loss/Termination among Slum and Non-slum Women in Nairobi, Kenya (Draft report). Nairobi: African Population and Health Research Center; 2012.

25. Chalasani S, Casterline JB, Koenig MA. Consequences of unwanted childbearing: A study of child outcomes in Bangladesh. Paper presented at the Annual Meeting of the Population Association of America, 2007; New York.

26. United Nations (UN). Programme of Action of the International Conference on Population and Development. New York: United Nations; 1994.

27. Kenya National Commission on Human Rights. Realising Sexual and Reproductive Health Rights in Kenya: A Myth or a Reality? A Report of the Public Inquiry into Violations of Sexual and Reproductive Health Rights in Kenya. Nairobi: Kenya National Commission on Human Rights; 2012.

28. UN Millennium Project. Public Choices, Private Decisions: Sexual and Reproductive Health and the Millennium Development Goals. New York; 2006.

29. National Council for Law Reporting (NCLR). Constitution of Kenya. Nairobi: NCLR with Authority of the Attorney General; 2010.

30. Okech CT, Wawire NHW, K. MT. Contraceptive use among women of reproductive age in Kenya's city slums. International Journal of Business and Social Science. 2011;2(1):22-43.

31. Phillips JF, Greene WL, Jackson EF. Lessons from Community-based Distribution of Family Planning in Africa (Policy Research Working Paper 121). New York: The Population Council; 1999.

32. Ministry of Health (MOH). National Reproductive Health Policy. Nairobi: Ministry of Health; 2007.

33. National Coordinating Agency for Population and Development. Adolescent Reproductive Health and Development Policy Plan of Action, 2005--2015. Nairobi: National Coordinating Agency for Population and Development (NCAPD) (Ministry of Planning and National Development, Kenya) and Division of Reproductive Health (Ministry of Health, Kenya); 2003. 
34. Republic of Kenya. National School Health Policy: Nairobi: Ministry of Public Health and Sanitation and Ministry of Education; 2009.

35. World Health Organization, UNICEF, UNFPA, Bank TW. Maternal Mortality in 2005: Estimates Developed by WHO, UNICEF, UNFPA, and the World Bank. Geneva: World Health Organization; 2007.

36. Izugbara CO, Kabiru CW, Zulu EM. Urban Poor Kenyan Women and Hospital-Based Delivery. Public Health Reports. 2009;124(4):585-589.

37. Center for Reproductive Rights, Federation of Women Lawyers-Kenya. Failure to Deliver: Violations of Women's Human Rights in Kenyan Health Facilities. New York: Center for Reproductive Rights and Federation of Women Lawyers-Kenya; 2007.

38. Conde-Agudelo A, Belizan J, Lammers C. Maternal-perinatal morbidity and mortality associated with adolescent pregnancy in Latin America: Cross-sectional study. American Journal of Obstetrics and Gynecology. 2004;192(2):342-349.

39. Zabin LS, Kiragu K. The health consequences of adolescent sexual and fertility behavior in sub-Saharan Africa. Studies in Family Planning. 1998;29(2):210-232.

40. USAID. Technical Areas: Adolescent Maternal Health. Available at: http://transition. usaid.gov/our_work/global_health $/ \mathrm{mch} / \mathrm{mh} /$ techareas/adolescent.html. Accessed November 18, 2012.

41. Rungheim K, Gribble J. Improving the Reproductive Health of Sub-Saharan Africa's Youth: A Route to Achieve the Millennium Development Goals. Washington, DC: Population Reference Bureau; 2010.

42. United Nations Population Fund (UNFPA). State of the World's Population. New York: United Nations Population Fund; 2003.

43. Ministry of Health. National Guidelines for Provision of Youth-Friendly Services (YFS) in Kenya. Nairobi: Ministry of Health; 2005.

44. National Coordinating Agency for Population and Development (NCAPD), Ministry of Health (MOH), Central Bureau of Statistics (CBS), Macro O. Kenya Service Provision Assessment (KSPA) Survey 2004. Nairobi: NCAPD, MOH, CBS and ORC Macro; 2004.

45. Schueller J, Liku J, Hubbard G, Odede W, Shaban S, Njeri A. Assessment of Youth Reproductive Health and HIVIAIDS Programs in Kenya. Nairobi and Arlington: Family Health International; 2006.

46. Birungi $\mathrm{H}$, Mugisha JF, Obare F, Nyombi JK. Sexual behavior and desires among adolescents perinatally infected with Human Immunodeficiency Virus in Uganda: Implications for programming. Journal of Adolescent Health. 2009;44(2):184-187.

47. Obare F, van der Kwaak A, Adieri B, et al. HIV-positive adolescents in Kenya. Access to sexual and reproductive health services. Amsterdam: KIT Publishers; 2010.

48. Birungi H, Obare F, Namwebya HJ, Mohammed M, Gitau M, Makumi M. Sexual and Reproductive Health Needs of Adolescents living with HIV in Kenya. Nairobi: APHIA II OR Project in Kenya/ Population Council; 2011.

49. National Coordinating Agency for Population and Development, Division of Reproductive Health. Adolescent Reproductive Health and Development Policy. Nairobi: National Coordinating Agency for Population and Development (NCAPD) (Ministry of Planning and National Development, Kenya) and Division of Reproductive Health (Ministry of Health, Kenya); 2003. 
50. National Coordinating Agency for Population and Development (NCAPD), Kenya National Bureau of Statistics (KNBS). Kenya National Survey for Persons with Disabilities Main Report: Nairobi: NCAPD and KNBS; 2008.

51. National AIDS Control Council (NACC), Office of the President Kenya. UNGASS 2008 Country Report for Kenya. Nairobi: NACC; 2008.

52. Biemba G, Njoka J, Simon J, Costello J, Beard J, Brooks B. Kenya Research Situation Analysis on Orphans and Other Vulnerable Children. Country Brief. Boston and Nairobi: Center for Global Health and Development - Boston University and Institute for Development Studies - University of Nairobi; 2009.

53. UNHCR. Reproductive Health in Refugee Situations: An Inter-Agency Field Manual. Geneva: UNHCR; 1999.

54. Arnaldo C. Ethnicity and marriage patterns in Mozambique. African Population Studies. 2004;19(1):143-164.

55. Olungah CO. Culture and Reproductive Health: The Politics of Pregnancy and Childbirth among the Luo of Western Kenya. Saarbrücken: Lambert Academic Publishing; 2012.

56. Otieno JAM, Ocholla-Ayayo ABC. Marriage patterns in Kenya and their inter-relation with fertility. Paper presented at the African Population Conference, 1988; Dakar, Senegal.

57. Jolly C, Gribble J. The proximate determinants of fertility. In: Foote KA, Hill KH, Martin LG, eds. Demographic Change in Sub-Saharan Africa. Washington, DC: National Academy of Sciences; 1993.

58. Mosley WH, Werner LH, Becker S. The dynamics of birth-spacing and marital fertility in Kenya. World Fertility Survey Scientific Reports, No. 30. Voorburg: International Scientific Institute; 1982.

59. Odimegwu $\mathrm{CO}$, Zerai A. Understanding the proximate determinants of fertility of a Nigerian ethnic group. Genus. 1996;52(3-4):67-87.

60. Mensch B, ClarkWH, Lloyd CB, Erulkar AS. Premarital sex, schoolgirl pregnancy, and school quality in rural Kenya. Studies in Family Planning. 2001;32(4):285-301.

61. National Council for Population and Development (NCPD) Ministry of Home Affairs and National Heritage, Institute for Resource Development (IRD)/Macro Systems Inc. Kenya Demographic and Health Survey 1989. Nairobi, Kenya and Columbia, Maryland USA: NCPD and IRD/Macro Systems, Inc.; 1989.

62. Ezeh AC, Dodoo FNA. Institutional change and African fertility transition: the case of Kenya. Genus. 2001;57(3-4):53-73.

63. Caldwell JC, Caldwell P, Orubuloye IO. The family and sexual networking in subSaharan Africa: historical regional differences and present-day implications. Population Studies. 1992;46(3):385-410.

64. Hayase Y, Liaw K-L. Factors on polygamy in sub-Saharan Africa: findings based on the demographic and health surveys. The Developing Economies. 1997;35(3):293327.

65. Lesthaeghe R, Eelens $F$. The components of Sub-Saharan reproductive regimes and their social and cultural determinants: Empirical evidence. In: Lesthaeghe RJ, ed. Reproduction and Social Organization in Sub-Saharan Africa. Berkeley: University of California Press; 1989. 
66. Karanja WW. The phenomenon of 'Outside Wives': Some reflections on its possible influence on fertility. In: Bledsoe C, Pison G, eds. In Nuptiality in Sub-Saharan Africa: Contemporary Anthropological and Demographic Perspectives. Oxford: Clarendon Press; 1994.

67. Central Bureau of Statistics (Kenya), International Statistical Institute. Kenya World Fertility Survey 1978. Voorburg: International Statistical Institute; 1980.

68. Ezeh AC, Dodoo FNA. Institutional change and the African fertility transition: the case of Kenya. Nairobi, Kenya: African Population \& Health Research Center; 2002.

69. Harwood-Lejeune A. Rising age at marriage and fertility in southern and eastern Africa. European Journal of Population/Revue europenne de Demographie. 2001;17(3):261280.

70. Department for International Development (DFID). Improving Reproductive, Maternal and New born Health: Reducing Unwanted Pregnancies. Evidence Overview (Working Paper: Version 1.0); 2010.

71. Samandari G, Speizer IS, O'Connell K. The role of social support and parity on contraceptive use in Cambodia. International Perspectives on Sexual and Reproductive Health. 2010; 36(3): 122-131.

72. Ali MM, Cleland J, Shah IH. Causes and Consequences of Contraceptive Discontinuation: Evidence from 60 Demographic and Health Surveys. Geneva: World Health Organization; 2012.

73. Kazuyo Machiyama, Cleland J. Insights into Unmet Need in Kenya. London: London School of Hygiene and Tropical Medicine; 2013.

74. African Population and Health Research Center (APHRC), Ministry of Health (MOH), Ipas, Guttmacher Institute. Incidence and Complications of Unsafe Abortions in Kenya: Key Findings of a National Study. Nairobi: APHRC, MOH, Ipas, Guttmacher Institute; 2013.

75. African Union of the Blind. State of Disabled People's Rights in Kenya (2007) Report. Nairobi: Africa Union of the Blind; 2007.

76. Ministry of Health, National Council for Population and Development, ORC Macro. Kenya Service Provision Assessment Survey 1999. Calverton: Ministry of Health, National Council for Population and Development, and ORC Macro; 2000.

77. National Coordinating Agency for Population and Development (NCAPD), Ministry of Medical Services (MOMS), Ministry of Public Health and Sanitation (MOPHS), Kenya National Bureau of Statistics (KNBS), ICF Macro. Kenya Service Provision Assessment Survey 2010. Nairobi: NCAPD, MOMS, MOPHS, KNBS, and ICF Macro; 2011.

78. Chege J, Askew I. AnAssessment of Community-Based Family Planning Programmes in Kenya. Africa Operations Research Technical Assistance. Nairobi: The Population Council; 1997.

79. Ndhlovu L. Quality of care in family planning service delivery in Kenya: Clients' and providers' perspectives. Nairobi: The Population Council's Africa OR/TA Project; 1995.

80. Solo J, Billings DL, Aloo-Obunga C, Ominde A, Makumi M. Creating linkages between incomplete abortion treatment and family planning services in Kenya. In: Huntington D, Piet-Pelon NJ, eds. Postabortion Care: Lessons from Operations Research. New York: Population Council; 1999:38-60. 
81. Ministry of Medical Services. Standards and guidelines for reducing morbidity \& mortality from unsafe abortion in Kenya. Nairobi: Ministry of Medical Services; 2012.

82. Winikoff $B$, Sheldon $W$. Use of medicines changing the face of abortion. International Perspectives on Sexual and Reproductive Health. 2012;38(3):164-166.

83. World Health Organization. Safe Abortion: Technical and Policy Guidance for Health Systems. Geneva: World Health Organization; 2003.

84. Ong'ech J, Osur J, Makanyengo M, Mathai M, Gebreselassie H, Brookman-Amissah E. The Status of Misoprostol Use in Kenya. Nairobi: Ipas Africa Alliance and the National Health and Development Organization (NAHEDO); 2008.

85. Ipas. In Kenya, use of misoprostol for postabortion care gains momentum. Ipas. Available at: http://www.ipas.org/News/Newsletter-Articles/misoprostol-for-PAC-inKenya.aspx. Accessed March 22, 2013.

86. Crichton J. Changing fortunes: analysis of fluctuating policy space for family planning in Kenya. Health Policy and Planning. 2008;23(5):339-350.

87. Ministry of Economic Planning and Development. Family Planning in Kenya. A Report submitted to the Government of the Republic of Kenya by an Advisory Mission of the Population Council of the United States of America. Nairobi: Ministry of Economic Planning and Development; 1967.

88. Aloo-Obunga C. Country Analysis of Family Planning and HIVIAIDS: Kenya. Washington, DC: POLICY Project; 2003.

89. National Council for Population and Development (NCPD). Family Planning Achievements and Challenges. Nairobi: NCPD, Ministry of National Planning and Development, Division of Reproductive Health, Ministry of Health, Government of Kenya, Family Planning Association of Kenya and the POLICY Project.; 2003.

90. Miller K, Miller R, Askew I, Horn MC, Ndhlovu L. Clinic-Based Family and Reproductive Health Services in Africa: Finding from Situational Analysis Studies. New York: Population Council; 1998.

91. Extending Service Delivery Project. A Description of the Private Nurse Midwives Networks (Clusters) in Kenya: A Best Practice Model. Washington DC: Extending Service Delivery Project; 2007.

92. Foreit J, Raifman S. Increasing Access to Family Planning (FP) and Reproductive Health $(R H)$ Services through Task-sharing between Community Health Workers (CHWs) and Community midlevel Professionals in Large-scale Public-sector Programs: A Literature Review to Help Guide Case Studies. New York: Population Council; 2011.

93. Lewis GL, Keyonzo NA, Mott P. Community-based family planning services: Insights from the Kenyan experience. Paper presented at the Annual Meeting of the Population Association of America, Denver; 1992.

94. Toroitich-Ruto $\mathrm{C}$. The evolution of the family planning programme and its role in influencing fertility change in Kenya. Journal of Biosocial Science. 2011;33(2):245260.

95. Pathfinder International. Community Based Family Planning in Kenya: Meeting New Challenges. Watertown: Pathfinder International; 2005.

96. Division of Reproductive Health, National Council for Population and Development, Population Council. CBD Policy Guidelines Workshop Report Silver Springs Hotel, Nairobi, 12-15 August, 1990 (Unpublished Report) 1991. 
97. Olawo AA, Bashir I, Solomon M, Ndugga B, Isaac M. A cup of tea with our CBD agent. Community provision of injectables contraceptives in Kenya is safe and feasible. Global Health Science and Practice. 2013. doi: 10.9745/GHSP-D-13-00040

98. Arur A, Gitonga N, O'Hanlon B, Kundu F, Senkaali M, Ssemujju R. Insights from Innovations: Lessons from Designing and Implementing Family Planning/ Reproductive Health Voucher Programs in Kenya and Uganda. Bethesda: Private Sector Partnerships - One project, Abt Associates Inc,. 2009.

99. Tunza Health Network/ PSI/ Kenya. Clinical Social Franchising: Case Study Series: Nairobi: PSI Kenya; 2010.

100.The Global Health Group. Clinical Social Franchising Compendium: An Annual Survey of Programs, 2012. San Francisco: The Global Health Group: University of California, San Francisco.; 2012.

101.Family Health International. Expanding commercial sector participation in family planning. Issues in the financing of family planning services in sub-Saharan Africa. Policy Brief No. 3. Research Triangle Park, NC: Family Health International; 1999.

102.Barnes J, O'Hanlon B, III FF, McKeon K, Gitonga N, Decker C. Private Health Sector Assessment in Kenya. World Bank Working Paper No. 193. Washington DC: The International Bank for Reconstruction and Development/The World Bank; 2010.

103. Briscombe B, Sharma S, Saunders M. Improving Resource Allocation in Kenya's Public Health Sector. Washington, DC: Futures Group, Health Policy Initiative, Task Order 1.; 2010.

104. The POLICY Project. Core Package Final Report: Improving Access to Family Planning Services in Public Sector Facilities for Poor/Underserved Populations in Kenya. Washington, DC: The POLICY Project; 2005.

105.Cieza N, Holm F. Estimated government spending 2009/2010 Kenyan health sector - budget analysis. Available at: http://www.marsgroupkenya.org/pdfs/2010/04/Kenya_ Govt_Health_Sector_Budget_Analysis_19.09.2009_GTZ_Kenya_Health_Sector_ Programme.pdf\#7404. Accessed November 26, 2012.

106. Nyakundi CK, Teti C, Akimala H, et al. Health Financing in Kenya: The Case of RH/FP. Nairobi: German Foundation for World Population (DSW) and Institute For Education In Democracy (IED); 2011.

107.Netherlands Interdiscliplinary Demographic Institute (NIDI), African Population and Health Research Center (APHRC). Reproductive Health and Family Planning Financing in Kenya. A Mapping of Resource Flows. Available at: http://resourceflows. org/sites/default/files/SRH\%20Mapping\%20Report_Kenya.pdf. Accessed March 21, 2013.

108. Ministry of Health (MOH), National AIDS Control Council (NACC). National Condom Policy and Strategy, 2001-2005. Nairobi: National AIDS \& STI Control Programme (NASCOP); 2001.

109. International Development Association. A Review of the Use of Output-Based Aid Approaches. Washington, DC: International Development Association, Global Partnership on Output-Based Aid (GPOBA), Finance, Economics and Urban Department; 2009. 
110. The World Bank, GAVI Alliance. Brief 19: Innovative Financing - Results Based Financing. Available at: http://www.who.int/immunization_financing/tools/Brief_19_ Results_Based_Financing.pdf.

111. Warren C, Abuya T, Obare F, et al. Evaluation of the impact of the voucher and accreditation approach on improving reproductive health behaviors and status in Kenya. BMC Public Health. 2011;11:177. doi:10.1186/1471-2458-11-177

112. Bellows N. Vouchers for Reproductive Health Care services in Kenya and Uganda: Approaches supported by Financial Cooperation. Discussion Paper. Frankfurt: KfW Bank Group; 2012.

113. Armstrong S. Vouchers: Making Motherhood Safer for Kenya's Poorest women. Bonn and Eschborn: Deutsche Gesellschaft für, Internationale Zusammenarbeit (GIZ) $\mathrm{GmbH} ; 2012$.

114. Bellows NM, Bellows BW, Warren C. Systematic review: The use of vouchers for reproductive health services in developing countries. Tropical Medicine \& International Health. 2011;16(1):84-96.

115. Obare F, Warren C, Njuki R, et al. Community-level impact of the reproductive health vouchers programme on service utilization in Kenya. Health Policy and Planning 2013;28(2):165-175.

116. Chuma J, Okungu V. Viewing the Kenyan health system through an equity lens: implications for universal coverage. International Journal for Equity in Health. 2011;10(1):22.

117. Tsui A, Creanga AA. Does contraceptive use reduce neonatal and infant mortality? Findings from a multi-country analysis. Paper presented at the Annual Meeting of the Population Association of America, Detroit, Michigan; 2009.

118. Ahmed S, Li Q, Liu L, Tsui AO. Maternal deaths averted by contraceptive use: an analysis of 172 countries. The Lancet. 2012;380(9837):111-125. 


\section{Appendix: Chapter Three Tables}

Table A1: Percentage of currently married and sexually active unmarried women aged 15-49 who knew specific contraceptive methods, KDHS 1993, 1998, 2003, $2008 / 09$

\begin{tabular}{|l|c|c|c|c|c|c|c|c|c|c|c|c|}
\hline & \multicolumn{9}{|c|}{ Currently Married } & \multicolumn{7}{c|}{ Sexually Active Unmarried } & \multicolumn{7}{c|}{ All Women } \\
\cline { 2 - 17 } & 93 & 998 & 03 & $08 / 09$ & 993 & 998 & 03 & $08 / 09$ & 93 & 998 & $\circ 03$ & $08 / 09$ \\
\hline Method & $\%$ & $\%$ & $\%$ & $\%$ & $\%$ & $\%$ & $\%$ & $\%$ & $\%$ & $\%$ & $\%$ & $\%$ \\
\hline Any Method & 97.2 & 98.3 & 95.5 & 96.4 & 97.4 & 99.3 & 99.2 & 97.6 & 95.6 & 96.8 & 94.6 & 94.6 \\
\hline $\begin{array}{l}\text { Any Modern } \\
\text { Method }\end{array}$ & 96.9 & 97.7 & 95.3 & 96.2 & 96.8 & 99.1 & 99.2 & 97.6 & 95.2 & 96.3 & 94.4 & 94.5 \\
\hline $\begin{array}{l}\text { Traditional } \\
\text { Method }\end{array}$ & 75.9 & 78.1 & 76.3 & 74.3 & 76.5 & 78.2 & 71.4 & 69.2 & 71.9 & 72.6 & 70.0 & 68.5 \\
\hline N & 4,629 & 4,834 & 4,919 & 4,928 & 452 & 434 & 267 & 318 & 7,540 & 7,881 & 8,195 & 8,444 \\
\hline
\end{tabular}

Table A2: Percentage of all women, currently married women, and sexually active unmarried women aged 15-49 who knew a contraceptive method, KDHS 2008/2009

\begin{tabular}{|l|c|c|c|}
\hline \multirow{2}{*}{ Method } & All Women & $\begin{array}{c}\text { Currently Married } \\
\text { Women }\end{array}$ & $\begin{array}{c}\text { Sexually Active } \\
\text { Unmarried Women }\end{array}$ \\
\cline { 2 - 4 } Any Method & $\%$ & $\%$ & $\%$ \\
\hline Any Modern Method & 94.6 & 96.4 & 97.6 \\
\hline Female Sterilization & 94.5 & 96.2 & 97.6 \\
\hline Male Sterilization & 66.8 & 73.9 & 63.3 \\
\hline Pill & 38.1 & 41.6 & 40.0 \\
\hline IUD & 87.9 & 92.8 & 86.6 \\
\hline Injectables & 61.1 & 70.1 & 62.5 \\
\hline Implants & 88.5 & 93.9 & 89.6 \\
\hline Male Condom & 67.2 & 76.9 & 67.7 \\
\hline Any Traditional Method & 89.2 & 90.1 & 95.8 \\
\hline Rhythm & 68.5 & 74.3 & 69.2 \\
\hline Withdrawal & 61.5 & 67.1 & 60.4 \\
\hline Other/Folk Methods & 47.6 & 53.4 & 54.6 \\
\hline Total number of women & 8.8 & 8.3 & 5.3 \\
\hline
\end{tabular}




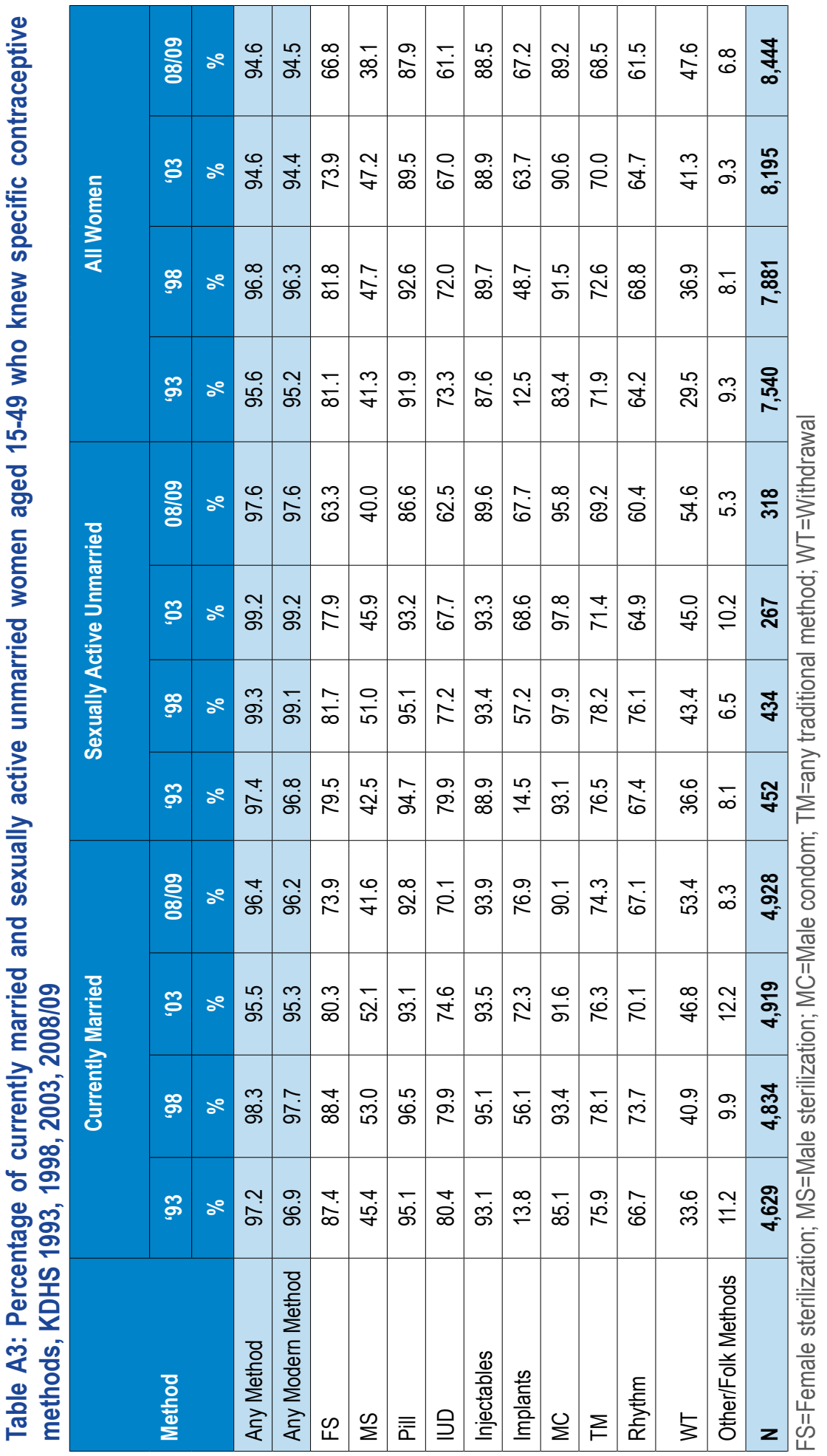


Table A4: Percentage of all women 15-49 who knew specific contraceptive methods by background characteristics, Kenya KDHS 1993, 1998, 2003, 2008/09

\begin{tabular}{|c|c|c|c|c|c|c|c|c|c|c|c|c|}
\hline \multirow{3}{*}{$\begin{array}{l}\text { Background } \\
\text { Characteristics }\end{array}$} & \multicolumn{3}{|c|}{1993} & \multicolumn{3}{|c|}{1998} & \multicolumn{3}{|c|}{2003} & \multicolumn{3}{|c|}{$2008 / 09$} \\
\hline & AM & МM & TM & AM & MM & TM & AM & MM & TM & AM & MM & TM \\
\hline & $\%$ & $\%$ & $\%$ & $\%$ & $\%$ & $\%$ & $\%$ & $\%$ & $\%$ & $\%$ & $\%$ & $\%$ \\
\hline \multicolumn{13}{|l|}{ Age } \\
\hline $15-24$ & 98.0 & 97.3 & 0.7 & 97.4 & 96.3 & 1.2 & 94.7 & 94.6 & 0.1 & 94.2 & 93.7 & 0.5 \\
\hline $25-34$ & 98.2 & 97.9 & 0.3 & 98.5 & 97.9 & 0.7 & 95.4 & 95.4 & 0.1 & 97.4 & 97.3 & 0.2 \\
\hline$>35$ & 95.0 & 94.6 & 0.4 & 98.3 & 97.9 & 0.4 & 95.7 & 95.3 & 0.4 & 95.8 & 95.7 & 0.2 \\
\hline \multicolumn{13}{|l|}{ Education } \\
\hline No Education & 91.5 & 90.3 & 1.2 & 94.3 & 91.5 & 2.8 & 73.9 & 72.8 & 1.1 & 76.9 & 75.6 & 1.3 \\
\hline Primary Education & 98.6 & 98.4 & 0.2 & 98.6 & 98.3 & 0.3 & 99.2 & 99.1 & 0.1 & 98.5 & 98.5 & 0.0 \\
\hline Secondary + & 99.8 & 99.8 & 0.0 & 99.7 & 99.6 & 0.1 & 100.0 & 100.0 & 0.0 & 99.7 & 99.7 & 0.0 \\
\hline \multicolumn{13}{|l|}{ Wealth } \\
\hline Low & 94.8 & 94.1 & 0.7 & 97.4 & 96.3 & 1.1 & 90.2 & 89.9 & 0.3 & 92.2 & 91.7 & 0.5 \\
\hline Medium & 98.3 & 98.0 & 0.3 & 99.0 & 98.5 & 0.5 & 97.9 & 97.5 & 0.4 & 98.8 & 98.7 & 0.1 \\
\hline High & 99.2 & 99.1 & 0.1 & 98.9 & 98.8 & 0.1 & 99.3 & 99.3 & 0.0 & 98.7 & 98.7 & 0.0 \\
\hline \multicolumn{13}{|l|}{ Marital Status } \\
\hline Never married & 92.5 & 92.1 & 0.4 & 92.5 & 92.3 & 0.3 & 91.2 & 91.0 & 0.1 & 88.5 & 88.5 & 0.0 \\
\hline Currently married & 97.8 & 97.6 & 0.2 & 98.1 & 97.7 & 0.4 & 92.4 & 92.1 & 0.2 & 92.5 & 92.4 & 0.1 \\
\hline Formerly married & 97.3 & 97.0 & 0.3 & 98.0 & 97.7 & 0.3 & 95.2 & 95.1 & 0.1 & 95.5 & 95.5 & 0.0 \\
\hline \multicolumn{13}{|l|}{ Residence } \\
\hline Urban & 98.5 & 98.3 & 0.2 & 98.5 & 98.5 & 0.0 & 98.5 & 98.5 & 0.0 & 98.3 & 98.3 & 0.0 \\
\hline Rural & 97.0 & 96.6 & 0.4 & 98.2 & 97.5 & 0.7 & 94.6 & 94.4 & 0.2 & 95.8 & 95.6 & 0.2 \\
\hline \multicolumn{13}{|l|}{ Province } \\
\hline Nairobi & 96.9 & 96.4 & 0.5 & 99.5 & 99.5 & 0.0 & 99.4 & 99.4 & 0.0 & 97.0 & 97.0 & 0.0 \\
\hline Central & 99.8 & 99.8 & 0.0 & 99.0 & 98.9 & 0.1 & 100.0 & 100.0 & 0.0 & 99.5 & 99.3 & 0.2 \\
\hline Coast & 94.6 & 93.7 & 0.9 & 96.0 & 96.0 & 0.0 & 95.0 & 95.0 & 0.0 & 99.2 & 99.2 & 0.0 \\
\hline Eastern & 99.0 & 99.0 & 0.0 & 99.8 & 99.5 & 0.3 & 88.7 & 88.7 & 0.0 & 90.0 & 90.0 & 0.0 \\
\hline Nyanza & 99.1 & 99.1 & 0.0 & 99.6 & 99.4 & 0.2 & 99.9 & 99.9 & 0.0 & 99.3 & 99.3 & 0.0 \\
\hline Rift Valley & 92.9 & 92.1 & 0.8 & 95.2 & 92.9 & 2.3 & 92.2 & 91.5 & 0.7 & 96.1 & 95.5 & 0.6 \\
\hline Western & 98.6 & 98.2 & 0.4 & 99.8 & 99.8 & 0.0 & 99.3 & 99.3 & 0.0 & 98.9 & 98.9 & 0.0 \\
\hline North Eastern & - & - & - & - & - & - & - & - & - & - & - & - \\
\hline Total & 97.2 & 96.9 & 0.3 & 98.3 & 97.7 & 0.6 & 95.5 & 95.3 & 0.2 & 96.4 & 96.2 & 0.2 \\
\hline
\end{tabular}


Table A5: Percentage of currently married and sexually active unmarried women who approved of family planning, by selected background characteristics, KDHS 1993, 1998, 2003

\begin{tabular}{|l|c|c|c|c|c|c|}
\hline \multirow{2}{*}{} & \multicolumn{5}{|c|}{ Currently Married Women } & \multicolumn{3}{c}{ Sexually Active Unmarried Women } \\
\cline { 2 - 7 } & 1993 & 1998 & 2003 & 1993 & 1998 & 2003 \\
\hline Age & & & & & & \\
\hline $15-24$ & 91.8 & 87.2 & 75.7 & 93.8 & 88.9 & 89.5 \\
\hline $25-34$ & 92.4 & 90.7 & 80.9 & 90.0 & 91.2 & 94.4 \\
\hline$>35$ & 87.1 & 85.6 & 78.2 & 88.9 & 63.6 & 80.0 \\
\hline Education & & & & & & \\
\hline No Education & 80.6 & 74.3 & 37.3 & 84.6 & 50.0 & $*$ \\
\hline Primary Education & 92.2 & 89.1 & 85.9 & 92.3 & 86.1 & 86.3 \\
\hline Secondary & 96.5 & 94.1 & 93.7 & 95.3 & 95.1 & 95.7 \\
\hline Wealth & & & & & & \\
\hline Low & 84.7 & 85.5 & 72.4 & 83.3 & 88.4 & 86.1 \\
\hline Medium & 92.3 & 88.9 & 85.8 & 96.2 & 86.0 & 84.2 \\
\hline High & 93.2 & 90.9 & 89.9 & 94.0 & 93.0 & 93.4 \\
\hline Residence & & & & & & \\
\hline Urban & 92.8 & 83.0 & 84.0 & 94.5 & 94.3 & 92.5 \\
\hline Rural & 90.1 & 89.0 & 76.4 & 92.4 & 86.0 & 87.3 \\
\hline Province & & & & & & \\
\hline Nairobi & 92.3 & 90.0 & 89.6 & 94.1 & 92.0 & 90.7 \\
\hline Central & 94.0 & 94.0 & 92.9 & 96.1 & 93.9 & 96.2 \\
\hline Coast & 83.2 & 75.0 & 71.6 & 91.9 & 81.6 & 93.8 \\
\hline Eastern & 92.3 & 92.9 & 85.0 & 93.2 & 91.9 & 91.7 \\
\hline Nyanza & 90.2 & 92.7 & 87.3 & 90.8 & 92.3 & 75.0 \\
\hline Rift Valley & 89.0 & 84.6 & 75.1 & 93.2 & 83.9 & 93.3 \\
\hline Western & 95.2 & 93.3 & 87.7 & 91.7 & 91.7 & 81.8 \\
\hline North Eastern & - & - & 3.1 & - & - & - \\
\hline Total & 89.7 & 88.2 & 82.0 & 92.2 & 89.7 & 89.1 \\
\hline Wumber of & 4844 & 4876 & 478 & 424 & 273 \\
\hline Women & & & & & \\
\hline
\end{tabular}

An asterisk indicates that a figure is based on fewer than 25 unweighted cases and has been suppressed; a hyphen indicates that data are unavailable; data unavailable for 2008/09 
Table A6: Percentage distribution of currently married women age 15-49 who were using a method and had reported to their husband/partner, by background characteristics, KDHS 2008/09

\begin{tabular}{|c|c|c|c|c|}
\hline \multirow[t]{2}{*}{ Background Characteristics } & Knows & Does not Know & $\begin{array}{l}\text { Unsure } \\
\text { Whether } \\
\text { Knows }\end{array}$ & N \\
\hline & $\%$ & $\%$ & $\%$ & \\
\hline \multicolumn{5}{|l|}{ Age } \\
\hline $15-24$ & 84.1 & 14.9 & 1.1 & 390 \\
\hline $25-34$ & 90.0 & 7.3 & 2.8 & 1021 \\
\hline$>35$ & 88.7 & 9.7 & 1.6 & 830 \\
\hline \multicolumn{5}{|l|}{ Education } \\
\hline No Education & 75.6 & 14.4 & 10.0 & 80 \\
\hline Primary Education & 86.4 & 11.5 & 2.1 & 1272 \\
\hline Secondary + & 93.9 & 4.7 & 1.4 & 890 \\
\hline \multicolumn{5}{|l|}{ Wealth } \\
\hline Low & 82.7 & 14.1 & 3.3 & 529 \\
\hline Medium & 92.3 & 6.1 & 1.7 & 1238 \\
\hline High & 87.7 & 10.6 & 1.7 & 474 \\
\hline \multicolumn{5}{|l|}{ Place of residence } \\
\hline Urban & 92.1 & 5.6 & 2.3 & 613 \\
\hline Rural & 88.1 & 9.9 & 2.0 & 1,628 \\
\hline \multicolumn{5}{|l|}{ Province } \\
\hline Nairobi & 92.6 & 4.6 & 2.8 & 201 \\
\hline Central & 92.6 & 6.1 & 1.3 & 357 \\
\hline Coast & 90.7 & 6.2 & 3.1 & 146 \\
\hline Eastern & 93.8 & 5.4 & 0.8 & 439 \\
\hline Nyanza & 81.0 & 16.2 & 2.8 & 310 \\
\hline Rift Valley & 87.8 & 9.7 & 2.5 & 542 \\
\hline Western & 86.0 & 11.6 & 2.4 & 241 \\
\hline North Eastern & * & * & * & 4 \\
\hline Total & 89.2 & 8.7 & 2.1 & 2,241 \\
\hline
\end{tabular}

Note: An asterisk denotes a figure based on fewer than 25 unweighted cases that has been suppressed. 


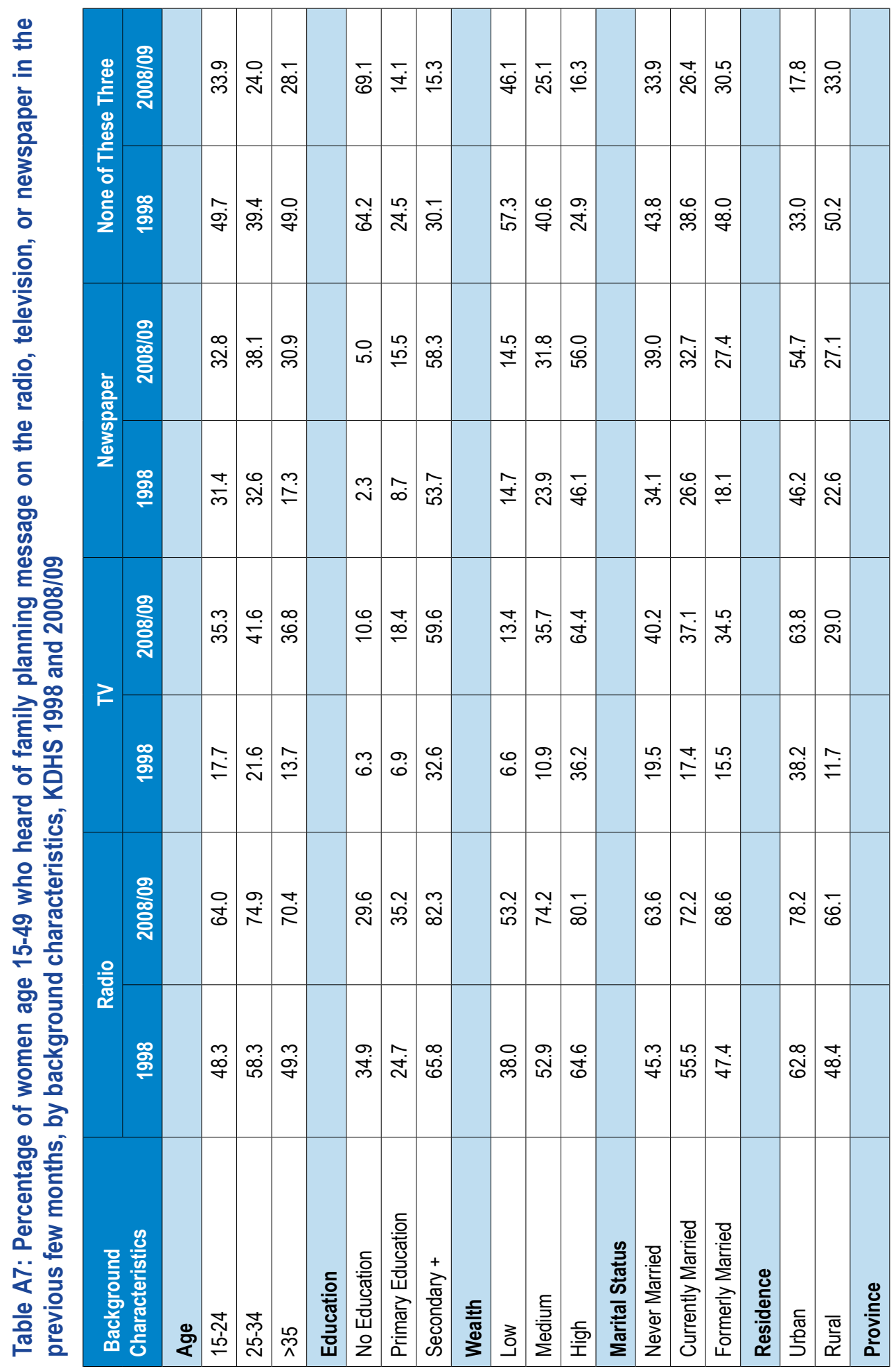




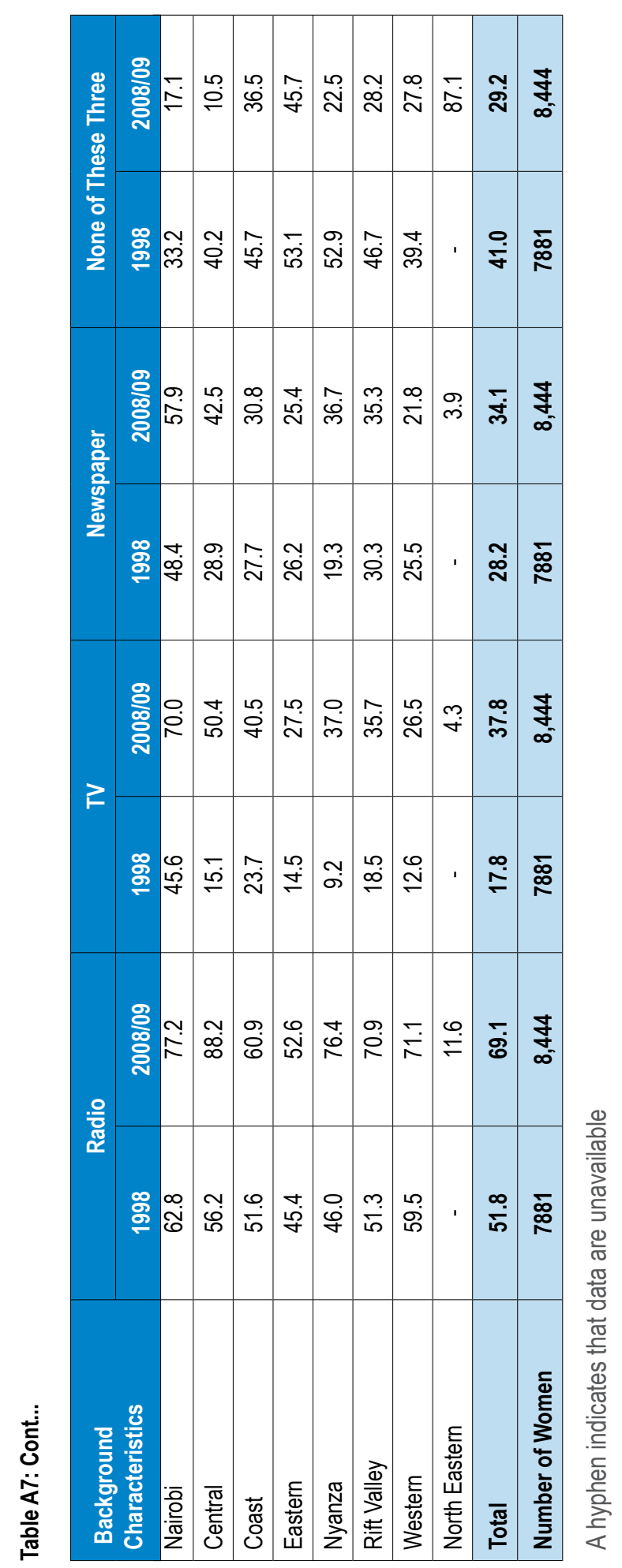




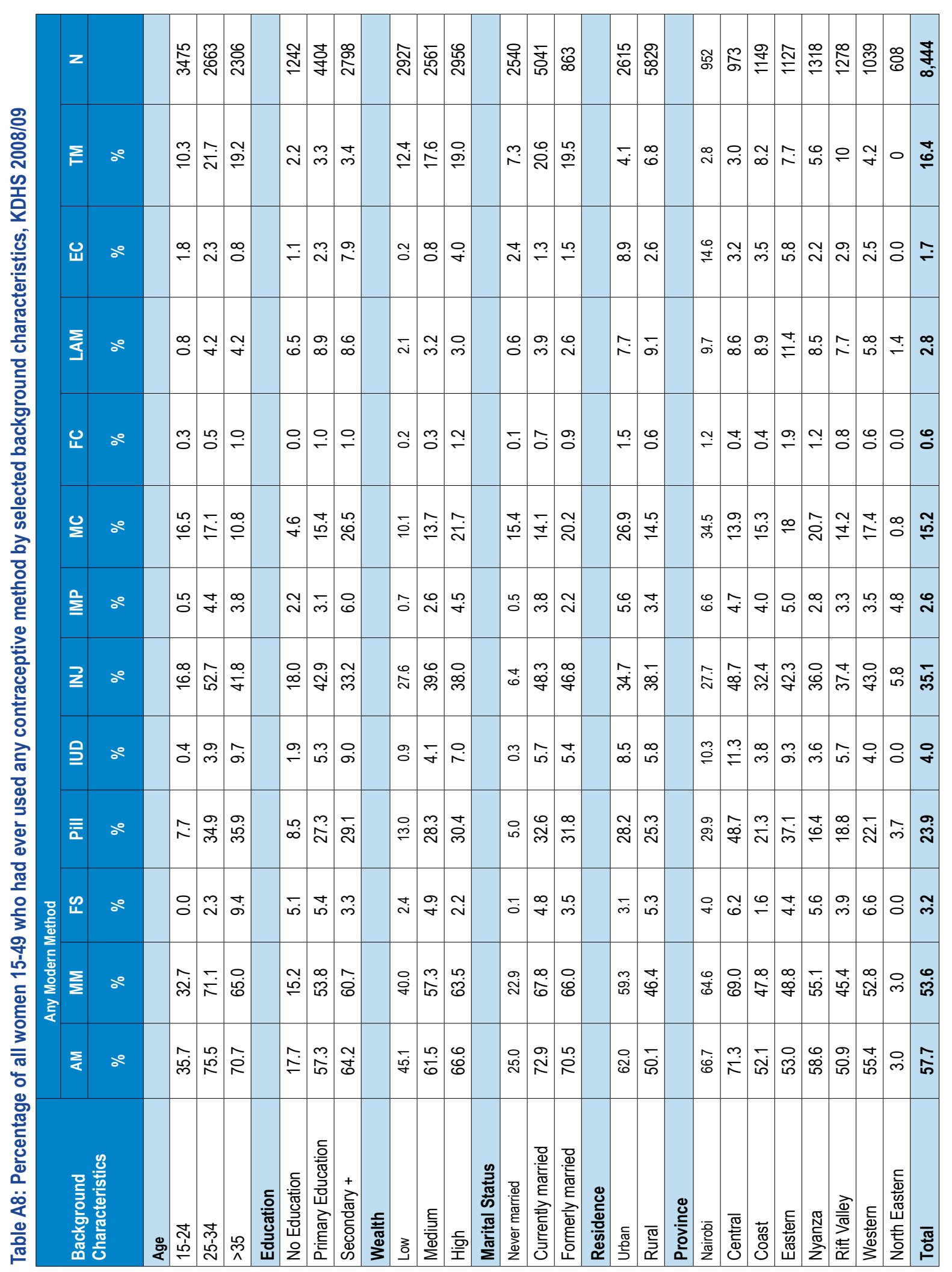




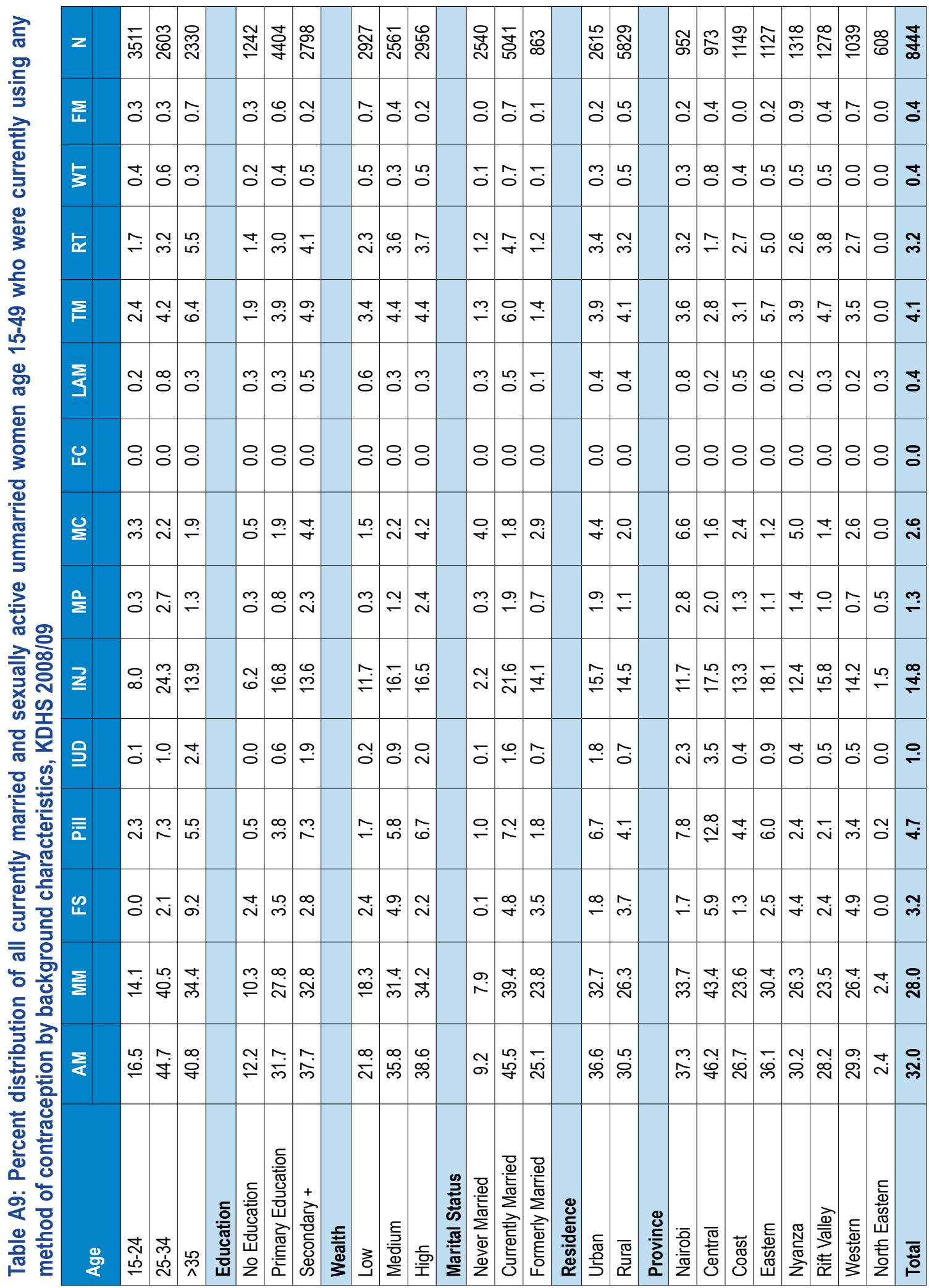




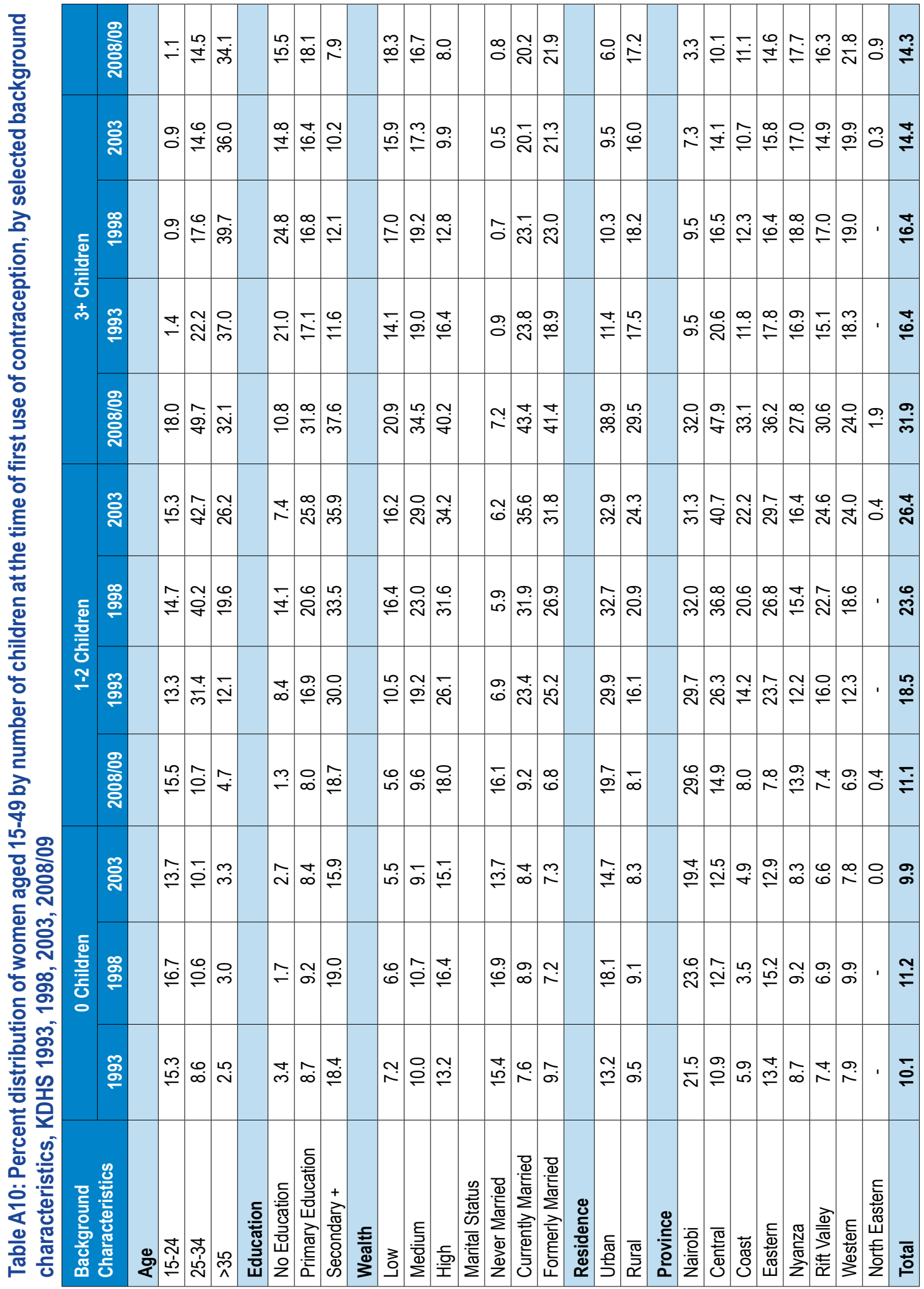




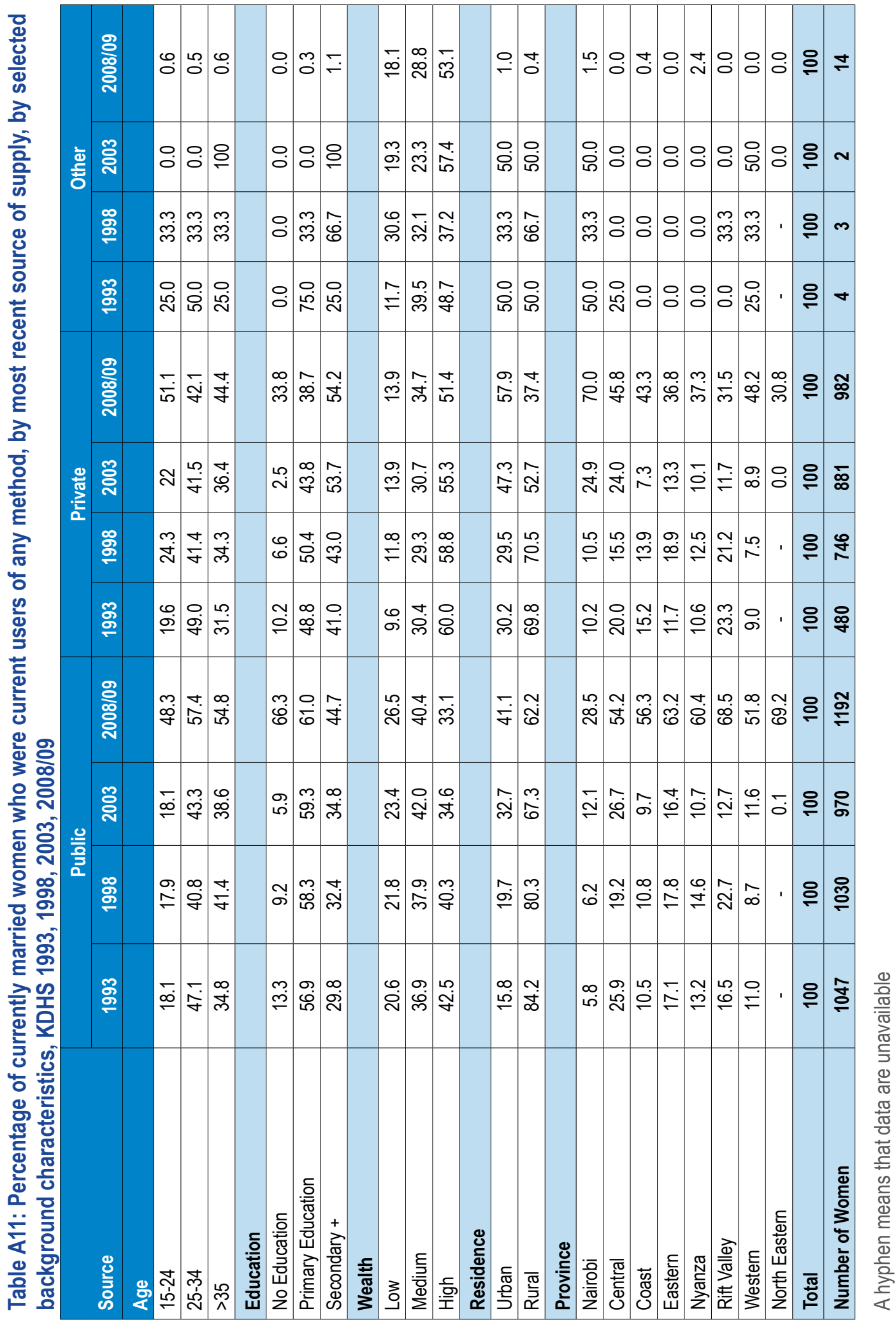


Table A12: Percentage distribution of currently married aged 15-49 by intention to use contraception in future, according to selected background characteristics, KDHS 1993, 1998, 2003, 2008/09

\begin{tabular}{|c|c|c|c|c|c|c|c|c|c|c|c|c|}
\hline \multicolumn{13}{|c|}{ Contraceptive Use Intention } \\
\hline \multirow{2}{*}{$\begin{array}{l}\text { Background } \\
\text { Characteristics }\end{array}$} & \multicolumn{4}{|c|}{ Intend to use } & \multicolumn{4}{|c|}{ Does not intend to use } & \multicolumn{4}{|c|}{ Unsure/ Missing } \\
\hline & 1993 & 1998 & 2003 & $2008 / 09$ & 1993 & 1998 & 2003 & $2008 / 09$ & 1993 & 1998 & 2003 & $2008 / 09$ \\
\hline \multicolumn{13}{|l|}{ Age } \\
\hline $15-24$ & 68.5 & 78.0 & 69.6 & 67.1 & 18.8 & 16.1 & 26.6 & 27.8 & 12.6 & 6.0 & 3.8 & 5.1 \\
\hline $25-34$ & 63.1 & 72.9 & 66.7 & 66.2 & 25.0 & 22.6 & 27.7 & 29.9 & 11.9 & 4.5 & 5.6 & 3.9 \\
\hline$>35$ & 33.2 & 36.0 & 34.1 & 31.0 & 59.1 & 60.8 & 62.5 & 63.9 & 7.7 & 3.2 & 3.4 & 5.1 \\
\hline \multicolumn{13}{|l|}{ Education } \\
\hline No Education & 35.3 & 35.5 & 26.2 & 24.7 & 52.2 & 58.5 & 66.5 & 69.2 & 12.4 & 6.0 & 7.3 & 6.1 \\
\hline $\begin{array}{l}\text { Primary } \\
\text { Education }\end{array}$ & 60.7 & 66.5 & 65.9 & 60.9 & 28.8 & 28.9 & 30.3 & 34.2 & 10.5 & 4.5 & 3.8 & 4.8 \\
\hline Secondary + & 71.7 & 73.0 & 70.8 & 63.5 & 19.5 & 23.8 & 26.9 & 33.5 & 8.7 & 3.3 & 2.2 & 3.0 \\
\hline \multicolumn{13}{|l|}{ Wealth } \\
\hline Low & 53.4 & 63.4 & 52.2 & 50.3 & 33.5 & 31.3 & 42.4 & 44.3 & 13.1 & 5.3 & 5.4 & 5.3 \\
\hline Medium & 58.5 & 59.2 & 60.9 & 58.4 & 33.3 & 37.2 & 35.3 & 37.3 & 8.2 & 3.6 & 3.7 & 4.4 \\
\hline High & 55.3 & 64.0 & 64.9 & 59.2 & 35.2 & 31.7 & 32.0 & 37.1 & 9.5 & 4.3 & 3.1 & 3.8 \\
\hline \multicolumn{13}{|l|}{ Residence } \\
\hline Urban & 54.0 & 62.4 & 60.3 & 58.9 & 32.6 & 34.6 & 36.7 & 38.2 & 13.4 & 3.1 & 3.0 & 2.9 \\
\hline Rural & 55.6 & 62.2 & 57.2 & 54.0 & 34.0 & 33.0 & 38.1 & 40.9 & 10.4 & 4.8 & 4.7 & 5.1 \\
\hline \multicolumn{13}{|l|}{ Province } \\
\hline Nairobi & 57.9 & 73.2 & 62.0 & 52.6 & 30.8 & 25.8 & 35.7 & 44.4 & 11.2 & 1.0 & 2.4 & 3.1 \\
\hline Central & 48.0 & 55.8 & 67.2 & 58.6 & 50.5 & 36.7 & 29.1 & 37.3 & 1.5 & 7.5 & 3.7 & 4.1 \\
\hline Coast & 31.8 & 47.2 & 41.0 & 46.2 & 42.7 & 44.3 & 49.1 & 47.6 & 25.5 & 8.5 & 9.9 & 6.1 \\
\hline Eastern & 63.2 & 72.2 & 62.3 & 62.2 & 30.0 & 26.5 & 32.4 & 32.4 & 6.8 & 1.3 & 5.4 & 5.4 \\
\hline Nyanza & 64.0 & 65.2 & 64.0 & 67.8 & 30.3 & 30.5 & 34.1 & 28.7 & 5.8 & 4.2 & 1.9 & 3.5 \\
\hline Rift Valley & 49.8 & 57.3 & 57.9 & 53.2 & 35.8 & 36.2 & 37.1 & 41.5 & 14.4 & 6.4 & 5.0 & 5.3 \\
\hline Western & 64.9 & 62.8 & 69.0 & 56.3 & 25.1 & 34.5 & 28.5 & 40.2 & 10.0 & 2.8 & 2.5 & 3.5 \\
\hline North Eastern & - & - & 0.6 & 3.5 & - & - & 95.0 & 91.4 & - & - & 4.4 & 5.1 \\
\hline \multicolumn{13}{|c|}{ Number of Living Children } \\
\hline 0 & 40.0 & 54.7 & 45.4 & 54.7 & 41.5 & 36.7 & 47.7 & 37.8 & 18.6 & 8.6 & 6.9 & 7.6 \\
\hline 1 & 58.0 & 70.1 & 61.5 & 64.0 & 29.6 & 24.4 & 35.0 & 31.1 & 12.4 & 5.5 & 3.6 & 4.9 \\
\hline 2 & 59.0 & 68.7 & 70.2 & 55.5 & 29.3 & 27.0 & 25.7 & 41.3 & 11.7 & 4.3 & 4.1 & 3.2 \\
\hline 3 & 59.0 & 65.7 & 62.8 & 61.4 & 30.4 & 28.7 & 33.4 & 34.9 & 10.6 & 5.7 & 3.9 & 3.8 \\
\hline $4+$ & 54.8 & 56.7 & 51.1 & 49.0 & 36.2 & 40.0 & 44.4 & 45.8 & 9.0 & 3.2 & 4.5 & 5.2 \\
\hline Total & 55.4 & 62.2 & 57.8 & 55.0 & 33.8 & 33.3 & 37.9 & 40.4 & 10.8 & 4.5 & 4.3 & 4.7 \\
\hline
\end{tabular}

A hyphen means that data are unavailable 
Table A13: Trends in unmet need for family planning among currently married women aged 15-49, KDHS 1993, 1998, 2003, 2008/09

\begin{tabular}{|c|c|c|c|c|c|c|c|c|c|c|c|c|}
\hline \multirow{2}{*}{$\begin{array}{l}\text { Background } \\
\text { Characteristics }\end{array}$} & \multicolumn{3}{|c|}{1993} & \multicolumn{3}{|c|}{1998} & \multicolumn{3}{|c|}{2003} & \multicolumn{3}{|c|}{$2008 / 09$} \\
\hline & SP & LIM & Total & SP & LIM & Total & SP & LIM & Total & SP & LIM & Total \\
\hline \multicolumn{13}{|l|}{ Age } \\
\hline $15-24$ & 34.3 & 5.1 & 39.4 & 27.2 & 4.5 & 31.7 & 28.3 & 5.6 & 33.9 & 23.8 & 6.5 & 30.3 \\
\hline $25-34$ & 23.4 & 14.4 & 37.8 & 18.8 & 11.0 & 29.8 & 15.8 & 11.7 & 27.5 & 13.7 & 11.1 & 24.8 \\
\hline$>35$ & 6.6 & 22.3 & 28.9 & 5.0 & 18.4 & 23.4 & 4.4 & 17.9 & 22.3 & 3.4 & 20.1 & 23.5 \\
\hline \multicolumn{13}{|l|}{ Education } \\
\hline No Education & 16.5 & 18.7 & 35.2 & 10.7 & 18.2 & 28.9 & 11.3 & 12.6 & 23.9 & 16.5 & 10.0 & 26.5 \\
\hline Primary & 23.9 & 14.8 & 38.7 & 19.3 & 12.8 & 32.1 & 18.9 & 14.4 & 33.3 & 14.1 & 16.0 & 30.1 \\
\hline Secondary + & 16.8 & 9.5 & 26.3 & 11.9 & 6.9 & 18.8 & 9.0 & 7.3 & 16.3 & 7.9 & 8.6 & 16.5 \\
\hline \multicolumn{13}{|l|}{ Wealth } \\
\hline Low & 25.6 & 17.0 & 42.6 & 23.1 & 15.2 & 38.3 & 18.6 & 15.7 & 34.3 & 17.6 & 18.0 & 35.6 \\
\hline Medium & 21.2 & 16.0 & 37.2 & 13.3 & 11.4 & 24.7 & 13.5 & 12.9 & 26.4 & 10.2 & 11.6 & 21.8 \\
\hline High & 14.0 & 10.1 & 24.1 & 10.2 & 8.4 & 18.6 & 12.7 & 7.2 & 19.9 & 9.4 & 9.3 & 18.7 \\
\hline \multicolumn{13}{|l|}{ Residence } \\
\hline Urban & 13.7 & 10.1 & 23.8 & 11.8 & 8.6 & 20.4 & 11.6 & 7.9 & 19.5 & 10.7 & 8.9 & 19.6 \\
\hline Rural & 22.0 & 15.4 & 37.4 & 17.2 & 12.8 & 30.0 & 16.2 & 13.5 & 29.7 & 13.1 & 14.4 & 27.5 \\
\hline \multicolumn{13}{|l|}{ Province } \\
\hline Nairobi & 15.3 & 10.2 & 25.5 & 10.4 & 5.9 & 16.3 & 13.5 & 5.0 & 18.5 & 6.5 & 8.7 & 15.2 \\
\hline Central & 11.2 & 13.4 & 24.6 & 7.1 & 8.0 & 15.1 & 7.3 & 7.5 & 14.8 & 6.2 & 9.3 & 15.5 \\
\hline Coast & 24.8 & 8.4 & 33.2 & 21.4 & 12.5 & 33.9 & 16.9 & 10.7 & 27.6 & 15.9 & 9.3 & 25.2 \\
\hline Eastern & 21.8 & 18.3 & 40.1 & 14.0 & 13.5 & 27.5 & 12.6 & 12.4 & 25.0 & 9.8 & 14.0 & 23.8 \\
\hline Nyanza & 21.9 & 14.6 & 36.5 & 16.7 & 12.4 & 29.1 & 20.8 & 16.7 & 37.5 & 18.2 & 14.0 & 32.2 \\
\hline Rift Valley & 20.9 & 15.0 & 35.9 & 18.8 & 12.8 & 31.6 & 15.8 & 14.0 & 29.8 & 13.0 & 17.6 & 30.6 \\
\hline Western & 25.7 & 16.0 & 41.7 & 21.3 & 14.7 & 36.0 & 20.0 & 16.6 & 36.6 & 13.5 & 12.6 & 26.1 \\
\hline North Eastern & - & - & - & - & - & - & 9.1 & 1.3 & 10.4 & 17.1 & 0.8 & 17.9 \\
\hline $\begin{array}{l}\text { Currently } \\
\text { Married }\end{array}$ & 20.7 & 14.6 & 35.3 & 16.0 & 11.9 & 27.9 & 15.2 & 12.2 & 27.4 & 12.5 & 13.1 & 25.6 \\
\hline $\begin{array}{l}\text { Currently } \\
\text { unmarried }\end{array}$ & 3.5 & 2.3 & 5.8 & 7.6 & 2.2 & 9.8 & 3.8 & 3.8 & 7.6 & 4.2 & 3.0 & 7.2 \\
\hline All Women & 14.1 & 9.8 & 23.9 & 12.8 & 8.2 & 21.0 & 10.6 & 8.9 & 19.5 & 9.1 & 8.9 & 18.0 \\
\hline
\end{tabular}




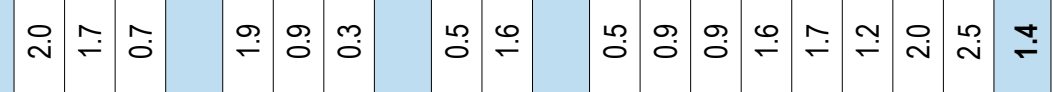

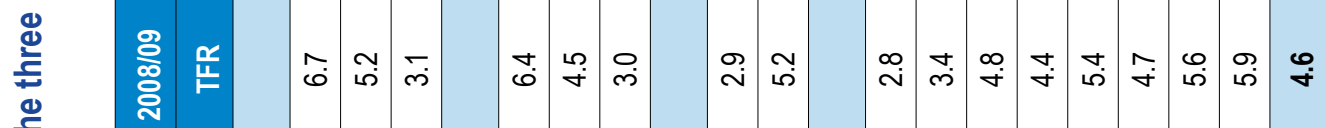

F

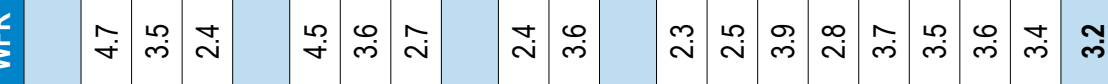

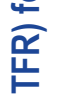

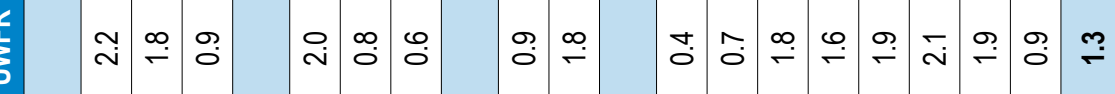

를

니

퓽

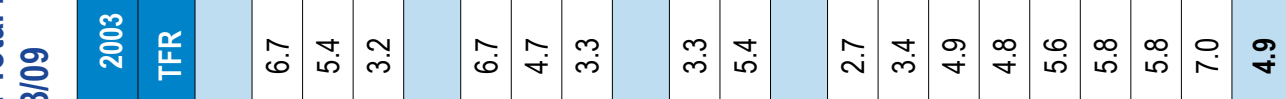

응 융

品

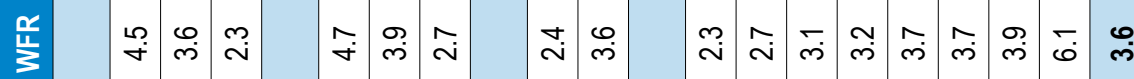

$\sum_{\infty}^{\infty}$

\&

बึ

총

등

눙오

क्ष

空

5 ฮ

뚠

옳 을

또응

넝

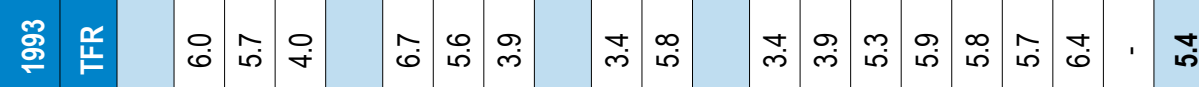

눈

荥

도

응

은 을

은 등

莳皆

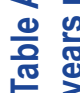

ปิ

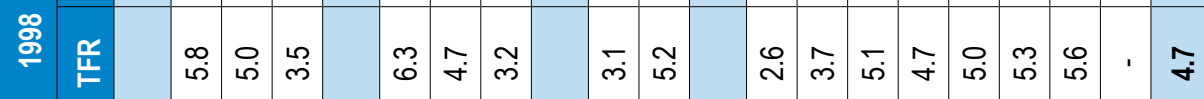

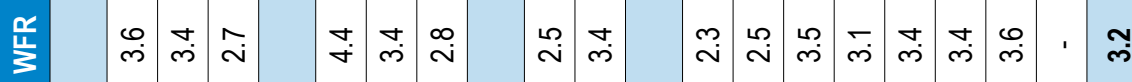

蕉 


\begin{tabular}{|c|c|c|c|c|c|c|c|c|c|c|c|c|c|c|c|c|c|c|c|c|c|c|c|c|c|c|}
\hline \multirow{4}{*}{ 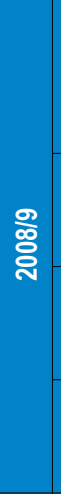 } & 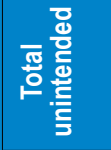 & & 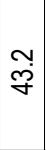 & 官 & 웅 & & $\stackrel{0}{\sim}$ & 寽 & กิ & & $\begin{array}{c}N \\
\stackrel{5}{f}\end{array}$ & 年 & 穴 & & $\frac{\infty}{\infty}$ & i⿱宀 & & 유 & $\begin{array}{l}\infty \\
\infty \\
\infty\end{array}$ & $\begin{array}{l}\infty \\
\stackrel{\infty}{\mp}\end{array}$ & $\begin{array}{c}N \\
\stackrel{n}{q}\end{array}$ & ث্. & 灾 & $\frac{\dot{\sigma}}{\dot{m}}$ & $\stackrel{\circ}{-}$ & $\stackrel{\mathscr{J}}{\mathcal{Y}}$ \\
\hline & 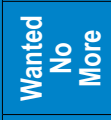 & & $\stackrel{m}{\stackrel{\sim}{\sim}}$ & $\check{\infty}$ & 电 & & ํ. & $\vec{\sigma}$ & $\stackrel{\infty}{\check{m}}$ & & $\begin{array}{l}\infty \\
\infty \\
\infty \\
\infty\end{array}$ & $\stackrel{\circ}{\circ}$ & 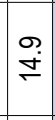 & & $\stackrel{+}{\check{E}}$ & $\stackrel{+}{\infty}$ & & 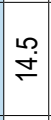 & ஓे & ब & 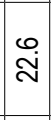 & $\underset{\infty}{\infty}$ & $\stackrel{\substack{0 \\
\infty}}{\infty}$ & $\stackrel{N}{\stackrel{2}{2}}$ & مْ & $\stackrel{乛}{\approx}$ \\
\hline & 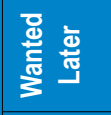 & & $\begin{array}{l}\text { o. } \\
\dot{p}\end{array}$ & ָ̃ & 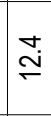 & & $\stackrel{\sim}{\check{Z}}$ & o & సి & & $\begin{array}{l}\infty \\
\stackrel{0}{0}\end{array}$ & 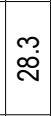 & 일 & & 灾 & 仓் & & $\stackrel{10}{+}$ & Ðே & $\begin{array}{l}0 \\
0\end{array}$ & 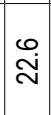 & $\begin{array}{l}\simeq \\
\infty \\
\infty\end{array}$ & 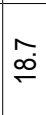 & 음 & م & ผึ \\
\hline & 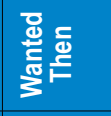 & & $\begin{array}{l}\infty \\
0 \\
\infty \\
1\end{array}$ & 同 & ஜு & & $\stackrel{\sim}{N}$ & $\begin{array}{l}n \\
\text { N్} \\
\text { N }\end{array}$ & テิ & & 芯 & స̃ & $\overline{\mathrm{\sigma}}$ & & $\begin{array}{l}\sim \\
00 \\
00\end{array}$ & 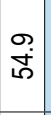 & & $\frac{0}{1}$ & $\frac{N}{\sigma}$ & 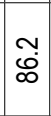 & $\begin{array}{l}\infty \\
\dot{0} \\
\end{array}$ & $\begin{array}{l}0 \\
\tilde{0}\end{array}$ & 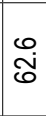 & $\begin{array}{l}0 \\
0 \\
0\end{array}$ & 옴 & 范 \\
\hline \multirow{4}{*}{ ஜำ } & 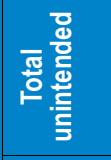 & & $\begin{array}{l}\infty \\
\stackrel{\sim}{\forall}\end{array}$ & 움 & $\begin{array}{l}0 \\
\infty \\
\infty \\
\infty\end{array}$ & & స̃ & চ் & $\stackrel{\mathscr{V}}{\mathcal{J}}$ & & $\begin{array}{l}10 \\
\dot{f}\end{array}$ & 守 & $\hat{\mathscr{\vartheta}}$ & & $\stackrel{\circ}{\stackrel{ }{*}}$ & ஜேं & & $\begin{array}{l}1 \\
\infty \\
\infty \\
\infty\end{array}$ & $\begin{array}{l}m \\
\stackrel{8}{q}\end{array}$ & 户் & $\begin{array}{c}\sim \\
\infty \\
\text { o }\end{array}$ & \begin{tabular}{l}
+ \\
\multirow{2}{*}{} \\
$\sim$
\end{tabular} & $\frac{N}{\dot{y}}$ & 里 & $\stackrel{10}{+}$ & $\stackrel{8}{8}$ \\
\hline & 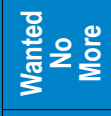 & & 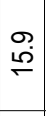 & $\begin{array}{l}0 \\
\stackrel{N}{2}\end{array}$ & \begin{tabular}{l}
$\mathscr{V}$ \\
\multirow{\checkmark}{*}{}
\end{tabular} & & $\stackrel{\infty}{\underset{\sim}{\tau}}$ & O্் & 움 & & $\begin{array}{l}\infty \\
\infty \\
\infty\end{array}$ & $\stackrel{\sim}{\tilde{N}}$ & 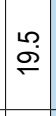 & & $\stackrel{m}{\stackrel{N}{=}}$ & $\check{\grave{N}}$ & & $\stackrel{ }{\circ}$ & $\stackrel{n}{N}$ & $\begin{array}{l}10 \\
0 \\
0\end{array}$ & $\check{\tilde{N}}$ & $\stackrel{6}{\underset{N}{N}}$ & $\underset{⿱}{\infty}$ & $\underset{\sim}{\stackrel{\Xi}{*}}$ & t. & $\stackrel{\mathscr{\sigma}}{\sigma}$ \\
\hline & 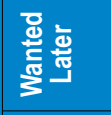 & & $\begin{array}{l}\sigma \\
\mathscr{Q} \\
\stackrel{v}{*}\end{array}$ & $\stackrel{n}{d}$ & $\stackrel{m}{F}$ & & $\stackrel{\overbrace{}}{\simeq}$ & $\stackrel{\sim}{\sim}$ & $\stackrel{\mathscr{N}}{\tilde{N}}$ & & $\begin{array}{l}6 \\
\stackrel{\sim}{\sim}\end{array}$ & 일 & $\underset{\sim}{\stackrel{\sim}{\sim}}$ & & $\stackrel{\sim}{\stackrel{\Xi}{\mathrm{J}}}$ & 울 & & 文 & $\begin{array}{l}0 \\
\infty \\
\varnothing\end{array}$ & $\stackrel{\Xi}{\overparen{N}}$ & $\check{\stackrel{\sim}{N}}$ & $\begin{array}{l}\infty \\
\text { ָె } \\
\end{array}$ & $\begin{array}{l}\infty \\
\tilde{N}\end{array}$ & 足 & $\check{\nabla}$ & $\stackrel{\text { g }}{\text { d }}$ \\
\hline & 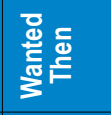 & & N̦ & 吕 & 亏ั & & $\stackrel{\overbrace{}}{N}$ & $\begin{array}{l}0 \\
0 \\
0 \\
0\end{array}$ & 芯 & & $\begin{array}{l}0 \\
10 \\
10 \\
10\end{array}$ & กิ & $\begin{array}{l}m \\
0 \\
0 \\
10\end{array}$ & & $\begin{array}{l}0 \\
\infty \\
\infty \\
\infty\end{array}$ & की & & $\frac{10}{6}$ & 芯 & $\begin{array}{l}6 \\
\mathscr{8} \\
\mathbb{8}\end{array}$ & $\underset{\text { in }}{\infty}$ & $\begin{array}{l}0 \\
\dot{f}\end{array}$ & $\begin{array}{l}\infty \\
\infty \\
\infty \\
10\end{array}$ & $\check{\text { ó }}$ & 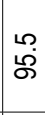 & 㐌 \\
\hline \multirow{4}{*}{$\stackrel{\circ}{\stackrel{8}{\circ}}$} & 홍 & & $\begin{array}{l}\dot{v} \\
\dot{\theta} \\
\dot{q}\end{array}$ & 웅 & 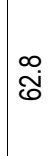 & & ণ্ & 울 & $\begin{array}{l}\mathscr{q} \\
\dot{q}\end{array}$ & & $\begin{array}{l}\infty \\
0 \\
0 \\
0\end{array}$ & 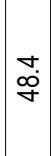 & 竎 & & $\begin{array}{l}\mathscr{O} \\
\stackrel{\mathcal{H}}{*}\end{array}$ & $\begin{array}{l}10 \\
P \\
\end{array}$ & & 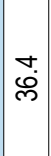 & 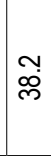 & 官 & 芛 & $\begin{array}{l}6 \\
\dot{\rho} \\
+\end{array}$ & $\begin{array}{l}\dot{y} \\
\dot{q} \\
\text { o }\end{array}$ & \begin{tabular}{l|}
$\infty$ \\
$\infty$ \\
$\infty$ \\
1
\end{tabular} & ' & $\stackrel{m}{\infty}$ \\
\hline & 을을을 & & $\begin{array}{l}\infty \\
\dot{m}\end{array}$ & $\check{m}$ & 웅 & & ָ̃ & $\stackrel{\circ}{\mp}$ & vं & & $\stackrel{\sim}{\stackrel{\sim}{\sim}}$ & $\stackrel{\infty}{\rightleftharpoons}$ & \begin{tabular}{l|}
$\infty$ \\
$\infty$
\end{tabular} & & $\check{r}$ & $\stackrel{\infty}{\mp}$ & & $\bar{T}$ & $\widehat{\infty}$ & $\bar{\sigma}$ & $\stackrel{\Re}{\stackrel{n}{\sigma}}$ & $\stackrel{m}{\rightleftharpoons}$ & $\begin{array}{l}\infty \\
0 \\
0\end{array}$ & $\infty$ & ' & $F$ \\
\hline & 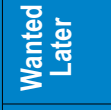 & & $\stackrel{\mathfrak{Y}}{\mathcal{Y}}$ & ळ్ & Ñ & & ํ. & 웅 & స̃ & & $\begin{array}{l}+ \\
\stackrel{m}{ }\end{array}$ & $\begin{array}{l}\mathscr{0} \\
\ddot{e} \\
\tilde{e}\end{array}$ & 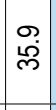 & & م & 只 & & m & 足 & @् & $\begin{array}{l}0 \\
\dot{e} \\
\end{array}$ & m & $\begin{array}{l}0 \\
\tilde{m}\end{array}$ & 움 & ' & $\stackrel{N}{\text { N }}$ \\
\hline & 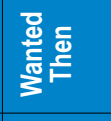 & & \begin{tabular}{|l|}
0 \\
$\tilde{N}$ \\
$\tilde{1}$
\end{tabular} & 오. & 穴 & & $\begin{array}{l}\infty \\
\dot{0}\end{array}$ & 움 & ホั & & テ̣ & $\frac{6}{50}$ & $\begin{array}{l}m \\
2 \\
L \\
0\end{array}$ & & 它 & \begin{tabular}{|l|}
10 \\
0 \\
0 \\
10
\end{tabular} & & ஜ્ & $\underset{6}{\infty}$ & $\begin{array}{l}m \\
\dot{H} \\
\text { L }\end{array}$ & $\begin{array}{l}\infty \\
\stackrel{\infty}{f} \\
\dot{f}\end{array}$ & 志 & $\frac{0}{i 5}$ & $\stackrel{\Upsilon}{Ð}$ & ' & 范 \\
\hline \multirow{4}{*}{ § } & 홍 을 을 을 & & 守 & $\begin{array}{l}0 \\
\text { లె } \\
\text { in }\end{array}$ & $\begin{array}{l}m \\
\tilde{N} \\
\text { ñ }\end{array}$ & & $\begin{array}{l}\infty \\
\stackrel{\infty}{q}\end{array}$ & $\begin{array}{l}\infty \\
\tilde{n} \\
\text { in }\end{array}$ & مَ & & $\begin{array}{l}\checkmark \\
\infty \\
\dot{y}\end{array}$ & 宫 & 年 & & 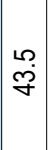 & กิ & & $\begin{array}{l}0 \\
\dot{f}\end{array}$ & 电 & $\begin{array}{l}\sim \\
\text { బٌ } \\
\tilde{e}\end{array}$ & $\begin{array}{l}ナ \\
\text { ப̇ }\end{array}$ & 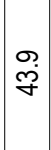 & $\begin{array}{l}0 \\
\dot{P}\end{array}$ & $\frac{\sqrt{5}}{\mathrm{i}}$ & ' & 옹 \\
\hline & 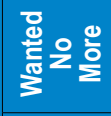 & & \begin{tabular}{|l|} 
\\
0 \\
0
\end{tabular} & 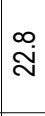 & శ্লি & & $\stackrel{\oplus}{\grave{N}}$ & $\stackrel{ }{ }$ & $\stackrel{\oplus}{\rightleftharpoons}$ & & 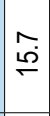 & $\check{\tau}$ & 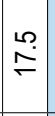 & & $\underset{\simeq}{\simeq}$ & $\stackrel{\nabla}{\sim}$ & & $\begin{array}{l}\infty \\
\infty \\
\infty\end{array}$ & $\hat{\tilde{N}}$ & 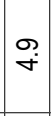 & Ð & $\begin{array}{l}\mathscr{\theta} \\
\varrho\end{array}$ & $\begin{array}{l}0 \\
\stackrel{0}{0}\end{array}$ & $\begin{array}{l}\checkmark \\
\stackrel{+}{2}\end{array}$ & ' & $\stackrel{\sigma}{\sigma}$ \\
\hline & 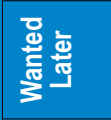 & & $\stackrel{m}{\frac{m}{\dot{v}}}$ & 穴 & $\stackrel{m}{\stackrel{m}{\rightleftarrows}}$ & & $\underset{\sim}{\stackrel{\sim}{\sim}}$ & $\begin{array}{l}\infty \\
0 \\
e\end{array}$ & $\begin{array}{l}\text { के } \\
\text { வि }\end{array}$ & & $\hat{\widetilde{n}}$ & $\begin{array}{l}\circ \\
\infty \\
\infty\end{array}$ & 吕 & & $\frac{m}{m}$ & లే & & $\begin{array}{l}0 \\
\dot{e}\end{array}$ & ه্ & $\begin{array}{l}m \\
\ddot{e}\end{array}$ & $\underset{\infty}{\infty}$ & $\stackrel{m}{N}$ & 울 & $\begin{array}{l}m \\
\dot{e}\end{array}$ & ' & 亗 \\
\hline & 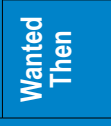 & & ָָ & $\bar{\sigma}$ & $\begin{array}{l}0 \\
\dot{\varphi}\end{array}$ & & $\underset{\text { N }}{\sim}$ & $\begin{array}{l}N \\
\mathscr{f} \\
\mathscr{f}\end{array}$ & กี & & $\frac{0}{5}$ & 号 & \begin{tabular}{|l|} 
\\
0 \\
0 \\
$q$
\end{tabular} & & $\mid \begin{array}{l}\mid \\
0 \\
0 \\
0\end{array}$ & $\begin{array}{c}0 \\
0 \dot{0} \\
\text { qे }\end{array}$ & & $\begin{array}{l}\searrow \\
\stackrel{0}{\circ}\end{array}$ & 守 & \begin{tabular}{l}
$\infty$ \\
\multirow{0}{*}{}
\end{tabular} & 吕 & 厄. & 范 & $\begin{array}{l}m \\
\infty \\
\infty\end{array}$ & ' & ঞ্ \\
\hline & 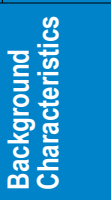 & $\stackrel{0}{\stackrel{\circ}{\leftarrow}}$ & 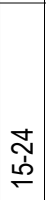 & 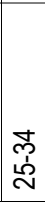 & $\underset{\sim}{\text { ñ }}$ & 을 & 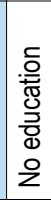 & 赁 & 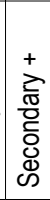 & 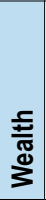 & 오 & 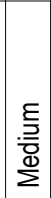 & 동 & 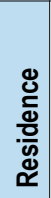 & 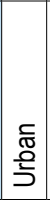 & 한 & 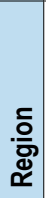 & 흥 & 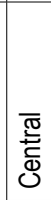 & 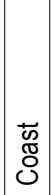 & 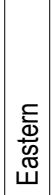 & $\underset{\substack{\mathbb{N} \\
\text { N }}}{\stackrel{N}{Z}}$ & 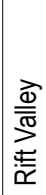 & $\begin{array}{l}\frac{5}{d} \\
\stackrel{5}{\mathscr{d}} \\
\stackrel{\$}{3}\end{array}$ & 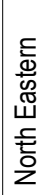 & 픙 \\
\hline
\end{tabular}





\section{www.stepup.popcouncil.org}

The STEP UP (Strengthening Evidence for Programming on Unintended Pregnancy) Research Programme Consortium generates policy-relevant research to promote an evidence-based approach for improving access to family planning and safe abortion. STEP UP focuses its activities in five countries: Bangladesh, Ghana, India, Kenya, and Senegal.

STEP UP is coordinated by the Population Council in partnership with the African Population and Health Research Center; icddr,b; the London School of Hygiene and Tropical Medicine; Marie Stopes International; and Partners in Population and Development. STEP UP is funded by UK aid from the UK Government. 